\title{
C, $P$ and water dynamics in Mycorrhiza
}

\author{
Dissertation \\ zur Erlangung des Doktergrades \\ der Fakultät für Agrarwissenschaften \\ der Georg-August-Universität Göttingen
}

vorgelegt von

Bernd Ditschar

Geboren in Kassel

Göttingen, Mai, 2005 
D7

1. Referent: Prof. Dr. Holm Tiessen

2. Korreferent: Prof. Dr. Gerhard Wolf

Tag der mündlichen Prüfung: 20. Mai 2005 


\section{CONTENT}

1. Indroduction 1

2. Objectives 3

3. Literature review 6

4. Materials and methods 15

4.1. Pot design 19

4.2. Plant material 21

4.3. Soil preparation and fertilization 23

4.4. Growth conditions 26

$\begin{array}{ll}\text { 4.5. Water supply } & 27\end{array}$

4.6. Labelling procedures of mycorrhizal hyphae 28

4.7. ${ }^{14} \mathrm{C},{ }^{32} \mathrm{P}$ and ${ }^{18} \mathrm{O}$ supply to mycorrhizal hyphae 28

4.8. Prevention of diffusion 28

4.9. Harvest of labelled hyphae 29

4.10. Harvest of plant material 30

4.10.1. Preliminary experiments 30

4.10.2. Hyphae labelling experiment 30

4.10.3. Experiment on the correlation between C-transfer and fertilization $\quad 30$

4.10.4. Double labelling experiment 31

4.10.5. Experiment on the role of (V)AM in water uptake and use of ${ }^{18} \mathrm{O} \quad 31$

4.11. Measurement of fresh and dry matter 32

4.12. Measurement of infection rate 32

4.13. Radioactivity measurement in the hyphae and their use as inoculum 33

4.14. Radioactivity measurement in colonized mycorrhizal roots 34

4.15. ${ }^{14} \mathrm{C}$-activity of shoots and roots $\quad 35$

4.16. ${ }^{14} \mathrm{C}$ and ${ }^{32} \mathrm{P}$ activity in shoots, roots and mycorrhizal hyphae 36

4.17. ${ }^{18} \mathrm{O}$ measurement in shoots

4.18. Extraction of labelled compounds 40 
4.19. Gel-electrophoresis 42

4.20. Experimental design 43

4.21. Statistical analysis 45

5. Results and discussion 45

5.1. First preliminary experiment 45

5.1.1. Conclusion 47

5.2. Second preliminary experiment 48

5.2.1. Conclusion 49

5.3. Hyphae labelling experiment 50

5.3.1. Radioactivity measurement in labelled hyphae $\quad 50$

5.3.2. Fresh and dry matter of shoots of roots 51

5.3.3. ${ }^{14} \mathrm{C}$ activity in shoots and roots 56

5.3.4. Use of Gel-electrophoresis $\quad 59$

5.3.5. "Dead" hyphae inoculation 61

5.3.6. Conclusion $\quad 65$

5.4. Investigation on a possible carbon transfer 66

5.4.1. Diffusion prevention $\quad 69$

$\begin{array}{ll}\text { 5.4.2. Conclusion } & 72\end{array}$

5.5. Experiment on correlation between C-transfer and fertilization 73

5.5.1. Dry matter of shoots, infection rate and ${ }^{14} \mathrm{C}$ activity of shoots 73

$\begin{array}{ll}\text { 5.5.2. Conclusion } & 77\end{array}$

5.6. Double labelling experiment 78

$\begin{array}{lll}\text { 5.6.1. Fresh and dry matter } & 78\end{array}$

5.6.2. ${ }^{14} \mathrm{C}$ and ${ }^{32} \mathrm{P}$ activity in mycorrhizal hyphae $\quad 79$

5.6.3. ${ }^{14} \mathrm{C}$ activity in shoots and roots 86

5.6.4. ${ }^{32} \mathrm{P}$ activity in shoots and roots 88

5.6.5. Use of gel electrophoresis 92

$\begin{array}{ll}\text { 5.6.6. Conclusion } & 94\end{array}$

5.7. Experiment on the role of (V)AM in plant water uptake 96

5.7.1. Growth parameters of plants 96

5.7.2. Physiological observations before harvest 98

$\begin{array}{ll}\text { 5.7.3. Shoots and roots dry matter and water content } & 100\end{array}$

5.7.4. Mycorrhizal infection 102

$\begin{array}{ll}\text { 5.7.5. } & { }^{18} \mathrm{O} \text { content in shoots and roots } \\ \end{array}$ 
7.0. Appendix 


\section{Indroduction}

Phosphate is an important macro-nutrient for plant growth and a component of key molecules, such as nucleic acids, phospholipids and ATP. Inorganic P (Pi) occurs in the soil solution, adsorbed to the surface of soil particles or as minerals. Plants take up phosphorus only as Pi from the soil solution. Because of the low solubility of Pi compounds in the soil, the amount of $\mathrm{P}$ in the soil solution pool is very low. Therefore, plants have less productivity in poor and/ or P-fixing soils without additional P fertilizers. In many agricultural systems the application of phosphorus is recommended to ensure the soil productivity, but the recovery of applied P by plants is low. More than $80 \%$ of the $\mathrm{P}$ applied to the soil becomes immobile and is no longer available to plants because of adsorption, fixation or conversion to an organic form (Holford, 1997).

Soils differ widely in the physical and chemical characteristics, that affect the form and solubility of their P components. Tropical acid soils have high P sorption because of their strong affinity to phosphorus to form iron- and aluminium- oxides and hydroxides, whereas in neutral and alkaline soils $\mathrm{P}$ is absorbed on the surface of $\mathrm{Ca}$ and $\mathrm{Mg}$ carbonates (Holford, 1997). Plants remove $P$ from soil solution by root absorption. The continuing supply of $P$ to plants depends on the ability of the soil to replace the Pi in the soil solution, which was taken up by the plant. In addition, microorganisms are important for increasing the $\mathrm{P}$ supply to plants in soil.

Microorganisms are involved in the transformation of soil phosphorus and are thus an integral component of the soil $\mathrm{P}$ cycle. Soil microorganisms are able to release $\mathrm{P}$ from organic and inorganic soil $\mathrm{P}$ through mineralization and solubilization, and thus main agents in the transfer of $\mathrm{P}$ from poorly available soil pools to plants.

Of these microorganisms, mycorrhizal fungi play an endophytic essential role in improving nutrient uptake, especially of phosphorus by plants. The (vesicular-) arbuscular mycorrhizal fungi (V)AMF belong to the order Glomales, family Glomacea, and the most important species are in the genus `Glomus`.

(V)AM endophytes are obligate symbiotic fungi and represent the most common plant/fungal infection. Obligate symbiotic fungi are incapable of completing their life cycle in the absence of a host plant. Hyphal growth is stimulated in the presence of living host roots (Mosse, 1988) or through the release of host root exudates (Bécard and Piché, 1989; Tawaraya et al., 1996). Various mechanisms for improved P uptake by mycorrhizal plants have been proposed in the literature. Tinker (1978), Pearson and Jakobson (1993) and Smith et al. (1994) explained the 
improved P uptake by a greater exploration of a soil volume by mycorrhizal roots. The external hyphal network, connected with the root system, decreases the distance for diffusion of phosphate ions and increases the surface area for absorption. Hattingh et al. (1973) showed in experiments with onions (infected with Endogene mosseae and Endogene fasciculata), that the mycorrhizal hyphae could intercept labelled $\mathrm{P}$ placed $27 \mathrm{~cm}$ away from the root system. The greater exploration of the soil is also described by Barley (1970). Barley considered the greater exploration as a result of the smaller diameter of hyphae compared with the diameter of root hairs. The hyphae (diameter of $2-4 \mu \mathrm{m}$ ) are able to grow into soil pores and organic matter that cannot be entered by root hairs.

A further hypothesis for the improved $\mathrm{P}$ uptake by the mycorrhizal root is the release of compounds to the soil, which dissolve fixed $\mathrm{P}$, at least in the rizosphere of plants (Lee and Lord, 1987; Fabig et al., 1989; Okeefe and Sylvia, 1992).

Mycorrhizal development depends upon molecular interactions between the two symbionts (Bonefante-Fasolo, 1984; Gianinazzi-Pearson and Gianinazzi, 1988). Signalling events could involve an exchange of C-compounds in the symbiosis. Recent literature shows, that a $\mathrm{P}$ transporter molecule could be involved in the $\mathrm{P}$ uptake mechanisms in mycorrhizal plants indicating that there is a $\mathrm{P}$ transfer mechanism to absorb phosphate from the soil to translocate it for considerable distances within the fungal structures towards the root and to transfer the phosphorus from fungus to plant across the symbiotic interface (Smith and Read, 1997). P transporters and/or other organic compounds (proteins, enzymes etc.) could be involved in such mechanisms. The main constituent of organic compounds is carbon and if there is a $\mathrm{P}$ transport within the hyphae it may be possible to identify and/or determine the $\mathrm{P}$ transporter or to trace compounds which incorporate phosphorus. Bidartondo et al. (2002) reported, that experimental evidence for inter-plant carbon transfer via arbuscular mycorrhizal fungi is equivocal. The authors suggested, that transferred carbon may remain in fungal structures within roots and, that a carbon flux from fungus to plant occurs within arbuscular mycorrhizal networks. Therefore, a carbon transport in Mycorrhiza may be bi-directional. However, they could not give an experimental answer for that. Generally it has been stated, that there is no carbon transfer from fungus to plant (Robison and Fitter, 1998).

Beside several advantages for plants being mycorrhizal, the improved phosphorus nutrition and the positive growth response of plants to colonization by (V)AMF are also an improved utilisation of soil water. The availability of soil water and phosphorus to the plant are interdependent (Olsen et al., 1961) due to the linear relationship between the diffusion 
coefficient of phosphate and soil moisture (Viets, 1972). In semi-arid climates the water-use efficiency (WUE) by plants becomes an increasingly important constraint on growth because of the climatic changes. Beside the involvement of mycorrhizal fungi in the improved nutrient uptake, (V)AMF can also contribute to a better water-use efficiency. (V)AMF are involved in the uptake of both phosphorus and soil water and in maintaining the $\mathrm{P}$ nutrition in plants even under drought stress (Faber et al., 1991; Ruiz-Lozano and Azcón, 1995). Because of this, (V)AMF are able to increase the drought tolerance of the plants (Sieverding, 1981; RuizLozano and Azcón, 1995; Al-Karaki and Clark, 1998a, 1998b).

\section{Objectives}

Phosphorus availability is considered as one of the major factors that limit plant growth in natural ecosystems. Plants have developed several mechanisms to overcome P deficiency. The increased synthesis of a high-affinity carrier system has been proposed to be responsible for enhanced Pi uptake by plants. High-affinity Pi transporter genes have been cloned and characterized from fungi and from several plant genera, including Solanum (tomato, potato), Medicago and Catharanthus (Muchhal and Raghothama, 1999). All Pi transporters are integral membrane proteins.

Pi transporters may play also an important role in Mycorrhiza to improve the phosphorus uptake via mycorrhizal hyphae. If such transporter proteins, initiated by the mycorrhizal fungi, are involved in phosphorus uptake mechanisms in Mycorrhiza, an exchange of transporter proteins could lead to a carbon transfer from fungi to the host.

Signalling compounds (enzymes, proteins, phenolic compounds etc.) could play also a key role during the initiation of the "acceptance" by the host root and constitute a $\mathrm{C}$ transfer.

The first objective of the present research was to study the $C$ transfer between fungus and plant and the relationship between the transferred carbon and the phosphorus uptake by mycorrhizal plants under different $\mathrm{P}$ treatments. 


\section{Hypothesis:}

There is a movement of carbon compounds from the mycorrhizal fungi to the host plant, which may be related to signalling compounds during the initiation of the mycorrhiza and $\mathrm{P}$ transporters across symbiotic fungus-plant interface (both $\mathrm{C}$ containing compounds).

In order to test this hypothesis, techniques were developed to:

a) label (V)A mycorrhizal fungal hyphae with ${ }^{14} \mathrm{C}$, extract the labelled hyphae from the soil, and utilize the labelled hyphae as inoculum to infect new plants,

b) determine the ${ }^{14} \mathrm{C}$ content in roots and stems of inoculated plants,

c) use gel-electrophoresis to identify possible ${ }^{14} \mathrm{C}$ labelled compounds in shoots and roots of mycorrhizal plants.

The second objective was, to determine if a relationship and/or correlation exist between the ${ }^{14} \mathrm{C}$ and ${ }^{32} \mathrm{P}$ transfer in the symbiosis e.g. if $\mathrm{P}$ transporters are involved in the phosphorus transfer between the mycorrhizal fungi and the host plant.

\section{Hypothesis:}

The transfer of carbon (e.g. P transporters) from fungus to plants, correlates with the phosphorus uptake through mycorrhizal hyphae, and the transfer of ${ }^{14} \mathrm{C}$ and ${ }^{32} \mathrm{P}$ within mycorrhizal hyphae are related.

Techniques were developed to:

a) extract labelled hyphae from soil, and to utilize the labelled hyphae as inoculum to infect new plants,

b) fertilize the mycorrhizal plants with a ${ }^{32} \mathrm{P}$ labelled phosphate, which was made available only to hyphae and not to plant roots in an experiment with ${ }^{14} \mathrm{C}$ and ${ }^{32} \mathrm{P}$ double labelling, d) use gel-electrophoresis to seperate possible ${ }^{14} \mathrm{C}$ and/ or ${ }^{32} \mathrm{P}$ labelled compounds in shoots and roots of mycorrhizal plants. 
A third objective was to study the effect of soil born mycorrhizal fungi and the wateravailability of mycorrhizal roots on the growth of Sorghum bicolor in two Yucatan (Mexico) soils. This objective should provide more details on the role of the Mycorrhiza in the plant water relationships and an evidence for active and/or real increase in water transport through mycorrhizal hyphae to plant roots.

The most discussed mechanisms of improved water-use efficiency (WUE) in Mycorrhiza is that of the improved water uptake and transport by the external hyphae. The growing units, which have been used in the first part of the present study, were also used in the third part to clarify, if there is an active water transport by mycorrhizal hyphae to the host.

\section{Hypothesis:}

Extraradical mycorrhizal hyphae are able to transport water to the host and to increase the water uptake and consequently also the drought tolerance of Sorghum bicolor plants, causing a higher yield of the plants.

Therefore, the similar techniques which have been used in the first and second part were modified to:

a) create a growing unit which could be used to separate mycorrhizal hyphae from plant roots,

b) add ${ }^{18} \mathrm{O}$ water to mycorrhizal plants, to be only available to hyphae and not to plant roots,

c) ensure that there is no diffusion of ${ }^{18} \mathrm{O}$ water from the hyphal compartment to the plant compartment,

d) reduce the water supply of Sorghum bicolor to increase the possible water transfer via mycorrhizal hyphae,

e) measure the ${ }^{18} \mathrm{O}$ content in Sorghum bicolor to clarify, if there is an active water transport via mycorrhizal hyphae to the plant. 


\section{Literature review}

\section{What is Mycorrhiza?}

Arbuscular mycorrhizae form a mutalistic association with plant roots characterized by bidirectional exchange of nutrients between the two symbionts through their plasma membranes (Smith and Smith, 1990). In their relationship the host plant acts as a carbon source for the fungus, whereas the fungus transports mineral nutrients, particularly phosphorus but also zinc and copper, to intraradical hyphae and then to the plant. (Gianinazzi-Pearson and Gianinazzi, 1983; Pfeffer et al., 1999).

\section{How infection occurs}

During the interaction morphogenetic changes of both fungus and plant take place (Smith and Read, 1997). Early observations suggested that there are two separate phases: an attachment to the root surface which may or may not be followed by penetration of the root ( Mosse and Hepper, 1975). Root exudates may promote the hyphal growth from spores as shown during infection processes of many fungal pathogens. Two decades later, Smith and Read (1997) reported, that the initiation of the "acceptance" by the host root of the (V)A mycorrhiza is attributed to a signalling event.

\section{Signalling events in Mycorrhiza}

Phenolic compounds are known to be important signal molecules in the interactions between Agrobacterium and/ or Rhizobium and host plants (Peters and Verma, 1990) and they may play a similar role in (V)A mycorrhiza. Phenolic compounds are formed during mycorrhizal development (Blilou et al., 2000) and it has been suggested that this is a short-lived event, which decreases after fungal penetration into the plant root (García-Garrido and Ocampo, 2002).

It has also been suggested that $\mathrm{C}$ transfer from fungus to host plant occurs during the initiation of infection. Gollotte et al. (1993) proposed a scheme to explain plant defence against pathogens and hypothesized that a mycorrhizal host plant recognizes a signal from the mycorrhizal fungus so that the host's defence responses would not be mobilized. Signalling 
events play an important role during the mycorrhizal development; however, signalling compounds could not yet be identified in mycorrhizal plants or fungi (Smith and Read, 1997). Bonfante-Fasolo (1987) reported, that the mycorrhizal fungi grow under the control of the host plasma-membrane and speculated that there is a complex regulation between the two symbionts. Signal molecules could stimulate some inducible genes, which produce enzymes. The author also reported that chitin could be one of such signal molecules. Chitin and Nacetyl-glucosamine oligomers may stimulate the production of enzymes such as chitinase, which is known to be an inducible enzyme.

During the initial interaction between mycorrhizal fungi and roots, enzymatic activities were observed by Blilou et al. (2000). Catalase and ascorbate peroxidase activities were examined during the early stage of infection between Nicotiana tabacum and Glomus mosseae. Other enzymes are also involved in the mycorrhiza, such as peroxidase, chitinase, $\beta-1,3$ glucanase and amylase (Dumas-Gaudot et al., 1992a; Mathur and Vyas, 1995; Ditschar, 2001). The occurrence of chitinase during the initial phase of Mycorrhiza establishment was reported in several publications (Dumas-Gaudot et al., 1992b; Dassi et al., 1996; Pozo et al., 1998). This suggests, that the chitinase activity plays not only a structural, but also an informational role. These enzymes may be involved in the early stage of infection, which could be initiated by signalling events.

\section{Role of $\mathbf{P}$ transporters in Mycorrhiza}

An orthophosphate transporter could play a role in (V)A Mycorrhiza to improve plant nutrient uptake. Rausch et al. (2001) identified the phosphate transporter gene StPF3 in potato (Solanum tuberosum) and showed, based on RNA localization and reporter gene expression the expression of StPF3 in root sectors infected with mycorrhizal hyphae.

Harrrison and van Buuren (1995) also identified a complementary DNA that encodes a transmembrane transporter (GvPT) from the mycorrhizal fungi Glomus versiforme. The expression of GvPT was localized to external hyphae, which could be the initial site of phosphate uptake from the soil.

These results suggest, that $\mathrm{P}$ transporters could be involved in the $\mathrm{P}$ transfer between the host and the mycorrhizal fungi. 
Besides signalling interactions or/ and the involvement of $\mathrm{P}$ transporters, there are also physiological interactions between the two symbionts in the (vesicular-) arbuscular mycorrhizal plants.

\section{Carbon transfer in Mycorrhiza}

In Mycorrhiza, the plants act as a carbon source for the fungi, while the fungi release mineral nutrients such as $\mathrm{P}$ to the plant (Gianinazzi-Pearson and Gianinazzi, 1988). A high $\mathrm{C}$ flow from plant to fungus has been shown (Ho and Trappe, 1973; Bevege et al., 1975; Jennings, 1995; Solaiman and Saito, 1997; Bago et al., 2000; Buee et al., 2000), at least partly in form of sugars (Smith and Smith, 1990). Such sugars are utilized in the hyphal metabolism (Solaiman and Saito, 1997). Gryndler et al. (1998) found, that glucose added to the soil of maize plants inoculated with Glomus fistulosum, had positive effects on root colonization, abundance of arbuscules and length of aseptic hyphae on the root surface ((V)AMF hyphae are aseptic hyphae). The effect of glucose as an additional carbon and energy source could be of importance for the establishment of Mycorrhiza especially for the formation of extraradical mycelium.

A high ${ }^{14} \mathrm{C}$ glucose uptake by mycorrhizal root segments in petri-dishes was observed by Gryndler et al. (1997), whereas there was no adsorption of carbon in hyphae which were exposed to formaldehyde (an agent killing the fungus and root tissues).

Mitchell and Meave ${ }^{1}$ carried out ${ }^{14} \mathrm{C}$ uptake studies on mycelium of Hymenoscyphus ericae. In their experiments the authors used fructose, glucose, 3 O-methyl glucose and sucrose as an additional carbon source for hyphae of $H$. ericae. Sucrose supported the growth of $H$. ericae and separate transporters were found in the hyphae for the uptake of glucose and fructose. This supports the supposition of an active vital process by mycorrhizal hyphae to take up carbon in form of monosaccharides out of the soil.

Contrary, Pfeffer et al. (1999) reported, that the extraradical mycelium did not use exogenous sugars for catabolism, storage or transfer to the host. The authors found, that mycorrhizal fungi convert sugars taken up by the root into lipids and which were then translocated to the extraradical hyphae.

\footnotetext{
${ }^{1}$ http://www-icom2.slu.se/abstracts/Mitchell.html
} 
The effectivity of the Mycorrhiza depends on the balance between fungal demands for energy and the plant needs for nutrients (Miller et al., 2002). It is well known that mycorrhizal fungus receives at least some of its carbon needs from the host plant (Jakobson and Rosendahl, 1990; Eisennstat et al., 1993; Wright et al., 1998). In the initial phase of the mycorrhizal symbiosis the relationship between the two symbionts is parasitic. The early stage of the establishment of mycorrhiza creates a "sink" for carbohydrates in roots, which initiates a carbon flow from the host plant to the fungus. This "sink" effect could account for an extra 10-23\% drain of C from the host by the mycorrhizal fungi (Snellgrove et al., 1982, Kucey and Paul, 1982; Koch and Johnsen, 1984). Black et al. (2000) reported on a significant C drain in cucumber (Cucumis sativus L.) plants infected with Glomus mosseae. An increase by $28 \%$ was detected in the translocation of ${ }^{14} \mathrm{C}$ (applied as ${ }^{14} \mathrm{CO}_{2}$ to the plants) to the roots. Similar amount of translocated C (17-26\%) was measured by Jakobsen and Rosendahl (1990) in cucumber plants infected with Glomus fasciculatum. Wright et al. (1998) carried out comparative analysis of daily carbon budgets and aspects of the $\mathrm{C}$ physiology of Trifolium repens plants colonized with mycorrhizal fungi. Growing conditions were designed to ensure that mycorrhizal and non-mycorrhizal plants were cultivated under the same nutrient status. Mycorrhizal plants had higher root sucrose, glucose and fructose pools from day 24. The analyses suggested that these sugars were utilized for trehalose and lipid synthesis, to produce extraradical mycelium. The allocation of carbon to roots was followed by a stimulation of activities of cell wall and cytoplasmic invertases and of sucrose synthase in mycorrhizal roots. The authors suggested, that such an increase of enzyme activity may provide the mechanism enabling increased allocation of carbohydrate both to the mycorrhizal root system and to the fungal symbiont. These results confirm, the high carbon requirements of mycorrhizal fungi, which must be covered by the plants in form of sugars. Therefore, glucose may be an important carbon source for the mycorrhizal fungi. Intraradical hyphae may metabolize five times more glucose to $\mathrm{CO}_{2}$ than non-mycorrhizal plants (Solaiman and Saito, 1997).

Johnson et al. (2002) used ${ }^{14} \mathrm{CO}_{2}$ labelling of plants and found out that $3.4 \%$ of the ${ }^{14} \mathrm{C}$ initially fixed was allocated to external mycelium, and the release of respiratory ${ }^{14} \mathrm{CO}_{2}$ by the mycorrhizal fungi accounted for $0.73 \%$ of the ${ }^{14} \mathrm{C}$ initially fixed by the plant.

Bevege et al. (1975) showed that there is a rapid translation of ${ }^{14} \mathrm{C}$ labelled photosynthate to the root system. The authors also found labelled compounds in external hyphae and in spores. Simard et al. (1997) demonstrated, that there is a carbon transfer between the two tree species Betula papyrifere and Pseudotsuga menziesii, which were linked by an ectomycorrhizal 
hyphal network. This indicates that the carbon transfer in linked ectomycorrhizal roots can be from fungus to host even though ectomycorrhizal fungi may satisfy their $\mathrm{C}$ needs mainly from the host roots (Fitter et al., 1998). It has been reported that arbuscular mycorrhizal fungi derive their carbon from the host (Ho and Trappe, 1973; Bevege et al., 1975; Jennings, 1995; Solaiman and Saito, 1997; Buee et al., 2000). Patrik (1989) concluded that the diffusion of sugar from host to fungus would prevent the transport of sugar back to the host. On the other hand, Smith and Smith (1990) described a possible mechanism of bi-directional movement of sugar and phosphate in Mycorrhiza. According to these authors, a flux of $\mathrm{K}^{+}$from fungus to the host could be responsible for a passive transfer of uncharged solutes like sugars to the fungus, on condition that the host root cells have a greater negative potential difference than the fungal cells, and the $\mathrm{K}^{+}$concentrations in both cells are more or less similar.

In contrast to the carbon transfer between trees linked by ectomycorrhiza, the endomycorrhiza symbiosis lacks examples of carbon transfer from fungus to plant (Bidartando et al., 2002). The authors argued, that experimental evidence for the inter-plant carbon transfer in (V)AM is equivocal and that transferred carbon may remain in fungal structures within roots and supposed, that carbon flux between autotrophs may be bi-directional, but the authors provided no experimental evidence and their discussion was mainly based on suggestions.

To understand the hypothesis of Bidartondo et al. (2002) it is important to follow the development of mycorrhizal infection and its degeneration.

Formation of infection and arbuscules and their degeneration are relatively rapid (Smith and Read, 1997). Brundrett et al. (1985) reported, that the penetration of root was determind after 1 day as a minimum time between contact of external hyphae with roots. The formation of arbuscules was determined after 2 and 3 days and the formation of vesicles after 3 and 4 days. The degeneration was observed until 4-5 days after arbuscule initiation. Similar results were reported by Toth and Miller (1984), who determined the time required for the formation and degeneration of arbuscules between 10 to 12 days.

In the initiation of arbuscule establishment, the hyphal branch penetrates the plant cell wall to form the arbuscule. The plasma-membrane is not breached but grows, so that the branches of the arbuscule remain surrounded by the plant membrane (peri-arbuscular membrane (PAM)). The fungal plasma-membrane and the PAM are forming an interfacial zone, which plays an important role in the nutrient transfer between the two symbionts. The interfacial zone is relatively big and its solute composition is still unknown (Smith and Read, 1997). The fungal plasma membrane surrounding the arbuscule is very thin compared to the thickness of fungal wall, because of the lower amounts of chitin in the fine branches (Bonfante-Fasolo, 1987). 
The short duration of the arbuscule cycle could be explained by the digestion of the arbuscule by host plant defence reaction against the fungal invasion or by programmed death for the fungus, which undergoes autolysis in what turns out to be the stressful environment of the cortical cell (Harley and Smith, 1983). A degeneration of the arbuscule was described by Toth and Millar (1984), who determined a rapid collapse of the fine branches resulting in the formation of large "clumps" which continued until only the trunk remains. The authors speculated, that the trunk collapses which produces a mass of residual material in the plant cell, and that the host cell returns to a pre-invasion state.

It therefore could be concluded, that these remaining fungal structures, as mentioned by Bidartondo et al. (2002) could be responsible for a bi-dirrectional carbon transport. The literature is not showing what happens with these residues of the arbuscule in the host cell. Therefore, a passive and/ or active carbon transfer from the fungus to host could be possible. Mitchell and Meave ${ }^{*}$ carried out ${ }^{14} \mathrm{C}$ uptake experiments using mycelium of Hymenoscyphus ericae in endomycorrhizal association with cranberry. The experiments were conducted on excised intact root systems of cranberry seedlings grown for 8 weeks in 1/5 Rorison`s liquid medium supplemented with glucose. Ericoid mycorrhizal cranberry had a greater root dry mass than those of non-mycorrhizal seedlings if the carbon supplement was either glucose or sucrose. According to the authors, this result indicates a possible transfer of carbon from the fungus to the plant, since ericaceous seedlings spend commonly the early part of their live in sub-optimal light under canopy of their adults.

It can therefore be assumed that within (V)AM there is not only a carbon flow from plant to fungus, but there may also be a reverse flow of $\mathrm{C}$ containing signalling molecules, transport molecules or fungal residues from the fungus to the host.

\section{WUE by mycorrhizal roots}

As mentioned before, (V)AM improve growth because of improved nutrient uptake. The extraradical mycorrhizal hyphae act as an extension of the root system. Because of the smaller diameter of mycorrhizal hyphae compared to plant roots, the hyphae contribute to a greater exploration of the soil for nutrients, especially phosphorus, but also zinc and copper (Pfeffer et al., 1999).

\footnotetext{
*http://www-icom2.slu.se/abstracts/Mitchell.html
} 
In semi-arid climates water availability in agricultural ecosystems is a more growth limiting factor than nutrient uptake by micro-organisms. Beside the key role of mycorrhizal fungi in the improved nutrient uptake, the mycorrhizal mycelium may play also an important role in water availability.

Various factors were discussed in the literature which could be involved in the effects of mycorrhizal hyphae on plant metabolic processes to explain their contribution to drought tolerance. These factors can be divided into 4 main groups: a) enhanced phosphorus nutrition of mycorrhizal hosts, b) increased water uptake and transport by external hyphae, c) changes in hormonal relations and d) effects on stomatal behaviour and root conductivity.

\section{a) Enhanced phosphorus nutrition of mycorrhizal hosts}

Graham and Syvertsen (1984) reported, that mycorrhizal seedlings of two citrus rootstocks with adequate phosphorus nutrition had more than twice the root hydraulic conductivity of Pdeficient non-mycorrhizal plants of equal size. Mycorrhizal plants had also higher transpiration rates, which were attributed to the increased conductivity of roots. The authors summarized, that the flow of water to roots via hyphae alone could not account for the greater water uptake by mycorrhizal plants and concluded that the enhancement of $\mathrm{P}$ nutrition was responsible for the greater conductivity of roots.

Similar conclusions were given by Nelson and Safir (1982). The improved drought tolerance of onion plants was caused by the mycorrhizal fungi, which maintain adequate $\mathrm{P}$ nutrition during water stress, and that the improved $\mathrm{P}$ nutrition by the mycorrhizal fungi was a major factor in increasing plant drought tolerance.

Fitter (1988) reported, that in experiments with red clover (Trifolium pratense L.) there was no evidence of increased water uptake caused by mycorrhizal fungi. These results suggest that the increased water uptake in mycorrhizal plants may be a secondary consequence of changes of the improved $\mathrm{P}$ uptake in mycorrhiza.

\section{b) Increased water uptake and transport by external hyphae}

Safir et al. (1971) suggested, that if mycorrhizal hyphae increased the root surface for phosphorus adsorption, they may perform a similar function in water uptake. Sieverding (1981) reported, that Mycorrhiza makes the plants less sensitive to temporary water shortage and that the drought tolerance is more pronounced in plants, which have a small root network 
and which depend on mycorrhizal symbiosis. The author summarized, that under conditions of insufficient soil moisture mycorrhiza can improve the water relations of crops, and that plant species (Sorghum bicolor vs. Chromolaena odorata) and soil type (strong P fixation vs. fair P availability) have a great influence on this effect. are two main factors of soil moisture on the efficiency of Mycorrhiza.

Hardie (1985) showed, that removal of extraradical mycorrhizal hyphae from colonized clover (Trifolium pratense) and leek (Allium porrum) had a detrimental effect on transpiration flux. If the transpiration flux reflects the water uptake capacity of roots, the removal of extraradical hyphae reduced the surface area of the mycorrhizal complex for water adsorption and increased the root resistance for water uptake.

Faber et al. (1991) designed a system which allows water uptake by mycorrhizal hyphae which were grown in a hyphae chamber separated with an air gap from the growing chamber. The authors showed an active role of external hyphae of Glomus clairodeum in water transport to Helianthus annuus plants. George et al. (1992) found no evidence for a significant direct water transport by vesicular-arbuscular mycorrhizal hyphae to plants, when a similar system to that of Faber et al. (1991) was used. Mycorrhizal hyphae were separated with a $45 \mu \mathrm{m}$ membrane and a $2 \mathrm{~mm}$ air gap from plant roots and tensiometers were used to measure the water loss in the hyphal compartments. The low rate of water losses in the hyphal compartment were explained as an effect of evaporation and not due to water uptake by the hyphae.

In addition, Bryla and Duniway (1998) reported, that there was no significant resistance to drought in Glomus etunicatum inoculated safflower- and wheat plants, which were compared with non-mycorrhizal plants.

Al-Karaki (1998) used two durum wheat (Trifolium durum L.) genotypes (one drought sensitive and the other drought tolerant) colonized with Glomus monosporum to demonstrate, that mycorrhizal plants were more efficient in their water-use than non-mycorrhizal plants. The mycorrhizal plants under water stress consumed less water to produce one unit of shoot dry matter than non-mycorrhizal plants. No differences were found between non-mycorrhizal plants under water stress and well watered plants. These results may indicate that (V)AM increased the ability of roots to adsorb soil moisture. Similar results were found by Kaya et al. (2003), where watermelon (Citrullus lanatus) colonized with Glomus clarum had significantly higher biomass and fruit yield than non-mycorrhizal plants. 


\section{c) Changes in hormonal relations}

Barea and Azcòn-Aquila (1982) reported, that Glomus mosseae synthesized two gibberellinlike substances and four substances with the properties of cytokinins which could lead to morphological and physiological changes in the host plants to be more efficient in their nutrient uptake. Gibberellins increased leaf area and the development of lateral roots, while cytokinins are involved in many basic processes of plant growth and therefore changes of phytohormone levels can affect the effectivity of Mycorrhiza.

Allen et al. (1982) found quantitative changes in gibberellin-like substances in leaves and roots of Bouteloua gracilis infected with Glomus fasciculatus. An increase of gibberellin-like substances was measured in leaves, while there was a tendency for decreased activities in the roots. A similar increase in abscisic acid was measured in leaves, but no changes in roots were detected. The increased phosphorus and water uptake and the increase in photosynthesis in mycorrhizal B. gracilis may be affected and regulated by alterations in phytohormone levels.

\section{d) effects on stomatal behaviour and root conductivity}

A higher hydraulic conductivity in mycorrhizal root systems was measured by Hardie and Leyton (1981) compared with uninfected root systems. The author found that per unit length of root, the conductivity of mycorrhizal roots were two to three times higher, which leads to a greater ability to extract water at lower soil moisture contents. The author suggested that this result was mainly due to hyphal growth in the soil, because of the greater length and total surface areas of the mycorrhizal roots.

Augè et al. 1986 reported that mycorrhizal plants had an improved stomata control. Low-P mycorrhizal plants of Rosa hybrida L. cv. "Samantha" showed greater leaf conductance than high-P mycorrhizal plants and non-mycorrhizal plants.

It can therefore be concluded, that water uptake by plant roots can be increased when they are infected by vesicular-arbuscular mycorrhizal fungi. Various possible mechanisms were discussed in the last three decades. However, several opinions exist concerning how the improved water uptake or the better drought tolerance by mycorrhizal plants could be explained.

The aim of the third part of the present research work was to use the growing units and to test if there is an active water transport via mycorrhizal hyphae. 
For a better overview about the main investigations, the flow-diagrams of the experiments are shown in the following Figures (Fig. 1, Fig. 2, Fig. 3 and Fig. 4). The dark black boxes represent the chapters about the results, while the normal black boxes represent chapters of the used materials and methods.

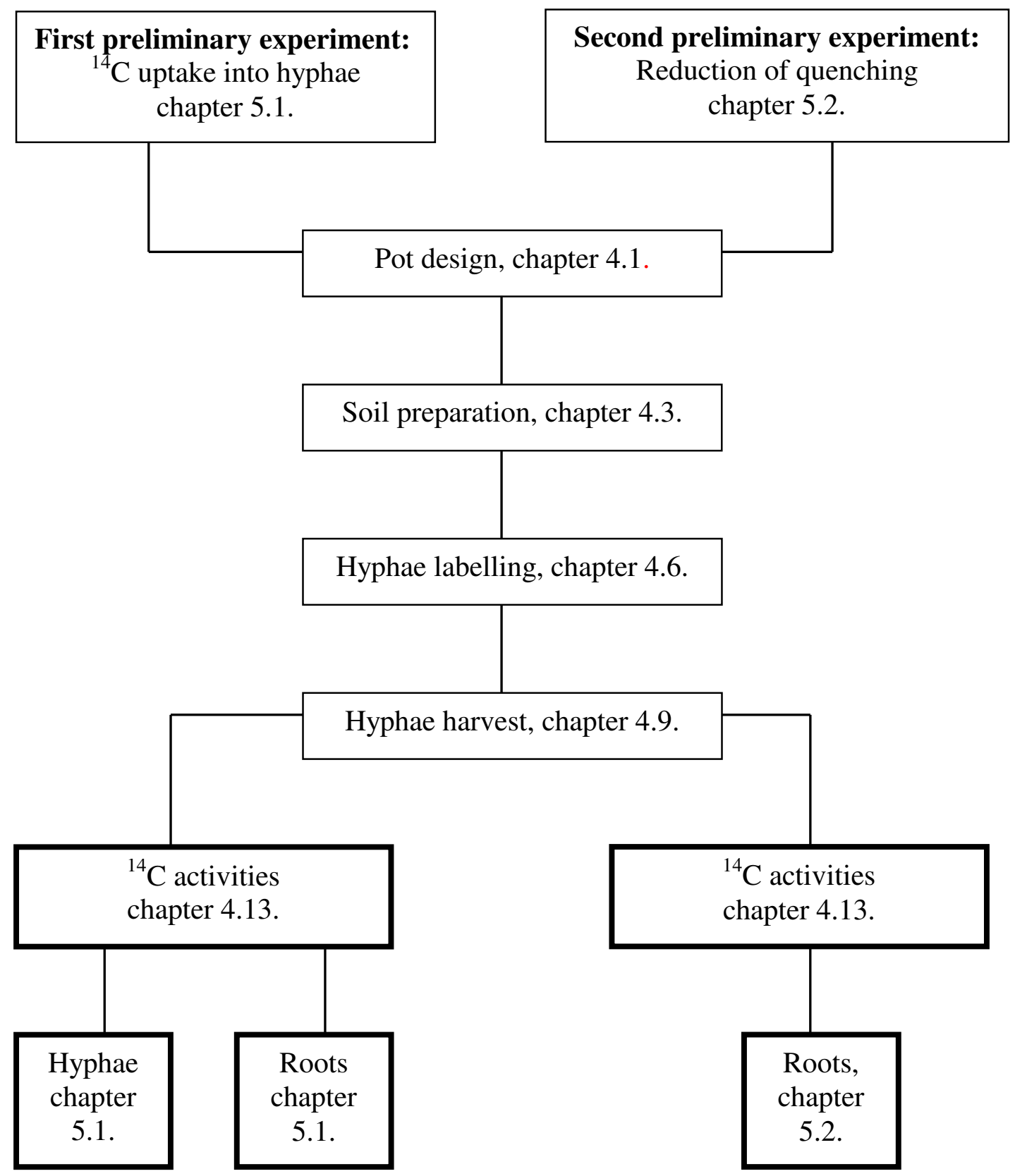

\section{Figure 1:}

Scheme of the first and second preliminary experiments 

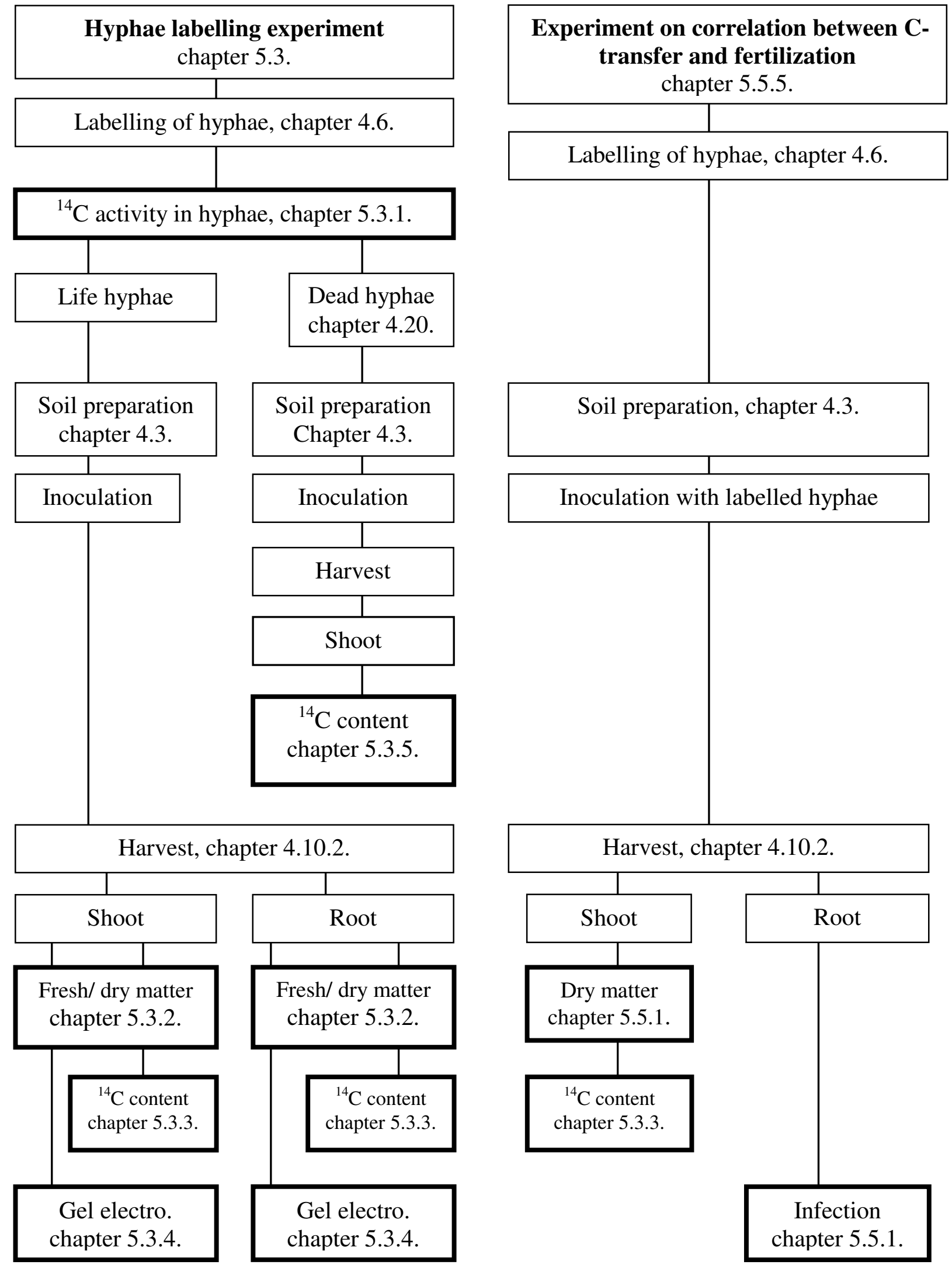

Figure 2:

Scheme of "Hyphae labelling experiment" and "Experiment on correlation between C-transfer and fertilization 


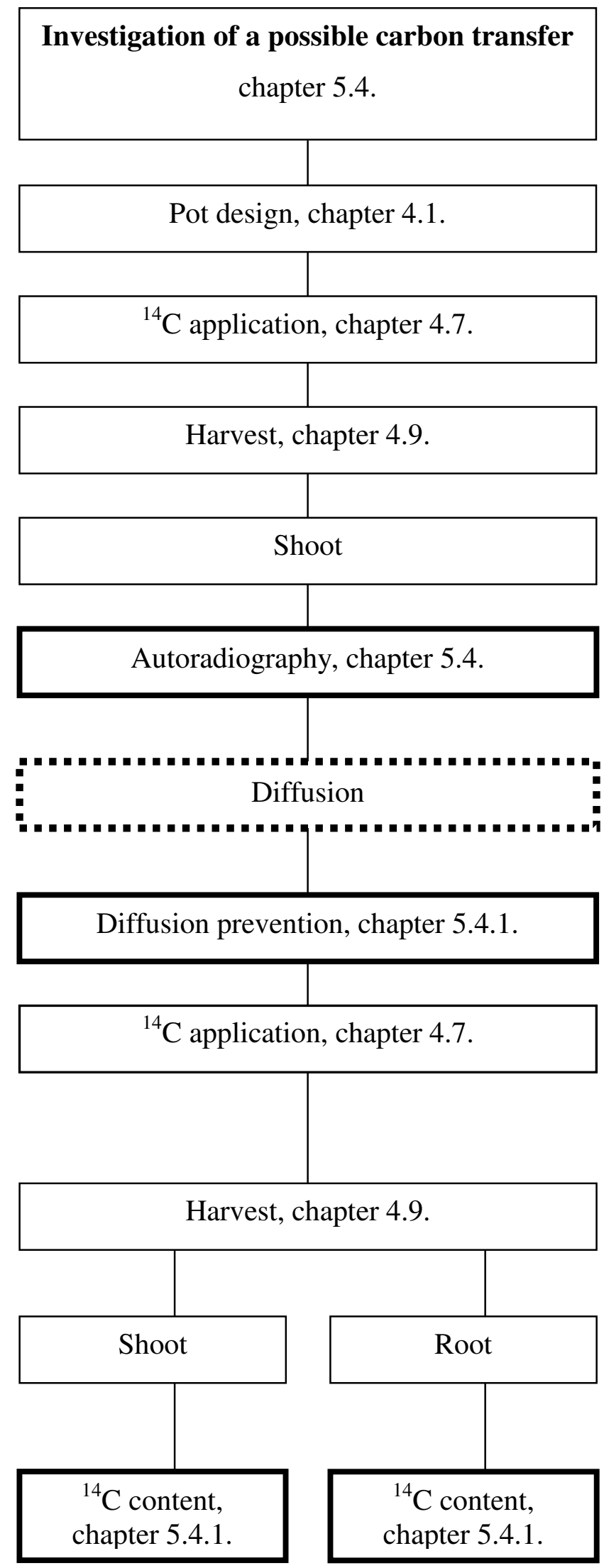

Figure 3:

Scheme of "Investigation on a possible carbon transfer" 


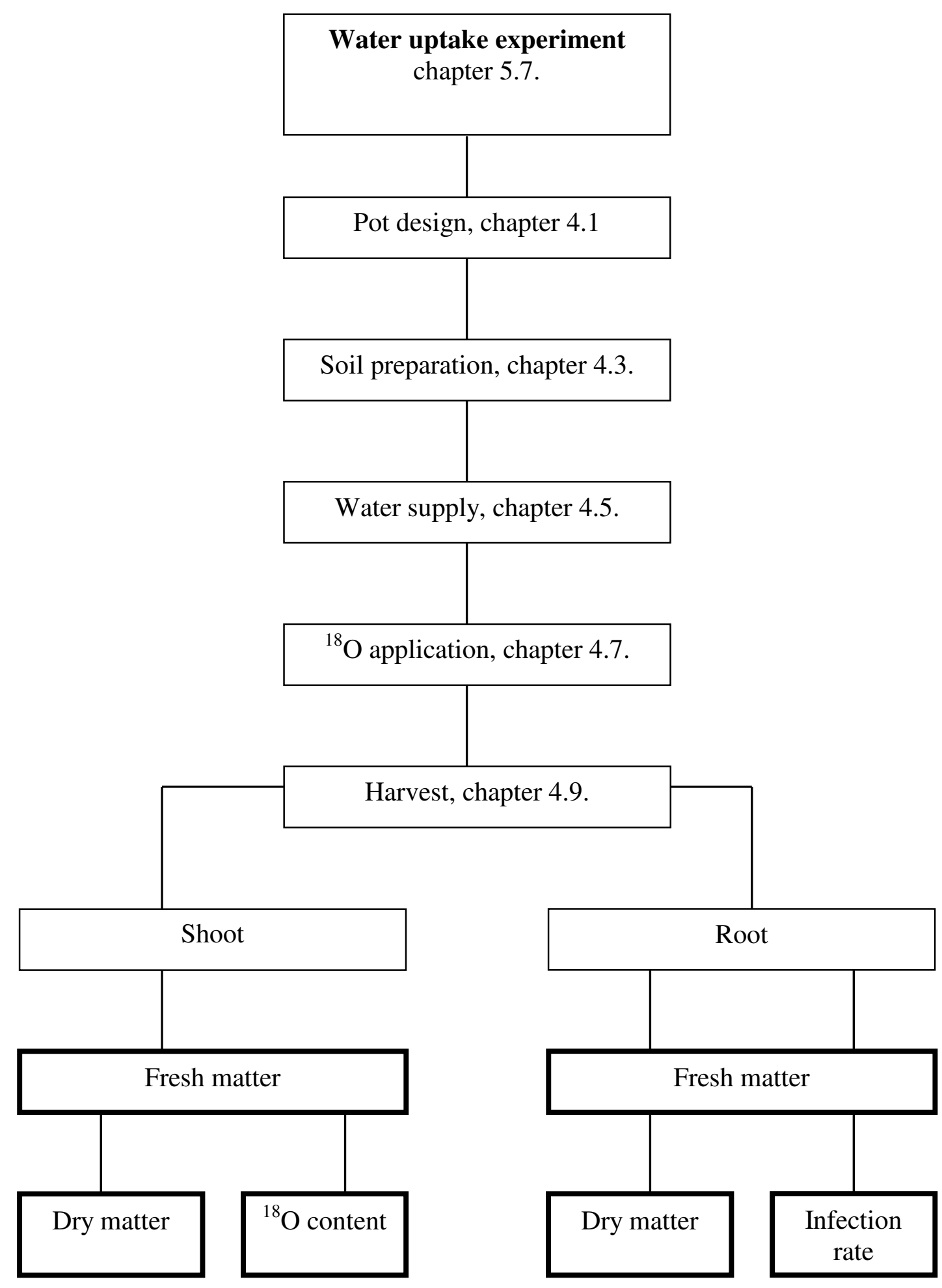

\section{Figure 4:}

Scheme of "Experiment on the role of (V)AM in plant water uptake" 


\subsection{Pot design}

Pots originally utilized by Lange Ness (1998) (Fig. 5) were used with slight modification. The pots were constructed from PVC-pipes $(70 \mathrm{~mm} \emptyset)$.

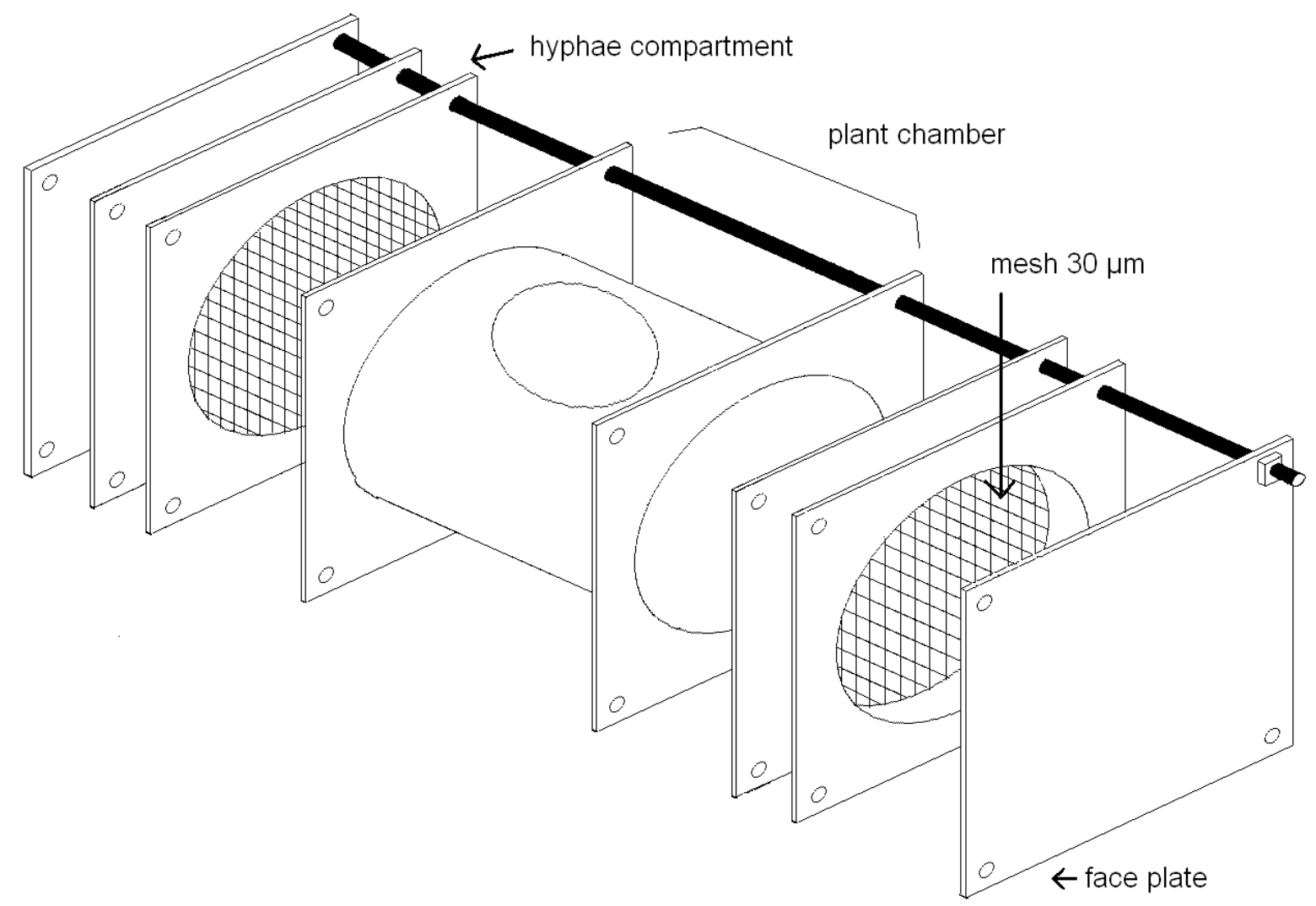

\section{Figure 5:}

Details of the growing units used in the experiments to separate mycorrhizal hyphae from plant roots.

Each unit consists of three chambers, a bigger central plant chamber flanked on both sides by smaller hyphae compartments. The plant chambers have a length of about $50 \mathrm{~mm}$ and the hyphae compartments have a length of $20 \mathrm{~mm}$. The compartments are flanged with PVCplates. The PVC-pipes and the PVC-plates are fixed with plastic glue. The side compartments are separated from the plant chamber by a screen of $30 \mu \mathrm{m}$ mesh (Polyester, W. Kranich GmbH, Germany, OrderNo.: 260124023), through which hyphae but no plant roots can grow. The hyphal compartments are closed by a PVC-plate $(100 \times 100 \mathrm{~mm})$ at both ends. Lag Bolts 
are put through holes $(5 \mathrm{~mm} \varnothing)$ in the corners of all three chambers to fix the plant chamber and PVC face-plates.

Because of the large losses of ${ }^{14} \mathrm{C}$ glucose when plants were watered during the labelling period (chapter 5.1., Tab. 8) the growing units were modified. The modified units were used in the "Hyphae labelling experiment" (chapter 5.3.) and in the "Double labelling experiment" (chapter 5.6.).

Rubber washers were added between each compartment and between the hyphae compartments and the face plates. In addition to the nuts, fixing the growing units, aluminium clips were used to press the compartments together to reduce ${ }^{14} \mathrm{C}$ glucose and water loss between the compartments.

As described in chapter 5.3., the growing units were used to label mycorrhizal hyphae and to use the labelled hyphae as an inoculum. However, the labelled hyphae could not be used to confirm the possible carbon transfer from the fungi to the host, so that the growing units were further adapted (Fig. 6).

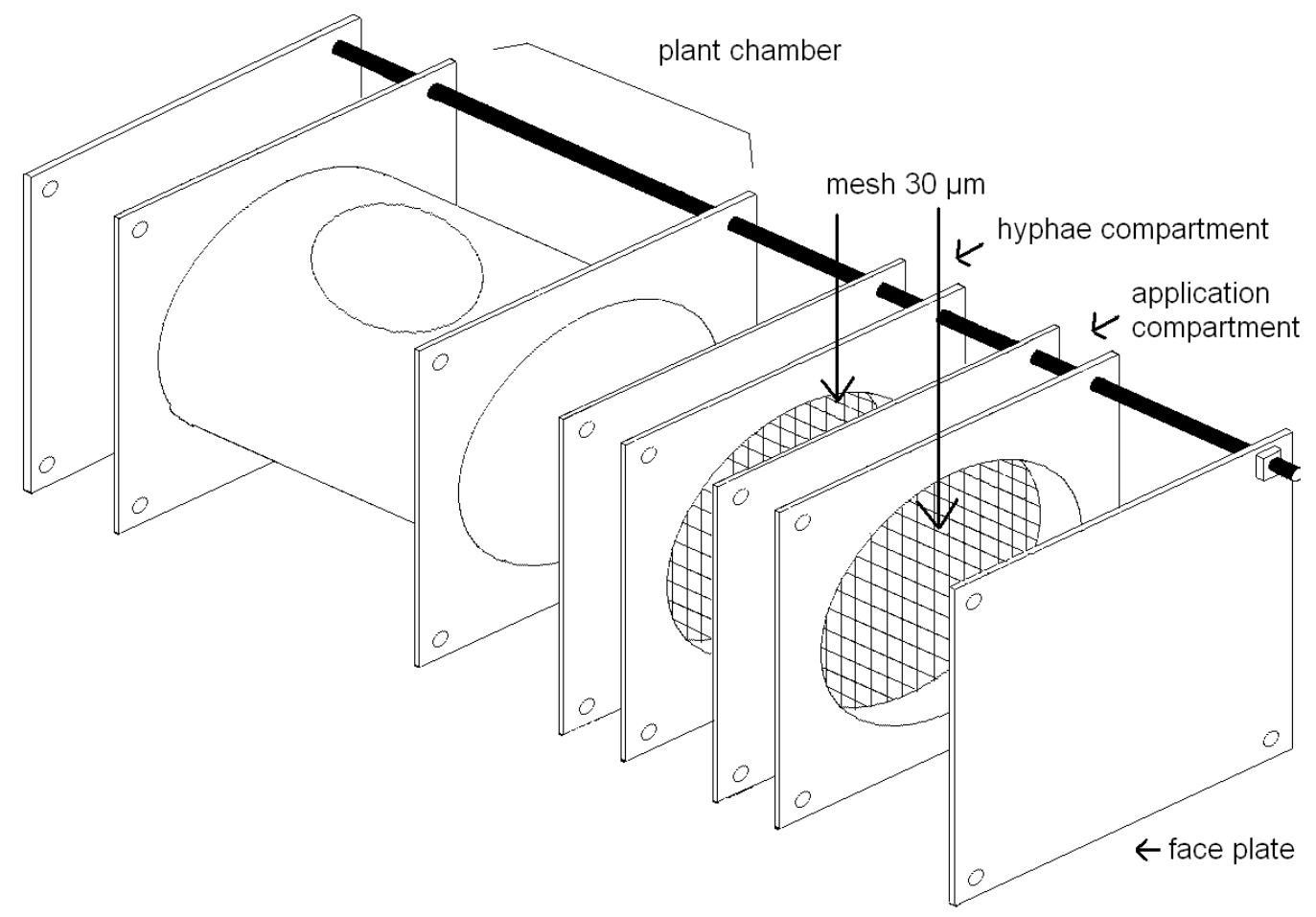

\section{Figure 6:}

Details of the growing units used in the double labelling (with ${ }^{14} \mathrm{C}$ and ${ }^{32} \mathrm{P}$ ) experiment to separate mycorrhizal hyphae from plant roots. 
Here, the same units were used as shown in Figure 5, but with a different arrangement of the compartments. Each unit consists again of three chambers, a bigger plant chamber flanked at one side only by two smaller compartments. The first small compartment (in the "Double labelling experiment": hyphae compartment) and the second small compartment (in the "Double labelling experiment": application compartment) had the same size and were separated from the plant compartment and from each other by a screen of $30 \mu \mathrm{m}$ mesh. Rubber washers and aluminium clips were used again to avoid water losses. These growing units with two hyphae compartments were also used to investigate the water uptake via mycorrhizal hyphae in chapter 5.7..

\subsection{Plant material}

Plants of the tropical weed Chromolaena odorata (family Compositae) were used in the first experiments to investigate the ${ }^{14} \mathrm{C}$ and ${ }^{32} \mathrm{P}$ transfer through mycorrhizal hyphae to the host. Chromolaena odorata is well known as an efficient mycorrhizal plant, with high mycorrhizal infection rates in form of both fungal propagules inside the roots and intensive networks of external mycelium in the soil. The infection is normally correlated with improved plant growth. Such properties were essential in the present investigation for producing large amounts of fungal hyphae, which were labelled and used as inoculum. The plant growth of mycorrhizal plants, in comparison to non-mycorrhizal plants of same ages, is the most important characteristic of a well established mycorrhiza (Fig. 7) and was used to indicate the appropriate time for the application of radioactivity $\left({ }^{14} \mathrm{C}\right.$ and $\left.{ }^{32} \mathrm{P}\right)$ in the present investigation. 


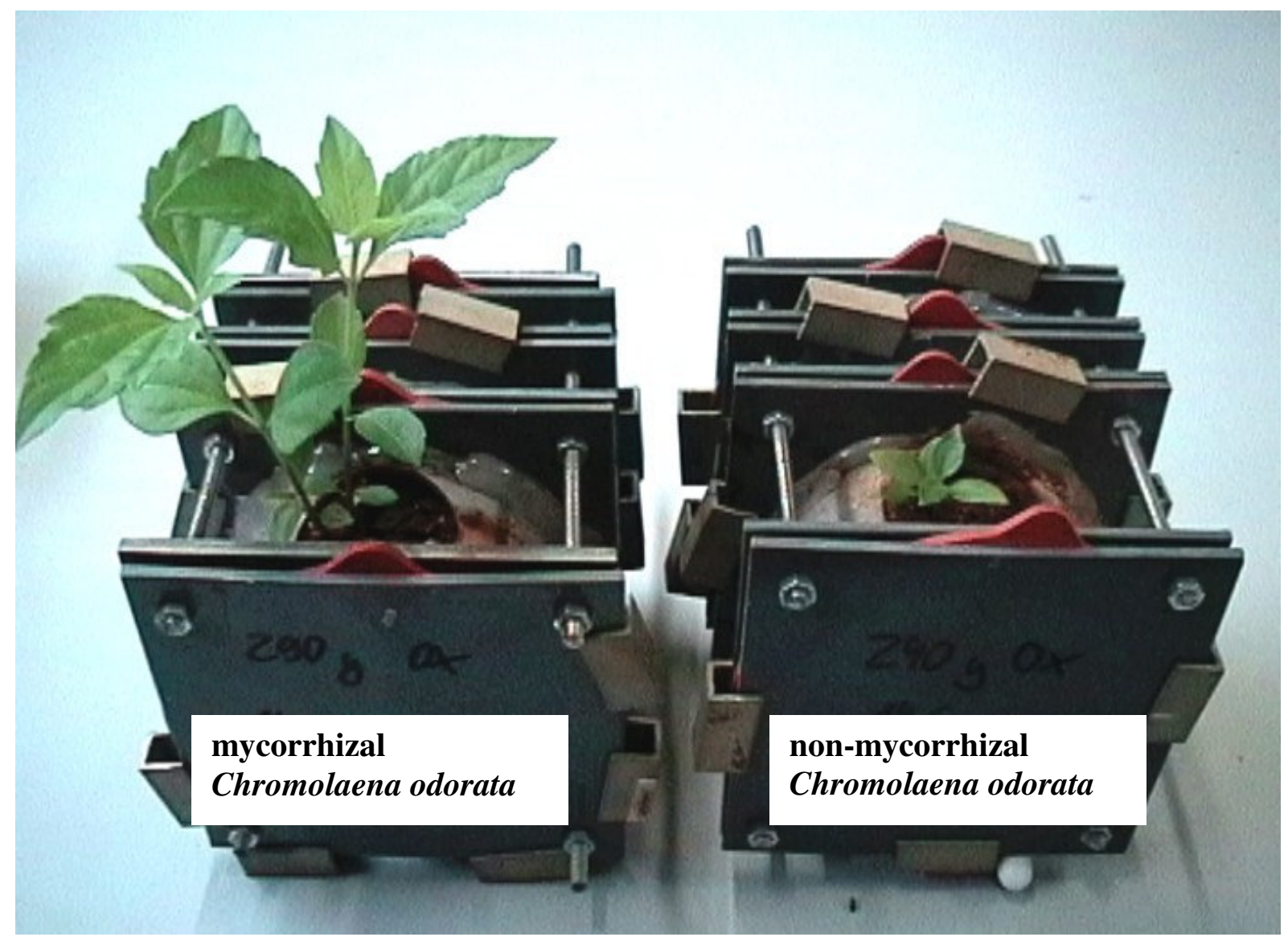

\section{Figure 7:}

Establishment of mycorrhiza of 6 weeks old mycorrhizal Chromolaena odorata plants inoculated with Glomus manihotis (left) and non-mycorrhizal control plants grown in the sterilized soil (right).

In experiments, where young Chromolaena odorata plants were used, the plant seeds were sown in sterile plastic trays and fertilized twice with $500 \mathrm{ml}$ of $1 \%$ Wuxal $^{\circledR}$ Super (8-8-6) during the growing period. After 10 weeks of growth, plants with height of about $10 \mathrm{~cm}$ were inoculated with the labelled hyphae or used as an unlabelled control.

Sorghum bicolor plants were used in the experiment investigating the water transfer via mycorrhizal hyphae (chapter 5.7.). Sorghum bicolor seeds were sowed in plastic pots containing natural 500g Tzekel-soil, 500g Kankab-soil (both from Yucatan/ Mexico) or 800g Paleustox (from Lich, Germany, mixed with quarz sand 1:1, and inoculated with mycorrhizal propagules of the (V)AMF Glomus manihotis. The same amount of the three soils was also used, but sterilized at $120^{\circ} \mathrm{C}$, to grow Sorghum bicolor in plastic pots. After 5 days of growth, 
two plants with a height of approximately $4 \mathrm{~cm}$ were transplanted into the plant compartments of each growing unit.

\section{Plant material for hyphae labelling}

Chromolaena odorata plants with a well developed mycorrhizal infection were used. In the preliminary experiments two mycorrhizal fungal species were tested. Half of the tested plants were inoculated with the mycorrhizal fungus Acaulospora longula, the other half with Gigaspora gigantea. The mycorrhizal plants, which were grown in $2 \mathrm{~kg}$ pots filled with the Paleustox, were transplanted into the plant chambers, together with some soil from their rhizosphere.

The second preliminary experiment had shown a low ${ }^{14} \mathrm{C}$ activity in Chromolaena roots infected with G. gigantea compared with roots colonized with A. longula (chapter 5.2.). Therefore, G. gigantea was replaced by Glomus manihotis, a very efficient and infective mycorrhizal fungi (Ditschar, 2001), which was used in the main experiments (chapter 5.3., 5.4., 5.5., 5.6. and 5.7.).

\subsection{Soil preparation and fertilization}

In the preliminary experiments, a Paleustox (from Lich, Germany) was used in the plant chambers. Chemical analysis of the soil was done by Breitenstein (1988, Tab. 1).

The soil was sieved through a $2 \mathrm{~mm}$ sieve and mixed with quarz sand in the ratio $1: 1$, and homogenized in a cement mixer (smaller amounts of soil were mixed by hand). The soil for the hyphae compartments was sterilized at $120^{\circ} \mathrm{C}$ for 48 hours and fertilized with the hardly soluble hydroxyapatite $\left(\mathrm{Ca}_{5}\left(\mathrm{PO}_{4}\right)_{3} \mathrm{OH}: 162 \mathrm{mg} \mathrm{P} \mathrm{kg} \mathrm{soil}{ }^{-1}\right)$ as a phosphorus source to stimulate the mycorrhizal development. The soil was inoculated with spores and hyphae obtained from the pots of mycorrhizal Chromolaena plants. 


\section{Table 1:}

Soil characteristics of the used paleustox (mg 100g dry soil ${ }^{-1}$ )

\begin{tabular}{l|cc}
\hline Extraction solution & Element & Content $\left(\right.$ mg $100 \mathrm{~g}$ dry soil $\left.{ }^{-1}\right)$ \\
\hline Double lactate & $\mathrm{P}$ & 0.70 \\
$\mathrm{HCl}(10 \%)$ & $\mathrm{N}$ & 6.00 \\
& $\mathrm{~K}$ & 11.63 \\
& $\mathrm{Mg}$ & 23.30 \\
& $\mathrm{Fe}$ & 224.50 \\
& $\mathrm{Al}$ & 247.00 \\
& $\mathrm{Mn}$ & 12.90 \\
& $\mathrm{Zn}$ & 0.77 \\
$\mathrm{n} \mathrm{HCl}$ & $\mathrm{Fe}$ & 9.44 \\
& $\mathrm{Al}$ & 32.25 \\
& $\mathrm{Mn}$ & 4.32 \\
& $\mathrm{Zn}$ & 0.33 \\
\hline
\end{tabular}

source: Breitenstein, 1988

Because of the difficulties to wash the mycorrhizal hyphae out of the Paleustox, in the "hyphae labelling experiment" (chapter 5.3.) two soils were used: the same red Paleustox (from Lich, Germany), used in the previous experiments and also "Schoninger" soil (from Schoningen, Germany).

The Paleustox was used in the plant chamber, whereas the "Schoninger" soil was used in the hyphae compartments. Because of the yellowish white colour and the high amount of sand of the "Schoninger" soil, it is easier to identify and to wash the hyphae out of this soil. The Schoninger soil contained $0.5 \mathrm{mg}$ P $100 \mathrm{~g}$ soil $^{-1}$ by using CAL Extraction (Aly, 2002). Hydroxyapatite $\left(\mathrm{Ca}_{5}\left(\mathrm{PO}_{4}\right)_{3} \mathrm{OH}\right)$ was added after sterilization to the "Schoninger" soil $(162 \mathrm{mg}$ $\mathrm{P} \mathrm{kg}$ soil $^{-1}$ ) as a phosphorous source to stimulate the symbiosis and the formation of mycorrhizal hyphae.

In the "Experiment on correlation between C-transfer and fertilization" (chapter 5.5.) the Paleustox was used, sieved through a $2 \mathrm{~mm}$ sieve and mixed with quarz sand in the ratio1:1. The soil was fertilized either with Mono-calciumphosphate $\left(\mathrm{Ca}\left(\mathrm{H}_{2} \mathrm{PO}_{4}\right)_{2} * \mathrm{H}_{2} \mathrm{O}: 122 \mathrm{mg} \mathrm{P} \mathrm{kg}\right.$ 
soil $\left.^{-1}\right)$, or with $\mathrm{HA}\left(\mathrm{Ca}_{5}\left(\mathrm{PO}_{4}\right)_{3} \mathrm{OH}=162 \mathrm{mg} \mathrm{P} \mathrm{kg} \mathrm{soil}{ }^{-1}\right)$ or left unfertilized as a control. Chromolaena odorata plants were planted into pots which were filled with $800 \mathrm{~g}$ soil and were grown for six weeks in the greenhouse.

In the "Double labelling experiment" three different soils (Kankab, Tzekel, and the Paleustox) were used to study the phosphorus translocation via mycorrhizal hyphae.

Kankab and Tzekel soils occur in the peninsula of Yucatan (Mexico). Kankab (Luvisol) is deeper and more fertile than the Tzekel (Lithosol) soil. It has a dark red colour and forms small discontinuous spots in alternation with Tzekel. The Tzekel soil is shallow, black and limited by the rocks. Their colour varies from clear coffee to dark red and contained outcrops of calcareous soils. Large litter and gravel were removed from the air dried soils, because of the small size of the growing units.

The three soils were filled into the outer hyphal compartments, where only mycorrhizal hyphae were able to grow and no plants roots. For all treatments, quarz sand was used in the first hyphae compartment to provide a buffer between the plant compartment and the outer hyphae compartment, and to increase the distance between the additional phosphorus source and the plant.

The $2 \mathrm{~mm}$ sieved paleustox was used in all plant compartments to have identical conditions for plant growth. Phosphorus in form of $\mathrm{MCP}\left(\mathrm{Ca}\left(\mathrm{H}_{2} \mathrm{PO}_{4}\right)_{2} * \mathrm{H}_{2} \mathrm{O}: 122 \mathrm{mg} \mathrm{P} \mathrm{kg} \mathrm{soil}{ }^{-1}\right)$ was mixed into half of the red Paleustox treatments to evaluate phosphorus transfer rates via mycorrhizal hyphae into P-fertilized and non-fertilized plants.

All treatments were fertilized once during the growing period at the following rates $\left(\mathrm{mg} \mathrm{kg}^{-1}\right.$ dry soil): $\mathrm{NH}_{4} \mathrm{NO}_{3}, 95 ; \mathrm{K}_{2} \mathrm{SO}_{4}, 60$ and $\mathrm{MgSO}_{4} * 7 \mathrm{H}_{2} \mathrm{O}, 135$. The nutrient supply was needed to obtain acceptable growth rates of Chromolaena odorata and therefore to increase the mycorrhizal infection.

In the "water uptake experiment" the same soils were used as in the "Double labelling experiment". Each soil was divided into two parts and one part was sterilized in a forced air oven at $120^{\circ} \mathrm{C}$. The other part of Tzekel and Kankab was used as "natural" in order to maintain its mycorrhizal infectivity. One part of the Paleustox was mixed with mycorrhizal propagules of Glomus manihotis (spores, hyphae and inoculated plant roots) for inoculation. The Paleustox, Kankab and Tzekel were weigted into each growing compartment to have same volumes of soil (Tab. 2). 


\section{Table 2:}

Weights of soil and quarz sand which were used in each compartment of the growing units

\begin{tabular}{l|ccc}
\hline Soil/ substrate & $\begin{array}{c}\text { Plant compartment } \\
(\mathrm{g} \text { dry soil })\end{array}$ & $\begin{array}{c}\text { Hyphae compartment } \\
(\mathrm{g} \text { dry soil })\end{array}$ & $\begin{array}{c}\text { Buffer compartment } \\
(\mathrm{g} \text { dry soil })\end{array}$ \\
\hline Kankab (red) & 200 & 80 & \\
Tzekel (black) & 220 & 85 & \\
Paleustox & 290 & 120 & 145 \\
& & & \\
Quarz sand (buffer) & & & \\
\hline
\end{tabular}

Because of the different structures in the soils of Kankab and Tzekel (stones, plant material, etc.) the soil was mixed and spooned into the growing compartments to achieve a representative soil amount and to get similar soil components in each growing unit.

All treatments were fertilized after one week of growth at the following rates $\left(\mathrm{mg} \mathrm{kg}^{-1} \mathrm{dry}\right.$ soil): $\mathrm{NH}_{4} \mathrm{NO}_{3}, 95 ; \mathrm{K}_{2} \mathrm{SO}_{4}, 60$ and $\mathrm{MgSO}_{4} * 7 \mathrm{H}_{2} \mathrm{O}, 135$.

After the soils were weighed into the different compartments, water was pipetted onto the substrates at the following rates: quarz sand (buffer compartment): 35ml, Kankab and Tzekel (outer compartment): $50 \mathrm{ml}$.

\subsection{Growth conditions}

Chromolaena plants of growing units were grown in the greenhouse under daylight and temperatures of about $28^{\circ} \mathrm{C}$ during the day and $21^{\circ} \mathrm{C}$ during the night. After the hyphae had grown into the hyphal compartments, the plants were transferred to a growth chamber, where the units were isotope-labelled and kept under similar conditions as in the greenhouse. Plants were watered daily with de-ionised water, and to increase the humidity in the growth chamber, a water bowl was put below the plants. Plants were put randomly into the growth chamber. 
In the "Double labelling experiment" Chromolaena plants were inoculated with ${ }^{14} \mathrm{C}$-labelled mycorrhizal hyphae and were grown in the greenhouse under daylight and $28 / 21{ }^{\circ} \mathrm{C}$ regime. After the establishment of the Mycorrhiza (6 weeks) plants were transferred to a growth chamber with similar growing conditions for one week. After a period of adaptation to the growing conditions, ${ }^{32} \mathrm{P}$ was added to the mycorrhizal hyphae in the outer application compartment and plants were left to grow for a further week in the growth chamber.

\subsection{Water supply}

All plants in the experiments were watered daily with de-ionised water according to their needs. Only the plants in the "water uptake experiment" (chapter 5.7.) were watered differently in which the plants of the same treatments received identical water amounts. The daily water supply is shown in figure 8. Slight differences in the water supply per unit in the last four weeks of the experiment, especially of the treatment Tzekel, reflect the greater plant growth and water demand of Sorghum bicolor in these treatments.

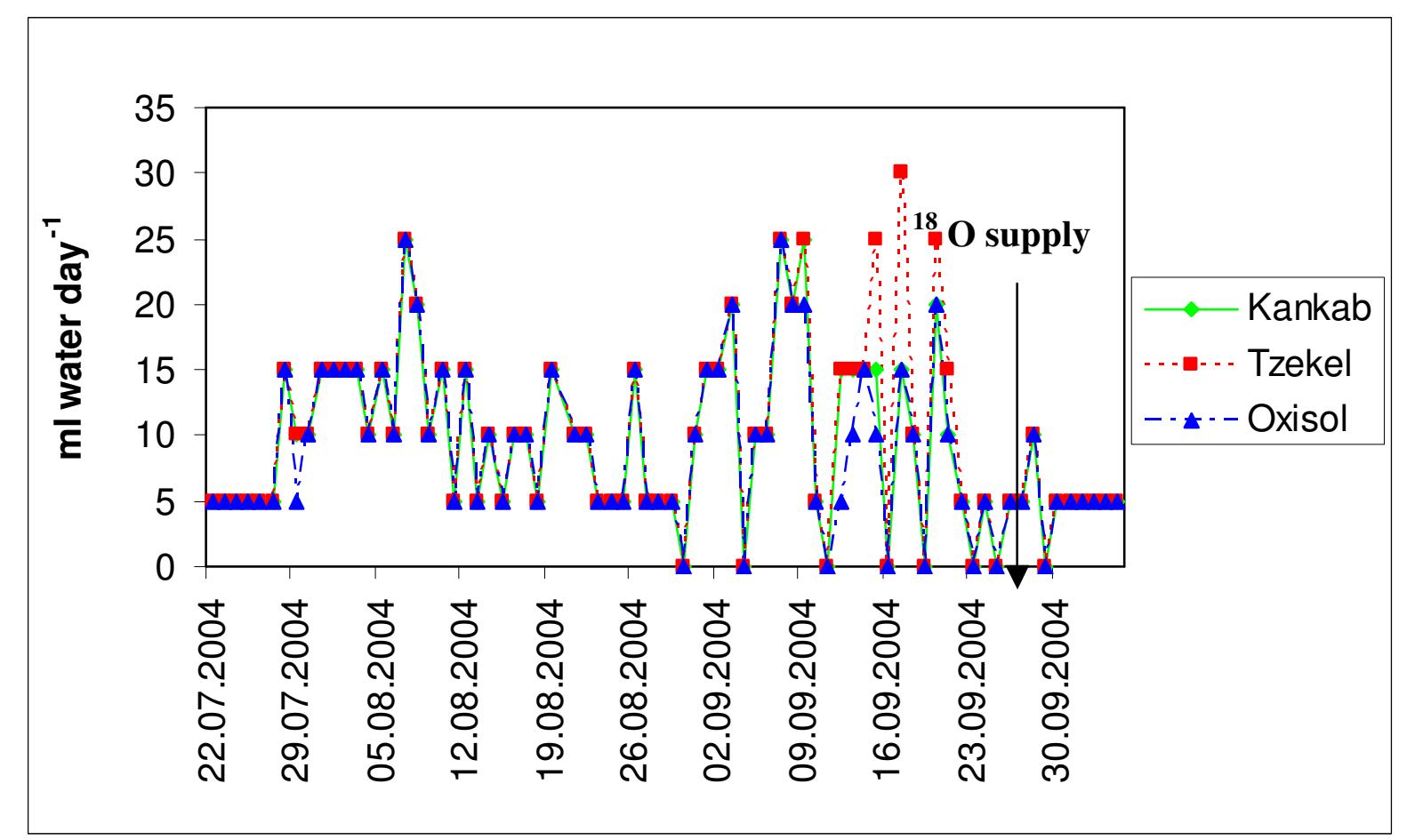

\section{Figure 8:}

Daily water supply per unit during the $\mathrm{H}_{2}{ }^{18} \mathrm{O}$ uptake experiment to Sorghum bicolor plants grown in the plant compartment with different soil types in the outer hyphae compartment (Kankab, Tzekel and Paleustox). 
The hyphae grew into the hyphae compartments within four weeks. These compartments were opened carefully without damaging the hyphal-network connected with the plants, and $2 \mathrm{ml}$ radioactive ${ }^{14} \mathrm{C}$ - glucose in aqueous solution $\left(185 \mathrm{kBq} \mathrm{ml}^{-1}\right)$ were pipetted into each compartment. The solution was prepared from a ${ }^{14} \mathrm{C}$ D-glucose solution with a specific

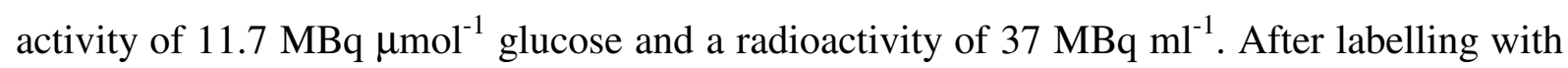
${ }^{14} \mathrm{C}$ - glucose the plants were transferred back to the growth chamber.

As shown in chapter 5.2., the total uptake of ${ }^{14} \mathrm{C}$ into the external mycorrhizal hyphae was relatively low in relation to the ${ }^{14} \mathrm{C}$ activity which was used to label the hyphae. To increase the ${ }^{14} \mathrm{C}$ glucose uptake by the mycorrhizal hyphae the activity of ${ }^{14} \mathrm{C}$ glucose in aqueous solution was doubled to $370 \mathrm{kBq} \mathrm{ml}^{-1}$ in the main experiments.

4.7. ${ }^{14} \mathrm{C},{ }^{32} \mathrm{P}$ and ${ }^{18} \mathrm{O}$ application to mycorrhizal hyphae

After the mycorrhizal hyphae were grown into the outer application compartment ${ }^{14} \mathrm{C}$ glucose was pipetted into this compartment as an additional source of carbon to the hyphae to investigate the ${ }^{14} \mathrm{C}$ uptake and the transport of ${ }^{14} \mathrm{C}$ through the mycorrhizal hyphae to the host (chapter 5.3.).

The same procedure was followed to pipette ${ }^{32} \mathrm{P}$ (chapter 5.6.) and ${ }^{18} \mathrm{O}$ (chapter 5.7.) into the outer compartment.

${ }^{32} \mathrm{P}$ solution was prepared from $\mathrm{KH}_{2}{ }^{32} \mathrm{PO}_{4} .200 \mu{ }^{32} \mathrm{P}$ in aqueous solution $\left(1075 \mathrm{~Bq} 200 \mu \mathrm{l}^{-1}\right)$ were pipeted into each compartment.

${ }^{18} \mathrm{O}$ enriched normalized water (nominal ${ }^{18} \mathrm{O}$ concentration 10 atom\%) were used to investigate the water transport through mycorrhizal hyphae. $1 \mathrm{ml}{ }^{18} \mathrm{O}$ enriched water was pipetted into each outer hyphae compartment.

\subsection{Prevention of diffusion}

To prevent diffusion of water, containing ${ }^{14} \mathrm{C}$ glucose, from the outer application compartment to the plant compartment, the first hyphae compartment was filled with coarse 
sand of $2 \mathrm{~mm}$ in diameter. Furthermore, the plant was carefully watered daily with few drops using a pipette to allow the soil in the plant compartment to absorb the water drops without water movement into the outer application compartment.

As shown in chapter 5.4. the coarse sand of $2 \mathrm{~mm}$ in diameter in the first hyphae compartment could not prevent the water diffusion from the application compartment to the plant compartment.

To prevent the diffusion in the growing units, the $32 \mu \mathrm{m}$ mesh must be so prepared, that the mycorrhizal hyphae must be able to grow through it, but no water should diffuse through.

Physiologically neutral Vaseline as a hydrophobic barrier was used as a diffusion inhibitor, because water is not able to pass the Vaseline-treated mesh. Mycorrhizal hyphae were able to grow through the treated mesh to establish an intensive hyphal network, in the hyphae compartment.

To test Vaseline as a diffusion barrier, three growing units were used as described in chapter 4.1.. The mesh of the hyphal compartment was rubbed with Vaseline and the compartment was filled with quarz sand.

One Chromolaena odorata plant, infected with G. manihotis, was transplanted in each of two growing chambers, which were flanked by two hyphal compartments at one side, which contained quarz sand. Another Chromolaena plant free of mycorrhizal infection was transplanted into the third growing unit.

After four weeks of growth the hyphal compartment of one growing unit was tested, for mycorrhizal hyphae. At the same time ${ }^{14} \mathrm{C}$ glucose in aqueous solution was pipetted into the other two hyphal compartments of the remaining two growing units to test, if there was a diffusion of glucose into the plant chamber.

One week after the addition of the ${ }^{14} \mathrm{C}$ glucose one leaf was harvested from each plant (infected and non-infected) to measure the radioactivity by imaging.

\subsection{Harvest of labelled hyphae}

Two and four days after addition of the ${ }^{14} \mathrm{C}$ - glucose the hyphae of the hyphae compartments were harvested by wet-sieving (Daniels and Skipper ,1982): the soil of each compartment was suspended in 11 water and after heavier particles settled, the remaining suspension including the hyphae and spores was poured through a $45 \mu \mathrm{m}$ mesh sieve. The hyphae were washed five 
times and transferred with de-ionised water from the sieve into a petri-dish and then pipetted into a second petri-dish to eliminate surplus water and soil particles. Approximately $50 \mu 1$ of the hyphae was used to measure the ${ }^{14} \mathrm{C}$ uptake by the hyphae (chapter 4.13.). The surplus water was checked for ${ }^{14} \mathrm{C}$ activity to ensure that the ${ }^{14} \mathrm{C}$ is only in the hyphae and not in the wash water.

\subsection{Harvest of plant material}

\subsubsection{Preliminary experiments}

In the preliminary-experiments plant shoots were cut at the surface of the soil and the roots were washed free of soil on a $2 \mathrm{~mm}$ sieve. Shoots were not used in the pre-experiments, because the aim was to measure ${ }^{14} \mathrm{C}$ activities in the mycorrhizal hyphae and in the infected roots of the Chromolaena plants.

\subsubsection{Hyphae labelling experiment}

Plant shoots were cut at the surface of soil and the roots were washed out of the soil on a 2 mm sieve. Labelled plants and roots and the control plants were weighted and frozen with liquid nitrogen without destroying leaves and roots and stored in a freezer at $-18^{\circ} \mathrm{C}$.

\subsubsection{Experiment on the correlation between C-transfer and fertilization}

Plants were cut at the surface of the soil and oven dried at $60^{\circ} \mathrm{C}$. Roots were washed out of the soil on a $2 \mathrm{~mm}$ sieve and conserved in ethanol (70\%) and acetic acid (3:1) solution for the measurement of infection rate. The activity of ${ }^{14} \mathrm{C}\left(\mathrm{Bq} \mathrm{g}^{-1}\right)$ was determined in single leaves and stem by burning the plant material in a Biological Oxidizer OX500 at $400{ }^{\circ} \mathrm{C}$ and by measuring the ${ }^{14} \mathrm{C}$-activity with a liquid scintillation-counter (chapter 4.16.). Roots were not measured for ${ }^{14} \mathrm{C}$ activity, because it was not possible to wash out the surplus inoculum from the roots, so that the inoculum will affect the ${ }^{14} \mathrm{C}$ activity of the roots. 


\subsubsection{Double labelling experiment}

Plants were cut at the surface of the soil and were divided into upper and lower part and separated in leaves and stem. $50 \%$ of the leaves and stems were used to measure the dry matter of the plants, $30 \%$ were used to measure the ${ }^{14} \mathrm{C}$ and ${ }^{32} \mathrm{P}$ content and the rest was used for gel-electrophoresis. The plant material for gel-electrophoresis was frozen with liquid nitrogen and stored in a freezer at $-18^{\circ} \mathrm{C}$.

Roots were washed out of the soil and approximately 50\% of the roots were used to measure the dry matter. The remaining roots were used to measure the ${ }^{14} \mathrm{C}$ and ${ }^{32} \mathrm{P}$ content in dry matter and for gel-electrophoresis (samples were also frozen and stored at $-18^{\circ} \mathrm{C}$ ). The first $2 \mathrm{~cm}$ of the root network was removed and were used to measure the dry matter. Surplus inoculum in this part could influence the ${ }^{14} \mathrm{C}$ activities in the roots.

4.10.5. Experiment on the role of (V)AM in water uptake and use of ${ }^{18} \mathrm{O}$

After five and after nine weeks of growth plant parameters were measured to investigate the plant growth in the different soils. One of these plant parameters was the height of the Sorghum plant, which was measured from the surface of the soil up to the top of the plant. The second plant parameter was the diameter of the shoot, which was measured directly over the soil surface. Additionally, physiological parameters were documented to describe the vitality of the experimental plants in each treatment.

After nine weeks the plants were cut at the surface of the soil and were weighted totally for fresh matter. Shoots then were homogenized by mixing and $1 \mathrm{~g}$ fresh weight from each shoot was dried out to calculate the dry matter of the respective shoot. The remaining fresh plant material was stored in a freezer for two weeks and was used to measure the ${ }^{18} \mathrm{O}$ content. Roots were washed out of the plant compartment and one part was used to measure the root dry matter and the other part was stored in ethanol (75\%) and acetic acid (60\%) (ratio 3:1) to measure the infection rate. 
The harvested shoots and roots were used to measure the ${ }^{14} \mathrm{C}$ transfer by autoradiography and counting the radioactivity upon burning of a sub-sample (chapter 4.16.). They were also used to extract possible labelled carbon compounds from the fresh shoot and root mass. Therefore, it was not possible to measure the dry matter of the shoots and roots in all plants in the "Hyphae labelling experiment" and "Experiment on correlation between C-transfer and fertilization". The statistical interpretation and discussion is based mainly on the fresh mass of the plants. To ensure that the results of fresh plant material were comparable, only well grown plants were harvested. The statistical analysis of the dry matter, when possible, was used to confirm the results of the fresh mass.

In the case of plants inoculated with ${ }^{14} \mathrm{C}$ labelled mycorrhizal hyphae of G. manihotis, half of the harvested shoots and roots were measured separately for dry matter before burning the plants. These plants were selected randomly. The remaining frozen shoots and roots were oven dried at $60^{\circ} \mathrm{C}$ to determine the dry matter.

To measure the dry matter production half of the fresh weight was used and dry weight for the whole sample was calculated.

\subsection{Measurement of infection rate}

Because of the expected low root biomass production and the use of root fresh weight for ${ }^{14} \mathrm{C}$ measurements no sample was available for measuring the mycorrhizal infection rate in either preliminary experiment (chapter 5.1. and chapter 5.2.) or in the hyphae labelling experiment (chapter 5.3.). Plants of Chromolaena odorata are very sensitive and strongly dependent in their growth on mycorrhizal fungi. A highly significant increase of the fresh mass production by Chromolaena odorata plants inoculated with Glomus manihotis, compared to nonmycorrhizal control plants, indicates, that there was an effective mycorrhizal colonization.

The infection rate was measured in the "Experiment on correlation between C-transfer and fertilization" (chapter 5.5.). Plant roots were stained by using the method of Phillips and Haymann (1970). Roots were cleared in $10 \% \mathrm{KOH}$ at $90^{\circ} \mathrm{C}$ for 40 minutes and washed in deionized water to remove the $\mathrm{KOH}$. The washed roots were then acidified with $2 \mathrm{~N} \mathrm{HCl}$ for 10 minutes and stained with $0.1 \%$ trypan blue in lactic acid for 20 minutes. The stained roots were stored in a solution consisting of glycerol, lactic acid and water (1:1:1). 
The infection rate was measured by cutting the roots into $5 \mathrm{~mm}$ segments. 100 root segments were randomly choosen and arranged on a glass-slide. All root segments out of 100 were counted which contained one or more mycorrhizal propagules and the number of infected root segments was considered the percentage of infection.

4.13. Radioactivity measurement in the hyphae and their use as inoculum

Approximately $50 \mu \mathrm{l}$ of the hyphae suspension were transferred with a pipette to a scintillation-vial (Polyvials, Zinsser Analytic) and mixed with $10 \mathrm{ml}$ Lumasafe $^{\mathrm{TM}}$ Plus (Lumac CSC B.V., Netherlands) to measure the ${ }^{14} \mathrm{C}$-activity with a liquid scintillation-counter (Philips). Additionally, $20 \mu \mathrm{l}$ surplus wash-water of the hyphae was measured.

The same method was used to measure the ${ }^{14} \mathrm{C}$-activity in the mycorrhizal roots. Roots were ground in a mortar to get a suspension, which was mixed with $5 \mathrm{ml}$ water. $500 \mu \mathrm{l}$ of the root suspension was measured in the liquid scintillation-counter.

The measuring time for hyphae and roots was $10 \mathrm{~min}$, after the suspensions were cooled to $15^{\circ} \mathrm{C}$ to stabilize the measurement procedure.

In the "Hyphae labelling experiment" it was necessary to measure the radioactivity of the inoculum. Therefore, the labelled hyphae were washed out five times by wet-sieving (chapter 4.6) and transferred with de-ionised water from the sieve into a petri-dish and then pipetted into a second petri dish to eliminate surplus water and soil particles. Approximately one quarter of the hyphae was transferred to a scintillation-vial, mixed with $10 \mathrm{ml}$ Lumasafe ${ }^{\mathrm{TM}}$ Plus and the ${ }^{14} \mathrm{C}$ was measured with a liquid scintillation-counter (Philips). The remaining $3 / 4$ were used for subsequent inoculation.

Because of the variability of ${ }^{14} \mathrm{C}$ activities in $3 / 4$ of the mycorrhizal hyphae, the labelled hyphal inoculum was weighed in the "Experiment on correlation between C-transfer and fertilization" (chapter 5.5.) and in the experiment of "Investigation of a possible carbon transfer" (chapter 5.4.) to have same amounts of labelled mycorrhizal hyphae and to ensure that mycorrhizal hyphae contain similar ${ }^{14} \mathrm{C}$ activities. The hyphae were transferred collectively into one petri dish. The wet mycorrhizal hyphae were weigted and were split into 27 parts of 100mg each, which were collected in Eppendorf caps. ${ }^{14} \mathrm{C}$ was measured in three out of the 27 hyphae samples to analyse the activity in the mycorrhizal hyphae which were 
used as inoculum in the double labelling experiment. An average of $3000 \mathrm{~Bq}$ was measured in 100mg mycorrhizal hyphae, which was used to inoculate a new Chromolaena odorata plant.

\subsection{Radioactivity measurement in colonized mycorrhizal roots}

After four days of labelling the hyphae in the hyphae compartments (chapter 4.1.), roots of Chromolaena odorata plant, grown in the plant compartment, were washed out of the soil. Two $\mathrm{ml}$ destilled water was added to $1 \mathrm{~g}$ roots, and the roots were ground to get a homogenous root-suspension. The root-suspensions were transferred with a pipette to a scintillation-vial (Polyvials, Zinsser Analytic) and mixed with $10 \mathrm{ml}$ Lumasafe $^{\mathrm{TM}}$ Plus (Lumac CSC B.V., Netherlands) to measure the ${ }^{14} \mathrm{C}$-activity with a liquid scintillation-counter (Philips).

In the first preliminary experiment $500 \mu \mathrm{l}$ of the root/ water suspension was measured for ${ }^{14} \mathrm{C}$ activity to show a possible carbon transport through the external mycorrhizal hyphae into the internal hyphae. Because of the high quench, caused by the red colour of the used soil, the ${ }^{14} \mathrm{C}$ activity was measured again in the second preliminary experiment.

In the second preliminary experiment, the root/ water suspension was measured again in a liquid scintillation-counter. After the first measurement (duration $1 \mathrm{~min}$ ) the sample was split into two equal parts and the volume was brought to $10 \mathrm{ml}$ with Lumasafe (fig. 11, fig. 12, step 2). The same dilution of the samples in step 2 was used in step 3. The duration of the measurement in step 3 was $60 \mathrm{~min}$ to stabilize the measurement procedure to get results as precise as possible. Scintillation of the diluted samples was used for quench correction. 
The activity of ${ }^{14} \mathrm{C}\left(\mathrm{Bq} \mathrm{g}^{-1}\right)$ was determined in single leaves, stem and roots by burning the plant material in a Biological Oxidizer OX500 at $400{ }^{\circ} \mathrm{C}$ (Fig. 9).

\section{Biological Oxidizer}

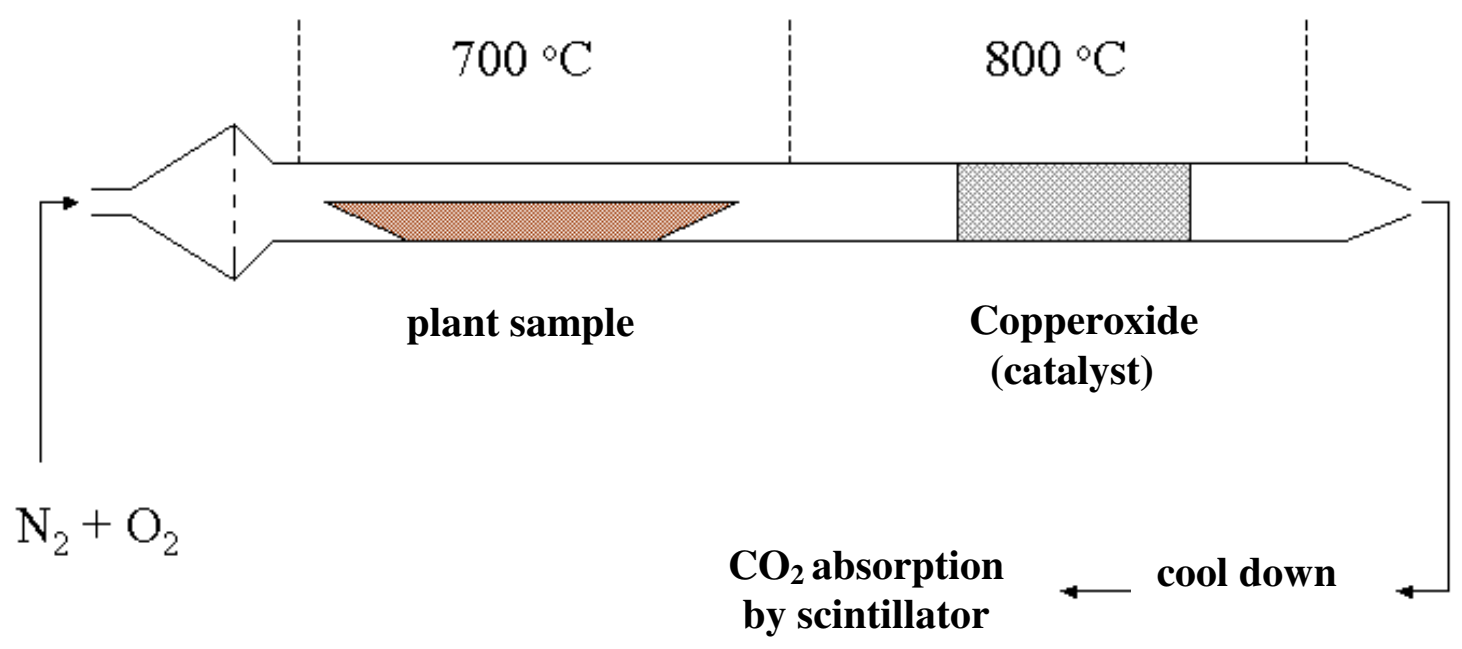

\section{Figure 9:}

Burning process by using the Biological Oxidizer

The released $\mathrm{CO}_{2}$ was transported by a nitrogen stream into a scintillation-vial, containing the scintillator (Oxysolve C400, Zinsser Analytic), where the carbon was collected. The ${ }^{14} \mathrm{C}$ concentration was measured with a liquid scintillation-counter (Philips).

Plants were also prepared to show the distribution of ${ }^{14} \mathrm{C}$ by autoradiography. Plants were dried in an oven $\left(60^{\circ} \mathrm{C}, 72\right.$ hours) between glass plates and paper. The dried plants were put on Imaging plates and exposed for 48 hours in the dark. The Imaging plates were evaluated with the Aida-Program (Version 3.1, Raytest $\mathrm{GmbH}$ ) to quantify ${ }^{14} \mathrm{C}$ in stems, leaves and roots using 2D-densitometry. The evaluation of the radioactivity was measured in PSL (photo-stimulated luminescence), which represent the intensity of the blackness of one region $\left(\mathrm{PSL} \mathrm{mm} \mathrm{m}^{-2}\right.$ ) and therefore, the ${ }^{14} \mathrm{C}$ accumulation in shoots and roots. The background intensity of the Imaging-plates was subtracted from the calculated intensity of the same region to result 
in the signal intensity of the region. For each region one individual background was subtracted. Different quantum levels as used by the autoradiography in Figure 14, Figure 16 and Figure 17 have no influence of the real blackness/ radioactivity of the plants, they only used to optimize the optical view.

\subsection{6. ${ }^{14} \mathrm{C}$ and ${ }^{32} \mathrm{P}$ activity in shoots, roots and mycorrhizal hyphae}

The activity of ${ }^{14} \mathrm{C}\left(\mathrm{Bq} \mathrm{g}^{-1}\right)$ was determined in single leaves, stem, roots and in mycorrhizal hyphae (from the buffer compartment) by burning the material in a Biological Oxidizer OX500 at $400{ }^{\circ} \mathrm{C}$ to measure the ${ }^{14} \mathrm{C}$ content. The ash was removed from the Biological Oxidizer, weighed and transferred into a scintillation-vial (Polyvials, Zinsser Analytic) with $10 \mathrm{ml}$ Lumagel Safe (Lumac) and water (ratio: 10:5). The ash and the luminator were mixed to give a homogenous suspension-gel. The ${ }^{32} \mathrm{P}$ concentration was measured with a liquid scintillation-counter (Packard, Tricarb C 2200). The measurement was carried out at $15^{\circ} \mathrm{C}$ for $10 \mathrm{~min}$.

The difficulty of ${ }^{14} \mathrm{C}$ and ${ }^{32} \mathrm{P}$ measurement in the plant material was, that both isotopes were in the same plant material, so that the same plant material had to be burnt for $\mathrm{C}$ and the remaining ash analysed for $\mathrm{P}$. To ensure, that there is no ${ }^{32} \mathrm{P}$ release by measuring the ${ }^{14} \mathrm{C}$ quantities a small preliminary experiment was carried out:

During the first burning step only ${ }^{14} \mathrm{C}$ activities were measured and therefore, a burning temperature was chosen, where only ${ }^{14} \mathrm{C}$ could be measured. To find out the optimal temperature, approximately $100 \mathrm{mg}$ of ${ }^{14} \mathrm{C}$ labelled plant material was measured by increasing the burning temperature stepwise during the burn, ${ }^{14} \mathrm{C}$ activities were measured at each temperature-step by scintillation-counting (Tab. 3). 


\section{Table 3:}

${ }^{14} \mathrm{C}$ activities determined in ground plant material burnt at different temperatures

\begin{tabular}{l|ccc}
\hline & Temperature & & \\
& $\left({ }^{\circ} \mathrm{C}\right)$ & $d p m$ & $B q g^{-1}$ \\
\hline Sample $1^{+}$ & & $\mathbf{2 1 5 8 . 0}$ & $\mathbf{3 4 9 . 1}$ \\
Sample $2^{++}$ & 100 & 36.9 & 5.5 \\
& 200 & 223.4 & 33.5 \\
& 300 & 584.0 & 87.7 \\
& 400 & 452.9 & 68.0 \\
& 500 & 412.9 & 62.0 \\
& 600 & 396.5 & 59.4 \\
& $700 / 800$ & 191.6 & 28.8 \\
\hline total & & $\mathbf{2 2 9 8 . 2}$ & $\mathbf{3 4 4 . 0}$ \\
\hline
\end{tabular}

${ }^{+}$Burning with Oximat (Zinsser), catalyst $681^{\circ} \mathrm{C}$, sample chamber $902^{\circ} \mathrm{C}$

${ }^{++}$Burning with Biological Oxidizer OX500, catalyst $600^{\circ} \mathrm{C}$

The plant samples, burned in two different ways, show the same total ${ }^{14} \mathrm{C}$ activities of $345 \mathrm{~Bq}$ $\mathrm{g}^{-1}$. The greatest release of ${ }^{14} \mathrm{CO}_{2}$ occurred in sample 2 between $300^{\circ} \mathrm{C}$ and $400^{\circ} \mathrm{C}$.

To ensure, that there is no ${ }^{32} \mathrm{P}$ release by burning the plant material at $600{ }^{\circ} \mathrm{C},{ }^{32} \mathrm{P}$ labelled $\mathrm{Zea}$ mays plants were burned at different temperature levels. The released gas of each temperature level was collected with the scintillator (18ml Oxysolve C400) and was measured by scintillation-counting. The ash from each temperature level was collected and measured with Lumagel Safe (Lumac) and water (ratio: 10:5) for ${ }^{32} \mathrm{P}$ activity by scintillation-counting. 


\section{Table 4:}

${ }^{32} \mathrm{P}$ release from ${ }^{32} \mathrm{P}$ labelled plants by burning the plant material stepwise at temperatures up to $600^{\circ} \mathrm{C}$.

\begin{tabular}{l|ccc}
\hline scintillator & Temperature & \\
& $\left({ }^{\circ} \mathrm{C}\right)$ & $d p m$ & $K B q g^{-1}$ \\
\hline Oxysolve C400 & 200 & 0 & 0 \\
& 300 & 0 & 0 \\
& 400 & 0 & 0 \\
& 500 & 0 & 0 \\
Lumagel Safe & 600 & 0 & 0 \\
(ash measurement) & & & \\
& 200 & 22709 & 6.0 \\
& 300 & 39457 & 9.5 \\
& 400 & 10702 & 2.6 \\
& 500 & 16714 & 4.1 \\
& 600 & 17510 & 5.6 \\
\hline
\end{tabular}

No ${ }^{32} \mathrm{P}$ activity was measured in the scintillator Oxysolve $\mathrm{C} 400$ at any temperature level, where the $\mathrm{CO}_{2}$ was absorbed (Tab. 4). Contrary, high radioactivities were detected after the remained ash of each plant sample was transferred into Lumagel Safe and measured by scintillation counting.

To summarize, there was no release of ${ }^{32} \mathrm{P}$ by burning the plant material at temperatures of $600{ }^{\circ} \mathrm{C}$ and also the measured results of ${ }^{14} \mathrm{C}$ activities in plant samples were not influenced by ${ }^{32} \mathrm{P}$ activities. These results showing, that it was possible to use the same plant material to measure ${ }^{14} \mathrm{C}$ and ${ }^{32} \mathrm{P}$ activities by using specific temperature levels. 


\subsection{7. ${ }^{18} \mathrm{O}$ measurement in shoots}

The mixed plant samples were placed in gas chromatography-vials (fig. 10, a) and were covered with $\mathrm{CO}_{2}$ (5\% in Helium). The samples were then left to equilibrate for 24 hours at $22{ }^{\circ} \mathrm{C}$, where the ${ }^{18} \mathrm{O}$ exchanged and equilibrate with the $\mathrm{O}_{2}$ of the $\mathrm{CO}_{2}$ (fig. 10, b):

$$
\mathrm{H}_{2}{ }^{18} \mathrm{O}+\mathrm{CO}_{2} \Leftrightarrow \mathrm{H}_{2} \mathrm{C}^{18} \mathrm{O}_{3} \Leftrightarrow \mathrm{C}^{18} \mathrm{O}_{2}+\mathrm{H}_{2} \mathrm{O}
$$

After equilibration, 30 $\mu$ l headspace-gas was removed with a gas-tight lockable-syringe (Hamilton) and was loaded onto a gas autosampler. The headspace gas then was passed through a chemical trap to remove water and through an open split interface, which allows the coupling a high flow ( $>5 \mathrm{cc} / \mathrm{min}$ ) Poraplot $\mathrm{Q}$ column flow to a mass spectrometer with a limited inlet flow capability. The headspace gas was measured for ${ }^{18} \mathrm{O}$ by mass spectrometry against SMOW (Standard Mean Ocean Water).

$\mathbf{a}$

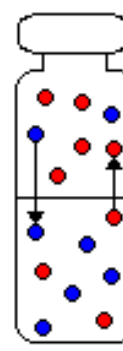

Gas phase

(headspace)

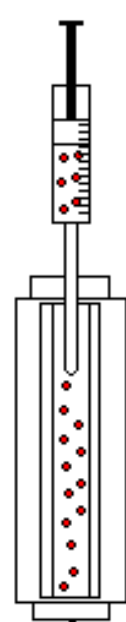

Water removal

Open split

Sample

phase

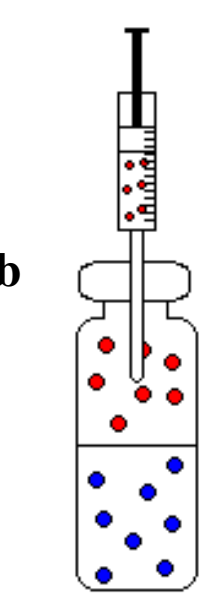

Extraction

from

headspace

Sample

reached equilibrium

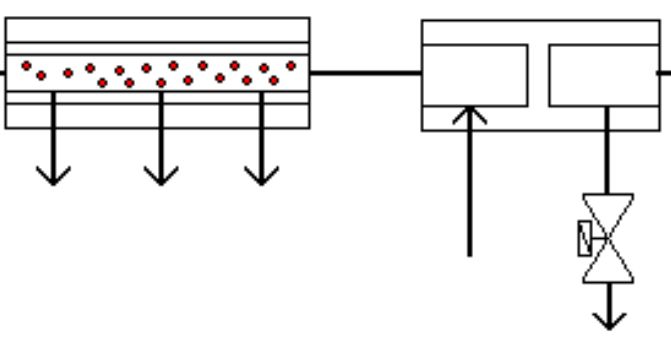

Mass-spectrometer

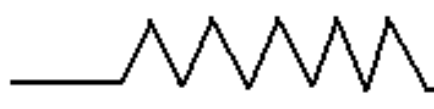

\section{Figure 10:}

Schematic diagram of GC-IRMS 


\subsection{Extraction of labelled compounds}

According to the hypothesis of the first objective of the present study (chapter 2.), signalling events or P transporters across the symbiotic fungus-plant interface could be responsible for a movement of carbon compounds from the mycorrhizal fungi to the host. The plant material (shoots, mycorrhizal roots and hyphae) from the experiment of inoculation with ${ }^{14} \mathrm{C}$ labelled mycorrhizal hyphae and/or the double labelling experiment $\left({ }^{14} \mathrm{C}\right.$ and $\left.{ }^{32} \mathrm{P}\right)$ could be used to extract possible labelled compounds out of the material and to determine these compounds by using the gel-electrophoresis.

\section{a.) labelled carbon compounds}

To extract possible labelled ${ }^{14} \mathrm{C}$ compounds out of the shoots and roots, the STEP buffer was used (Rosendahl and Sen, 1992). The buffer was prepared as described in Table 5, to extract proteins (e.g. enzymes).

\section{Table 5:}

Ingredients of STEP buffer for extraction of ${ }^{14} \mathrm{C}$ labelled compounds in shoots and roots

\begin{tabular}{l|l}
\hline $\mathrm{pH}$ & 8.0 \\
Tris-HCl & $20 \mathrm{mM}$ \\
$\mathrm{NaHCO}_{3}$ & $10 \mathrm{mM}$ \\
$\mathrm{MgCl}_{2}$ & $10 \mathrm{mM}$ \\
EDTA & $0.1 \mathrm{mM}$ \\
$\beta$-mercaptoethanol & $10 \mathrm{mM}$ \\
Sucrose & $10 \%(\mathrm{w} / \mathrm{v})$ \\
Triton X-100 & $0.1 \%(\mathrm{v} / \mathrm{v})$ \\
PVPP (polyvinylpolypyrrolidone) & \\
\hline
\end{tabular}

Shoots and roots were ground in a mortar with addition of liquid nitrogen, and the ground plant material was mixed with the extraction buffer $(1: 1, \mathrm{w} / \mathrm{v})$. After centrifugation at $16000 \mathrm{~g}$ for $20 \mathrm{~min}$ the supernatant was removed from the pellet and both were stored separately at cool temperature $\left(4^{\circ} \mathrm{C}\right)$ for electrophoresis. $40 \mu \mathrm{l}$ of the plant extracts (sample No., Tab. 6) were pipetted into the gel-bags. 


\section{Table 6:}

Extraction of labelled compounds from roots and shoots of $C$. odorata infected with labelled hyphae of G. manihotis.

\begin{tabular}{l|ccl}
\hline $\begin{array}{l}\text { Sample } \\
\text { No. }\end{array}$ & $\begin{array}{c}\text { buffer } \\
(\mu l)\end{array}$ & $\begin{array}{c}\text { plant material } \\
(\mathrm{g})\end{array}$ & $\begin{array}{l}\text { shoot }(\mathrm{s}) \text { - or root (r)- part, } \\
\text { number of plant (Appendix Tab. 31 ) }\end{array}$ \\
\hline 1 & 224 & 0.112 & s30, first and second leaf, G. manihotis \\
2 & 180 & 0.090 & s30, first and second leaf, G. manihotis \\
3 & 880 & 0.440 & r24, G. manihotis \\
4 & 1120 & 0.559 & r24, G. manihotist \\
5 & 1372 & 0.686 & r30, G. manihotis \\
6 & 1000 & 0.500 & r30, G. manihotis \\
7 & 1024 & 0.512 & r33, G. manihotis \\
8 & 970 & 0.485 & r33, G. manihotis \\
9 & 592 & 0.296 & unlabelled and uninfected roots \\
10 & 740 & 0.370 & unlabelled and uninfected roots \\
\hline
\end{tabular}

\section{b.) labelled phosphorus compounds}

STEP-buffer (Tab. 5) was used to extract phosphorus compounds out of shoots, roots and hyphae in the "Double labelling experiment".

Parts of the shoot $(0.5 \mathrm{~g})$, roots $(0.5 \mathrm{~g})$ and hyphae (whole harvest) were ground in a mortar with addition of liquid nitrogen, and the ground plant material was mixed with the extraction buffer $(1: 5, \mathrm{w} / \mathrm{v})$. After centrifugation at $14000 \mathrm{~g}$ for $20 \mathrm{~min}, 600 \mu \mathrm{l}$ of the supernatant was removed from the pellet and was pipetted into ultrafiltration tubes (Vivascience Vivaspin 4ml concentrator). The concentrator was centrifuged to reduce the extract to $200 \mu$ l and to increase the concentration of ${ }^{32} \mathrm{P}$ labelled compounds. From each extract one sample $(20 \mu 1$ and $70 \mu \mathrm{l})$ was removed from the bottom of the concentrate pocket with a pipette and transferred into the gel pocket for electrophoresis. 


\subsection{Gel-electrophoresis}

A vertical electrophoresis system (Hofer) with $160 * 160 * 2 \mathrm{~mm}$ gels was used to detect possible labelled carbon compounds in the extracts.

The electrode buffer was $0.01 \mathrm{M}$ Tris- $\mathrm{HCl}$ and $0.077 \mathrm{M}$ glycine at $\mathrm{pH} 8.3$ (Davis, 1964).

An acrylamide gradient gel was prepared with the range between 3\% and 20\% (Tab. 7).

\section{Table 7:}

Ingredients for gel preparation

\begin{tabular}{l|cc}
\hline Seperation gel & Solution A (3\%) & Solution B (20\%) \\
\hline & $0.863 \mathrm{ml}$ & $5.700 \mathrm{ml}$ \\
Acrylamid (40\%) & $1.438 \mathrm{ml}$ & $1.438 \mathrm{ml}$ \\
Tris-HCl, 3M,pH 8.9 & $0.135 \mathrm{ml}$ & $0.900 \mathrm{ml}$ \\
Glycerine & $9.065 \mathrm{ml}$ & $3.425 \mathrm{ml}$ \\
$\mathrm{H}_{2} \mathrm{O}$ & & $30.0 \mu l$ \\
Catalyst: & $75 \mu \mathrm{l}$ & \\
APS (10\%) & $75 \mu \mathrm{l}$ & \\
DMAPN & & \\
Stacking gel & & \\
Tris-HCl, pH 6.9 & & \\
H2O & $60.6 \mathrm{ml}$ \\
Acrylamid (40\%) & $4.620 \mathrm{ml}$ & \\
Catalyst: & $0.375 \mathrm{ml}$ & \\
TEMED & & \\
APS (20\%) & $25 \mu l$ & \\
\hline
\end{tabular}

A gradient maker was used for gel-preparation. The heavy solution (B, Tab. 7) was poured into the chamber closest to the outlet (mixing chamber) of the gradient maker and the light gel solution (A) beside. A small magnetic stir bar was added to the heavy solution, the channel between the two reservoirs of the gradient maker was opened and the outlet port was opened. 
A peristaltic pump pumped the gel solution down to the spacer into the prepared sandwich (two glass plates separated with spacer) at about $3 \mathrm{~cm}$ from the top. After polymerisation the stacking gel was pipetted on the top of the gel.

The gels were loaded with $40 \mu \mathrm{l}$ extract by using a Hamilton syringe beneath the buffer and the gel was put into the buffer chamber.

Electrophoresis was run over night at $125 \mathrm{~V}$ and $15 \mathrm{~mA}$ per gel at constant voltage, and the Tank buffer was cooled to $10^{\circ} \mathrm{C}$.

After removing the gel from the tank buffer, it was dried in a VacuDry L-40/20. The gel was placed on a stabilizing-support (filter-paper) and was put on a fritted plate, covered with a foil (Cellophane), and dried under vacuum for 2 hours at $80^{\circ} \mathrm{C}$.

\subsection{Experimental design}

In the first preliminary experiment four growing units were used to test if the growing units could be used to separate the mycorrhizal hyphae from the plant, and if the mycorrhizal hyphae are able to take up and transport the ${ }^{14} \mathrm{C}$ glucose.

In the second preliminary experiment four growing units were used to achieve a more precise determination of whole ${ }^{14} \mathrm{C}$ activities in the mycorrhizal roots, because the results of the first preliminary experiment were hardly influenced by quenching. Series of diluted root suspensions were prepared to precise the ${ }^{14} \mathrm{C}$ uptake into the mycorrhizal network. Plants of two units were inoculated with Acaulospora longula and the plants of other two units with Gigaspora gigantea.

In the hyphae labelling experiment, plants were grown simultaneously in five blocks. 18 pots were inoculated with hyphae of A. longula and the same number with $G$. manihotis. As a control eight pots were inoculated with unlabelled hyphae of both mycorrhizal fungi and 16 pots were prepared without mycorrhizal fungi. The five blocks and the plants within the blocks were moved randomly in the greenhouse every two weeks of growth. After four weeks of growth the plants were harvested.

In a separate experiment control units were set, in which the labelled hyphae were killed with potassium hypochlorite $(13 \%, 30 \mathrm{~min})$ and washed with de-ionised water. The dead labelled 
hyphae were used to inoculate a new Chromolaena plant to find out, if a passive carbon uptake into the Chromolaena plant occured.

To investigate the phosphorus translocation via mycorrhizal hyphae and a possible correlation between ${ }^{14} \mathrm{C}$ transfer and ${ }^{32} \mathrm{P}$ uptake, 24 growing units were used in a completely randomized double labelling experiment. Eight growing units were used for each soil type (Kankab, Tzekel and quarz sand), of these 8 growing units 4 were fertilized with phosphorus (MCP: $122 \mathrm{mg} \mathrm{P} \mathrm{kg} \mathrm{soil}{ }^{-1}$ ).

To measure the water flux through mycorrhizal hyphae a water-uptake experiment was carried out with 21 growing units. Of these, four growing units were used which were filled with "natural" non-fertilized soil of Kankab and Tzekel, and also four pots were filled with red Paleustox containing the mycorrhizal propagules. As a control, three growing units were established from each soil after sterilisation.

At the beginning of the experiment, plants were grown only in the plant compartments and were not flanked by the two hyphal compartments. After six weeks of growth and the establishment of the mycorrhiza, the two hyphae compartments were added.

\subsection{Statistical analysis}

Box-plots were used to display information about the performance of the experimental groups.

Furthermore, orthogonal contrasts were applied to the mycorrhizal fungi. To evaluate which treatments were different from others, planned comparisons were used. The planned contrasts applied are written under the tables. The significance levels are: *** at $\mathrm{P} \leq 0.001$; ** at $\mathrm{P} \leq 0.01$; $*$ at $\mathrm{P} \leq 0.05$. 


\subsection{First preliminary experiment}

The main objective of this preliminary experiment was to use the growth units (chapter 4.1.) to separate the mycorrhizal hyphae from the host roots and to test if the mycorrhizal hyphae are able to take up the ${ }^{14} \mathrm{C}$ glucose, which was only available to the hyphae in the hyphal compartments and not to plant roots.

An objective was to determine, if there is a transport of ${ }^{14} \mathrm{C}$ compounds within the mycorrhizal network into the internal hyphae and roots. It should therefore be possible to measure ${ }^{14} \mathrm{C}$ activities in the infected roots and possibly in the shoots of Chromolaena odorata.

The first results show, that there was an uptake and storage of the added ${ }^{14} \mathrm{C}$-glucose in the mycorrhizal hyphae (Tab. 8). Two days after the addition of ${ }^{14} \mathrm{C}$-glucose the ${ }^{14} \mathrm{C}$ activity in $50 \mu \mathrm{l}$ of the harvested labelled hyphae of A. longula was $139 \mathrm{~Bq}$ and in the hyphae of $G$. gigantea was $96 \mathrm{~Bq} .{ }^{14} \mathrm{C}$ activity in $20 \mu \mathrm{l}$ wash-water of the labelled hyphae was low. A relatively high activity $\left(34 \mathrm{~Bq} \mathrm{ml}^{-1}\right)$ was measured in the watering-water, which was leached between the growing chamber and hyphal compartment.

Four days after labelling the ${ }^{14} \mathrm{C}$ activity in $50 \mu \mathrm{l}$ of the harvested labelled hyphae of $A$. longula was $120 \mathrm{~Bq}$ and of $G$. gigantea was $681 \mathrm{~Bq}$. There was again a low ${ }^{14} \mathrm{C}$ activity in wash-water.

\section{Table 8:}

${ }^{14} \mathrm{C}$ uptake of hyphae (in $50 \mu \mathrm{l}$ ), ground roots (in $500 \mu \mathrm{l}$ ) and ${ }^{14} \mathrm{C}$ in wash-water (in $20 \mu \mathrm{l}$ ) and watering water (in $1 \mathrm{ml}$ ) after 2 and 4 days

\begin{tabular}{l|ccc|cccc}
\hline & \multicolumn{3}{|c|}{ after 2 days } & \multicolumn{4}{c}{ after 4 days } \\
\hline & hyphae & wash- & watering- & hyphae & wash- & ground & watering- \\
& & water & water & & water & $\begin{array}{c}\text { roots } \\
\text { water }\end{array}$ & Bq \\
& $\mathrm{Bq}$ & $\mathrm{Bq}$ & $\mathrm{Bq}$ & $\mathrm{Bq}$ & $\mathrm{Bq}$ & $\mathrm{Bq}$ & $\mathrm{Bq}$ \\
\cline { 2 - 8 } A. longula & 139 & 0.25 & 34 & 120 & 1.53 & 1.63 & 16.3 \\
G. gigantea & 96 & 0.51 & + & 681 & 0.95 & 2.36 & + \\
\hline
\end{tabular}

+ not measured 
In the case of $G$. gigantea there was a significantly higher uptake of ${ }^{14} \mathrm{C}$ after four days than after two days, whereas there was no increase in the radioactivity in the hyphae of A. longula. Four days after labelling the hyphae with ${ }^{14} \mathrm{C}$ glucose, the root suspensions of mycorrhizal Chromolaena odorata roots (in plant chamber) showed a low ${ }^{14} \mathrm{C}$ activity (Tab. 9).

\section{Table 9:}

${ }^{14} \mathrm{C}$ activity in Chromolaena roots (plant chamber) four days after addition of ${ }^{14} \mathrm{C}$-glucose to the hyphae in the hyphae compartments

\begin{tabular}{l|ccc}
\hline inoculation & root weight $(g)$ & added water $(\mathrm{ml})$ & activity in $500 \mu l(\mathrm{~Bq})$ \\
\hline A. longula & 0.089 & 5 & 1.45 \\
G. gigantea & 0.100 & 5 & 2.36 \\
\hline
\end{tabular}

Plant roots infected with G. gigantea had an activity of $2.36 \mathrm{~Bq}$. The activity in A. longula infected roots was $1.45 \mathrm{~Bq}$.

The high amount of ${ }^{14} \mathrm{C}$ in the mycorrhizal hyphae indicates that there was a carbon uptake by the hyphae in their compartments. An increase of the activity in G. gigantea was archieved by extending the time of uptake to 4 days. Similarly, Solaiman and Saito (1997) found a $20 \%$ higher glucose and fructose concentration in 9 week old mycorrhizal onion plants than in 6 weeks old plants, without further addition of sugars. Based on chromatography the sucrose content was shown to be higher in non-mycorrhizal than in mycorrhizal roots, while glucose and fructose were not affected. To identify the carbon compounds, which are metabolized by arbuscular mycorrhizal fungi in roots, Solaiman and Saito (1997) used radiorespirometry to measure the sugar uptake by mycorrhizal roots: intraradical hyphae metabolized five times more ${ }^{14} \mathrm{C}$ glucose to $\mathrm{CO}_{2}$ than non-mycorrhizal roots, and fructose was not used in intraradical hyphae. Shachar-Hill et al. (1995) demonstrated by NMR spectroscopy that A. porrum roots infected with Glomus etunicatum utilized exogenously supplied glucose while growing either alone or in association with (V)AM. ${ }^{13} \mathrm{C}$ NMR spectra of mycorrhizal roots in vivo and of extracts show the incorporation of label from glucose into trehalose, glygogen and mannitol by the fungus and into sucrose by the host. According to Pfeffer et al. (1999) these findings suggest, that carbon is exported from the root to extraradical hyphae where carbohydrates are converted to lipids. The location and pathway by which carbohydrates are converted into 
storage lipids was reported by Cox et al. (1975), Cooper and Lösel (1978) and Gaspar et al. (1994). Gaspar et al. (1994) found in alfalfa roots infected with Glomus versiforme an increase in total alfalfa root lipids which was proportional to the degree of mycorrhizal fungal colonization, while non-mycorrhizal roots did not show any increase in lipids. Lipids were characterized first by Cooper and Lösel (1978). Mycorhizal onion roots contained higher levels of triglyceride than non-mycorrhizal roots and external mycelium also contained high levels of neutral lipids (triglyceride), diglyceride and free fatty acids.

These results support the proposition that glucose is an important carbon source for the mycorrhizal fungi in the symbiosis. In the present investigation, the estimated high uptake of

${ }^{14} \mathrm{C}$-glucose by the external mycelium from a glucose solution applied to the soil (Tab. 1 and Tab. 10), confirms the results of Solaiman and Saito (1997) and Shachar-Hill et al. (1995), that glucose is a useful carbon source for mycorrhizal fungi.

This preliminary investigation showed that ${ }^{14} \mathrm{C}$ glucose can be used to label carbon compounds in mycorrhizal fungi. The results in Table 8 and Table 10 also suggest that mycorrhizal fungi could have different behaviour in taking up ${ }^{14} \mathrm{C}$, which may depend on the duration of the labelling time. It seems that mycorrhizal fungi may have different transport rates of ${ }^{14} \mathrm{C}$ in their network.

It was difficult to measure the ${ }^{14} \mathrm{C}$ activity in the roots, because of quenching. Therefore, a second preliminary experiment was carried out, in which a dilution of the red colour in the extracts was achieved to get more precise ${ }^{14} \mathrm{C}$ activity in the infected roots.

\subsubsection{Conclusion}

1. The growing units could be used to grow arbuscular mycorrhizal fungal hyphae separated from the host plant roots.

2. Based on the separation of mycorrhizal hyphae, the external hyphae took up and stored the ${ }^{14} \mathrm{C}$-glucose. External hyphae of Gigaspora gigantea showed a higher uptake of ${ }^{14} \mathrm{C}$ glucose than Acaulospora longula, but a lower ${ }^{14} \mathrm{C}$ activity in the root/water suspension. 


\subsection{Second preliminary experiment}

The aim of the second preliminary experiment was to achieve a more precise determination of whole ${ }^{14} \mathrm{C}$ activity in the mycorrhizal roots by reducing the intensity of the red-coloured suspension of the ground roots, which was the cause of imprecise ${ }^{14} \mathrm{C}$ measurements (because of quenching) in the liquid scintillation-counter in the first preliminary experiment. This was achieved by using series of diluted root suspensions (Fig. 11 and Fig. 12).

The results in figure 11 show, that the ${ }^{14} \mathrm{C}$ activity increased with increasing dilution, i.e. decreasing quenching the red colour in the suspension. The total ${ }^{14} \mathrm{C}$ activity in suspension 1 was $3.74 \mathrm{~Bq}$. After the first dilution the measured ${ }^{14} \mathrm{C}$ activity was four times higher than in the original suspension. The high difference between each $50 \%$ in dilution-step 2 was caused by the higher root residues in one half of the suspension, but more relevant than the difference was the sum of the two parts. After reducing the red colour in dilution 3 , the total ${ }^{14} \mathrm{C}$ activity in all fourth was $23 \mathrm{~Bq} \mathrm{~g}^{-1}$. This amount of labelled compounds was suggested to be enough to separate labelled molecules by using gel-electrophoresis.

\section{A. longula}

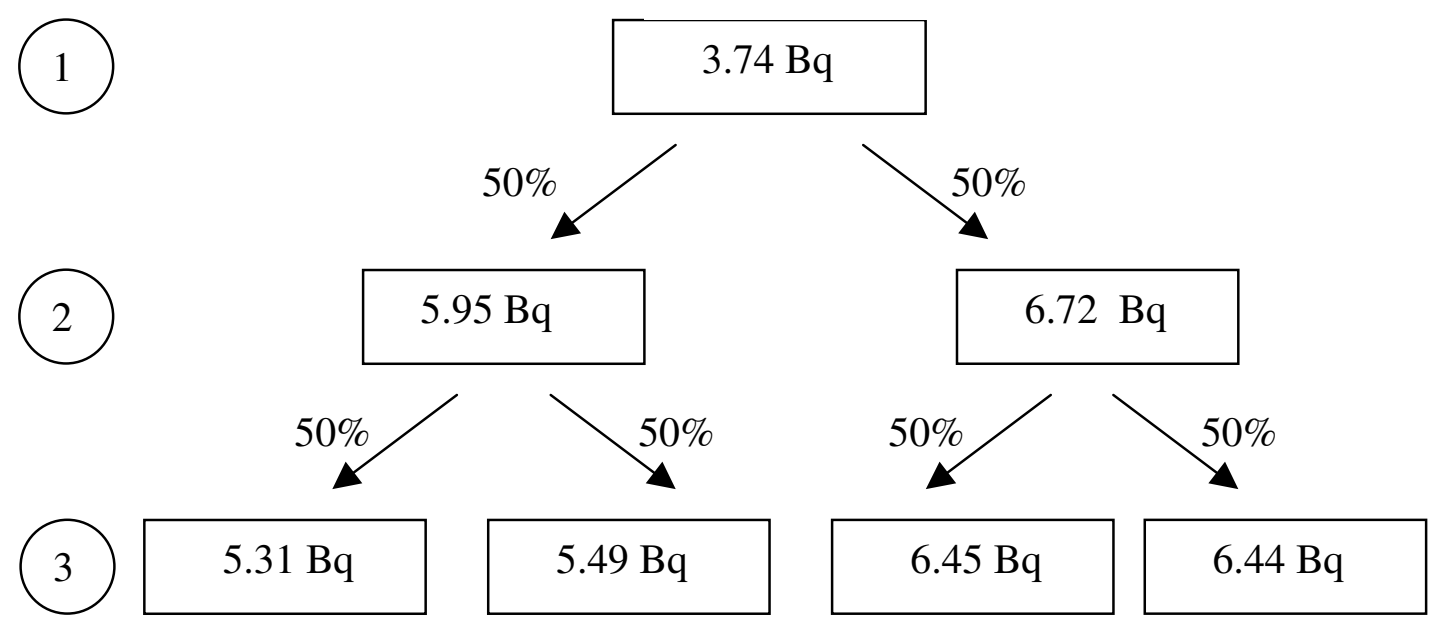

\section{Figure 11:}

The dilution of root suspension to measure the total amount of ${ }^{14} \mathrm{C}$ in $1 \mathrm{~g}$ of roots infected with the mycorrhizal fungus $A$. longula

Compared with the ${ }^{14} \mathrm{C}$ activity in roots infected with $A$. longula, roots infected with $G$. gigantea had lower ${ }^{14} \mathrm{C}$ activity (Fig. 12). After the first dilution the ${ }^{14} \mathrm{C}$ activity was three 
times higher $\left(7.24 \mathrm{~Bq} \mathrm{~g}^{-1}\right)$ than in the first measurement $\left(2.51 \mathrm{~Bq} \mathrm{~g}^{-1}\right)$. The total amount of ${ }^{14} \mathrm{C}$ activity in the third dilution was $8.49 \mathrm{~Bq} \mathrm{~g}^{-1}$.

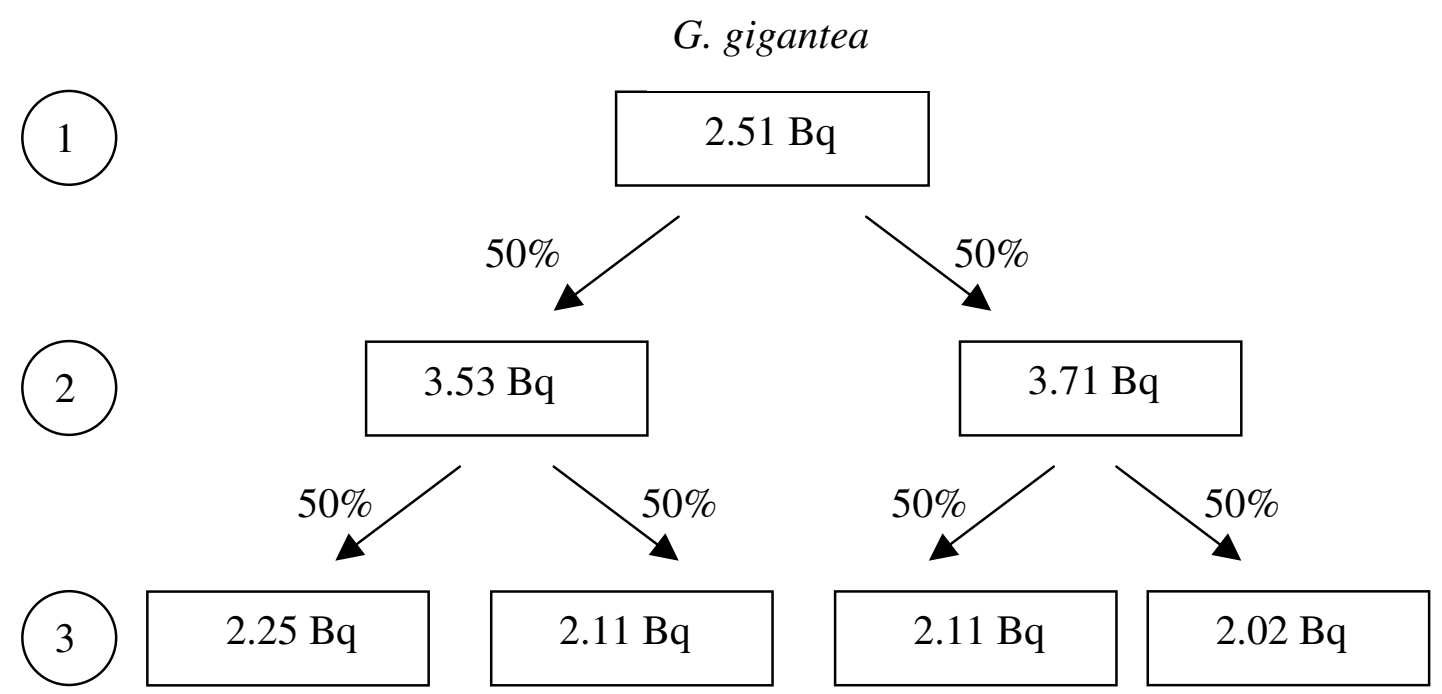

Figure 12:

The dilution of root suspension to measure the total amount of ${ }^{14} \mathrm{C}$ in $1 \mathrm{~g}$ of roots

Roots infected with $A$. longula had a total activity of $23.69 \mathrm{~Bq} \mathrm{~g}^{-1}$, whereas the activity of roots infected with $G$. gigantea was only one third of with A. longula infected roots.

Based on these results, G. gigantea was excluded and beside A. longula the mycorrhizal fungi Glomus manihotis was used for further experiments.

\subsubsection{Conclusion}

1. The results from the first preliminary experiment were confirmed.

2. The ground ${ }^{14} \mathrm{C}$ mycorrhizal roots showed relatively high radioactivities and a high quench (red colour caused by the red Paleustox) in un-diluted root suspension. The ${ }^{14} \mathrm{C}$ activity increased with increasing dilution. 
3. Mycorrhizal roots of $A$. longula showed a higher ${ }^{14} \mathrm{C}$ activity after decreasing the quench, than roots colonized by Gigaspora gigantea.

4. Based on point $3 \mathrm{G}$. gigantea appeared to transfer relatively little ${ }^{14} \mathrm{C}$ to plant roots. It was therefore excluded and the more effective mycorrhizal fungus Glomus manihotis was used in further experiments.

\subsection{Hyphae labelling experiment}

The first and second preliminary experiments showed that the growing unit systems could be used to separate arbuscular mycorrhizal fungal hyphae from the host plant roots and to label the mycorrhizal hyphae with ${ }^{14} \mathrm{C}$ - glucose. After harvesting the hyphae by wet-sieving (chapter 4.9.) and after measuring the ${ }^{14} \mathrm{C}$ activity in the mycorrhizal hyphae by scintillation counting (chapter 4.13.) a high ${ }^{14} \mathrm{C}$ glucose uptake into the hyphal network was measured (chapter 5.1.).

The aims of this experiment were to confirm the ${ }^{14} \mathrm{C}$ uptake of the hyphae and the transport of ${ }^{14} \mathrm{C}$ into the intraradical hyphae and to investigate the possibility to use the labelled hyphae as an inoculum to infect new Chromolaena odorata plants.

If it is possible to inoculate a new plant with the labelled mycorrhizal hyphae, it will be possible to measure labelled compounds in infected roots (e.g. proteins, enzymes, organic acids...), which could play a key role in the interaction between the host plant and the mycorrhizal fungi.

\subsubsection{Radioactivity measurement in labelled hyphae}

The two mycorrhizal fungi (A. longula and G. manihotis) had different abilities of taking up the ${ }^{14} \mathrm{C}$ glucose from the soil solution (Tab. 10). The ${ }^{14} \mathrm{C}$ activity in the labelled hyphae of $G$. manihotis was 4.5 times higher and highly significant compared to the ${ }^{14} \mathrm{C}$ activity in the labelled hyphae of A. longula.

It was not possible to isolate all the hyphae from the wash water, so that some ${ }^{14} \mathrm{C}$ activity remained in the water suspension. 


\section{Table 10:}

Comparison of ${ }^{14} \mathrm{C}$ labelled (+) hyphae of $G$. manihotis (GM) and A. longula (AL) as main factor on ${ }^{14} \mathrm{C}$ glucose uptake out of the soil solution during six days

\begin{tabular}{l|cc}
\hline mycorrhizal fungi & $\begin{array}{c}\text { labelled hyphae } \\
(B q)\end{array}$ & wash water \\
& 4200 & 8.41 \\
\hline GM+ hyphae (labelled with $\left.{ }^{14} \mathrm{C}\right)$ & 925 & 4.45 \\
AL+ hyphae (labelled with $\left.{ }^{14} \mathrm{C}\right)$ & $* * *$ & $* * *$ \\
GM+ hyphae versus AL+ hyphae & $*$ & \\
\hline
\end{tabular}

significance level was: $* * *$ at $\mathrm{P} \leq 0.001$

Large amounts of glucose were taken up from the soil solution and stored in the hyphae (discussion: see chapter 5.2.).

\subsubsection{Fresh and dry matter of shoots and roots}

The shoots and roots fresh weight of all plants inoculated with mycorrhizal fungi was significantly higher than the non-inoculated control plants (Tab. 11).

The shoots and roots fresh weight was higher in plants inoculated with G. manihotis (GM) than in those inoculated with A. longula (AL). The GM-plants produced 2.5 times higher plant bio-mass after four weeks of inoculation than the AL-group. Within the groups, plants inoculated with ${ }^{14} \mathrm{C}$ glucose labelled GM-hyphae produced a significantly higher shoot fresh mass production $\left(3.09 \mathrm{~g} \mathrm{chamber}^{-1}\right)$ compared to plants inoculated without glucose $(1.41 \mathrm{~g}$ chamber $^{-1}$ ). The same highly significant $100 \%$ increase of fresh matter was also observed in the roots.

The difference between the inoculation with ${ }^{14} \mathrm{C}$-glucose labelled AL-hyphae and non-glucose AL-hyphae was not significant. 


\section{Table 11:}

Effects of inoculation with ${ }^{14} \mathrm{C}$ labelled (+) and non-labelled mycorrhizal hyphae of $G$. manihotis (GM) and A. longula (AL) as main factor on shoots, roots and total fresh weight of 4 weeks old Chromolaena odorata plants

\begin{tabular}{l|ccc}
\hline & $\begin{array}{c}\text { g shoot/ plant } \\
\text { fresh mass }\end{array}$ & $\begin{array}{c}\text { g root/ plant } \\
\text { fresh mass }\end{array}$ & $\begin{array}{c}\text { g total/ plant } \\
\text { fresh mass }\end{array}$ \\
\hline GM+ (inoculated with ${ }^{14}$ C labelled hyphae) & 3.09 & 1.47 & 4.56 \\
GM (inoculated with non-labelled hyphae) & 1.41 & 0.70 & 2.11 \\
AL+ (inoculated with ${ }^{14}$ C labelled hyphae) & 0.91 & 0.59 & 1.50 \\
AL (inoculated with non-labelled hyphae) & 0.78 & 0.45 & 1.23 \\
control & 0.28 & 0.25 & 0.53 \\
& & & $* * *$ \\
mean of GM+, GM, AL+ and AL versus control & $* * *$ & $* * *$ & $* * *$ \\
mean of group GM versus mean of group AL & $* * *$ & $* * *$ & $* * *$ \\
GM+ versus GM & $* * *$ & $* *$ & n.s. \\
AL+ versus AL & n.s. & n.s. \\
\hline
\end{tabular}

significance level was: *** at $\mathrm{P} \leq 0.001 ; * *$ at $\mathrm{P} \leq 0.01 ; *$ at $\mathrm{P} \leq 0.05$

The same tendencies were measured in the dry weight (Tab. 12). However, as explained in chapter 4.11. the results were based on fewer replications, than in case of fresh weight. 


\section{Table 12:}

Effects of inoculation with ${ }^{14} \mathrm{C}$ labelled (+) and non-labelled mycorrhizal hyphae of $G$. manihotis (GM) and A. longula (AL) as main factor on shoots, roots and total dry weight of 4 weeks old Chromolaena odorata plants

\begin{tabular}{|c|c|c|c|}
\hline & $\begin{array}{l}\text { g shoot/ plant } \\
\text { dry mass }\end{array}$ & $\begin{array}{l}\text { g root/ plant } \\
\text { dry mass }\end{array}$ & $\begin{array}{l}\text { g total/ plant } \\
\text { dry mass }\end{array}$ \\
\hline $\mathrm{GM}+\left(\right.$ inoculated with ${ }^{14} \mathrm{C}$ labelled hyphae) & 0.49 & 0.13 & 0.64 \\
\hline GM (inoculated with non-labelled hyphae) & 0.19 & 0.07 & 0.27 \\
\hline $\mathrm{AL}+$ (inoculated with ${ }^{14} \mathrm{C}$ labelled hyphae) & 0.15 & 0.06 & 0.22 \\
\hline AL (inoculated with non-labelled hyphae) & 0.10 & 0.03 & 0.09 \\
\hline control & 0.05 & 0.02 & 0.07 \\
\hline mean of $\mathrm{GM}+, \mathrm{GM}, \mathrm{AL}+$ and $\mathrm{AL}$ versus control & $* * *$ & $* * *$ & $* * *$ \\
\hline mean of group GM versus mean of group AL & $* * *$ & $* * *$ & $* * *$ \\
\hline GM+ versus GM & $* * *$ & $* * *$ & $* * *$ \\
\hline $\mathrm{AL}+$ versus $\mathrm{AL}$ & n.s. & n.s. & n.s. \\
\hline
\end{tabular}

significance level was: *** at $\mathrm{P} \leq 0.001 ; * *$ at $\mathrm{P} \leq 0.01 ; *$ at $\mathrm{P} \leq 0.05$

The results of the plant mass production were characterized by high variability within each experimental group (Fig. 13). The highest variabilities were measured in plants inoculated with ${ }^{14} \mathrm{C}$ labelled hyphae of G. manihotis. Variabilities in both, shoot and root dry/ fresh matter of non-mycorrhizal plants was low. 

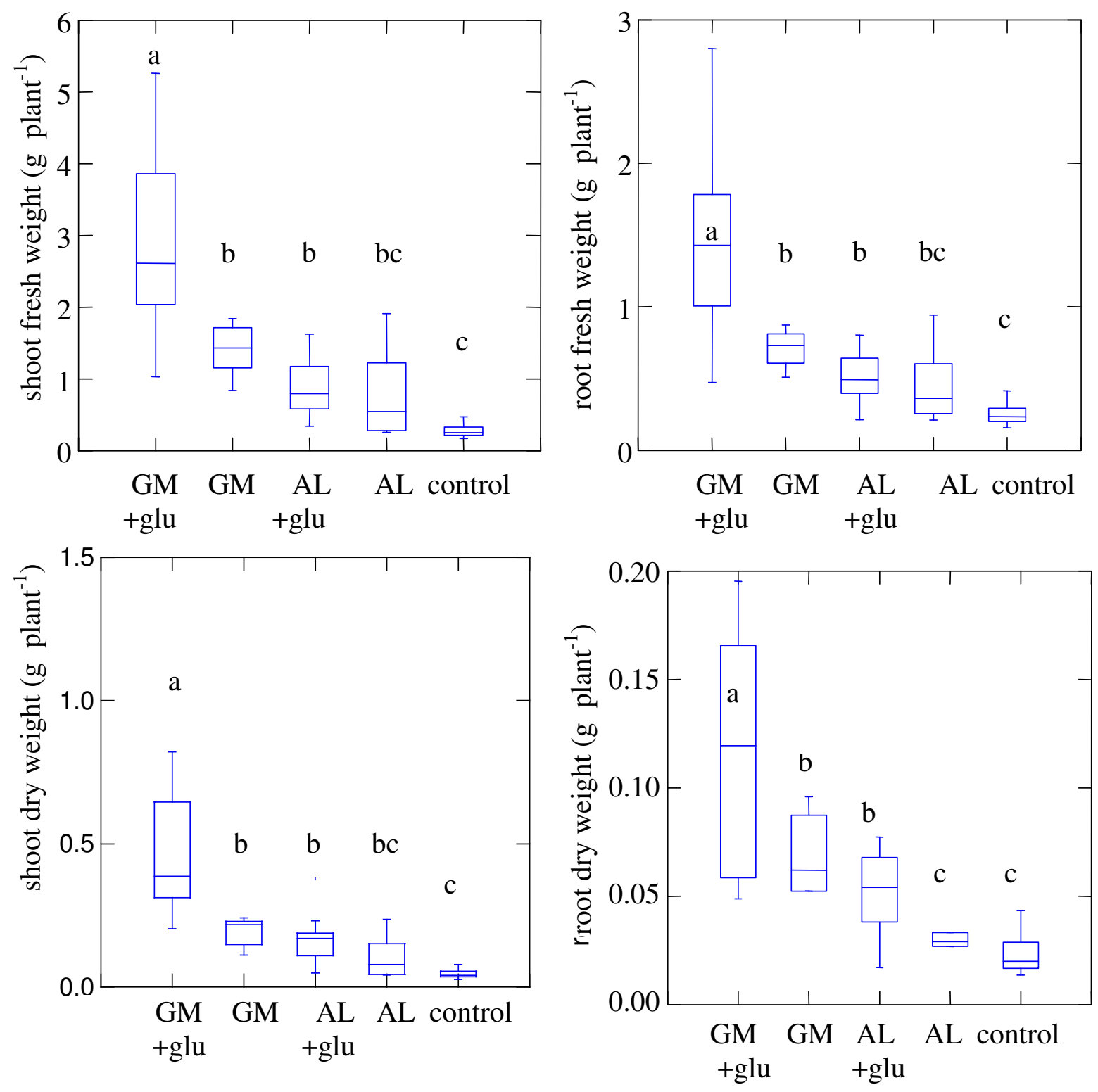

Figure 13:

Effects of inoculation with ${ }^{14} \mathrm{C}$ labelled (+glu) and non-labelled mycorrhizal hyphae of $G$. manihotis (GM) and A. longula (AL) as main factor on shoots, roots and total dry / fresh weight of four weeks old Chromolaena odorata plants. Letters given in the box plot are based on ANOVA.

The high variability of the dry/ fresh weight of the Chromolaena plants infected with $G$. manihotis and A. longula, as shown in Figure 13, could be a result of the different effectivities of the two mycorrhizal fungi. The production of plant biomass is influenced by the vitality of the applied fungal hyphae, the colonization rate of the fungi in the roots and the physiological 
conditions of the plant. The physiological state of the plant may have played here a secondary role, since the control plants produced similar weights.

The higher biomass production by plants inoculated with labelled hyphae of G. manihotis $(0.64 \mathrm{~g} \mathrm{DM})$ or unlabelled $(0.26 \mathrm{~g} \mathrm{DM})$ compared to the biomass production of plants with labelled hyphae of A. longula $(0.22 \mathrm{~g} \mathrm{DM})$ and unlabelled $(0.09 \mathrm{~g} \mathrm{DM})$ could be explained by the different capabilities of both fungal species of improving plant growth. Similar differences in the biomass production by Chromolaena plants inoculated with either mycorrhizal fungi (G. manihotis or A. longula) and fertilized with Hydroxyapatite (HA) and Monocalciumphosphate (MCP) were also found by Ditschar (2001).

In the present study, Chromolaena plants inoculated with ${ }^{14} \mathrm{C}$ glucose labelled hyphae of $G$. manihot (GM) produced significantly more dry matter compared to plants inoculated with non-labelled GM-hyphae (Tab. 10). During the ${ }^{14} \mathrm{C}$ labelling procedure GM-hyphae were able to take up ${ }^{14} \mathrm{C}$ glucose out of the soil to cover their carbon needs. After ${ }^{14} \mathrm{C}$ labelling, the hyphae were washed out of the soil and were used to inoculate a new Chromolaena plant. The stored glucose in the ${ }^{14} \mathrm{C}$ labelled mycorrhizal hyphae may mean, that the fungus was less of a "sink" for sugar in the initial phase of the mycorrhizal symbiosis. Therefore, it could be suggested, that the plants transferred less sugar to the roots, so that the carbohydrate assimilates, which were translocated to the mycorrhizal fungus in roots of non-labelled plants, could be used by the fungus for its own development to be able to improve the biomass production of the plants. Table 13 shows the quantity of ${ }^{14} \mathrm{C}$ glucose taken up by mycorrhizal hyphae of $G$. manihotis and A. longula. Highly significant differences in ${ }^{14} \mathrm{C}$ glucose quantities were found in both labelled hyphae.

The addition of relatively low amount of $71.410^{-9} \mathrm{~g}{ }^{14} \mathrm{C}$ glucose was sufficient to increase the dry mass by more than $100 \%$ of plants inoculated with ${ }^{14} \mathrm{C}$ labelled GM-hyphae compared to plants inoculated with non-labelled GM-hyphae. An increase of total plant dry mass was measured in plants inoculated with ${ }^{14} \mathrm{C}$ labelled AL-hyphae compared with plants inoculated with non-labelled AL-hyphae, but less so in the GM-treatment. 


\section{Table 13:}

Quantity of ${ }^{14} \mathrm{C}$ glucose in labelled hyphae $\left(10^{-9} \mathrm{~g}\right)$ and total plant dry mass (g) of 4 weeks old Chromolaena odorata plants inoculated with labelled (+) and non-labelled mycorrhizal hyphae of G. manihotis (GM) and A. longula (AL)

\begin{tabular}{l|cc}
\hline & $\begin{array}{c}\text { Total plant dry } \\
\text { mass }\end{array}$ & $\begin{array}{c}{ }^{14} \text { C glucose in } \\
\text { labelled hyphae } \\
\left(10^{-9} \mathrm{~g}\right)\end{array}$ \\
\hline GM+ (inoculated with ${ }^{14}$ C labelled hyphae) & 0.64 & 71 \\
GM (inoculated with non-labelled hyphae) & 0.27 & - \\
AL+ (inoculated with ${ }^{14}$ C labelled hyphae) & 0.22 & - \\
AL (inoculated with non-labelled hyphae) & 0.09 & $* * *$ \\
& & $* * *$ \\
\hline
\end{tabular}

significance level was: $* * *$ at $\mathrm{P} \leq 0.001$

A positive influence of an additional carbon source to mycorrhizal cranberry plants was also found by Mitchell and Meave*. After a carbon supplement in form of either glucose or sucrose to the growing medium (1/5 Rorisons liquid medium) the ability to acquire ${ }^{14} \mathrm{C}$ sucrose was higher in ericoid mycorrhizal cranberry roots than in non-mycorrhizal roots. Furthermore, ericoid mycorrhizal cranberry had a greater root dry mass than those of nonmycorrhizal seedlings with supplementation of either glucose or sucrose to the growing medium.

\subsection{3. ${ }^{14} \mathrm{C}$ activity in shoots and roots}

There was a significant uptake and accumulation of the added ${ }^{14} \mathrm{C}$-glucose in the mycorrhizal hyphae. The ${ }^{14} \mathrm{C}$ activity in approximately one quarter of the harvested labelled hyphae of Glomus manihotis was $1050 \mathrm{~Bq}$ (means of 18 samples). This gives an estimated ${ }^{14} \mathrm{C}$ activity of $4200 \mathrm{~Bq}$ for the total hyphal mass (chapter 5.3.1.).

\footnotetext{
* http://www-icom2.slu.se/abstracts/Mitchell.html
} 
Upon inoculuation and colonization of new plants with the remaining three quarters of the labelled hyphae, autoradiography (Fig. 14) showed the greatest accumulation of ${ }^{14} \mathrm{C}$ in the root system of the plant, but significant activity was also detected in the shoots.

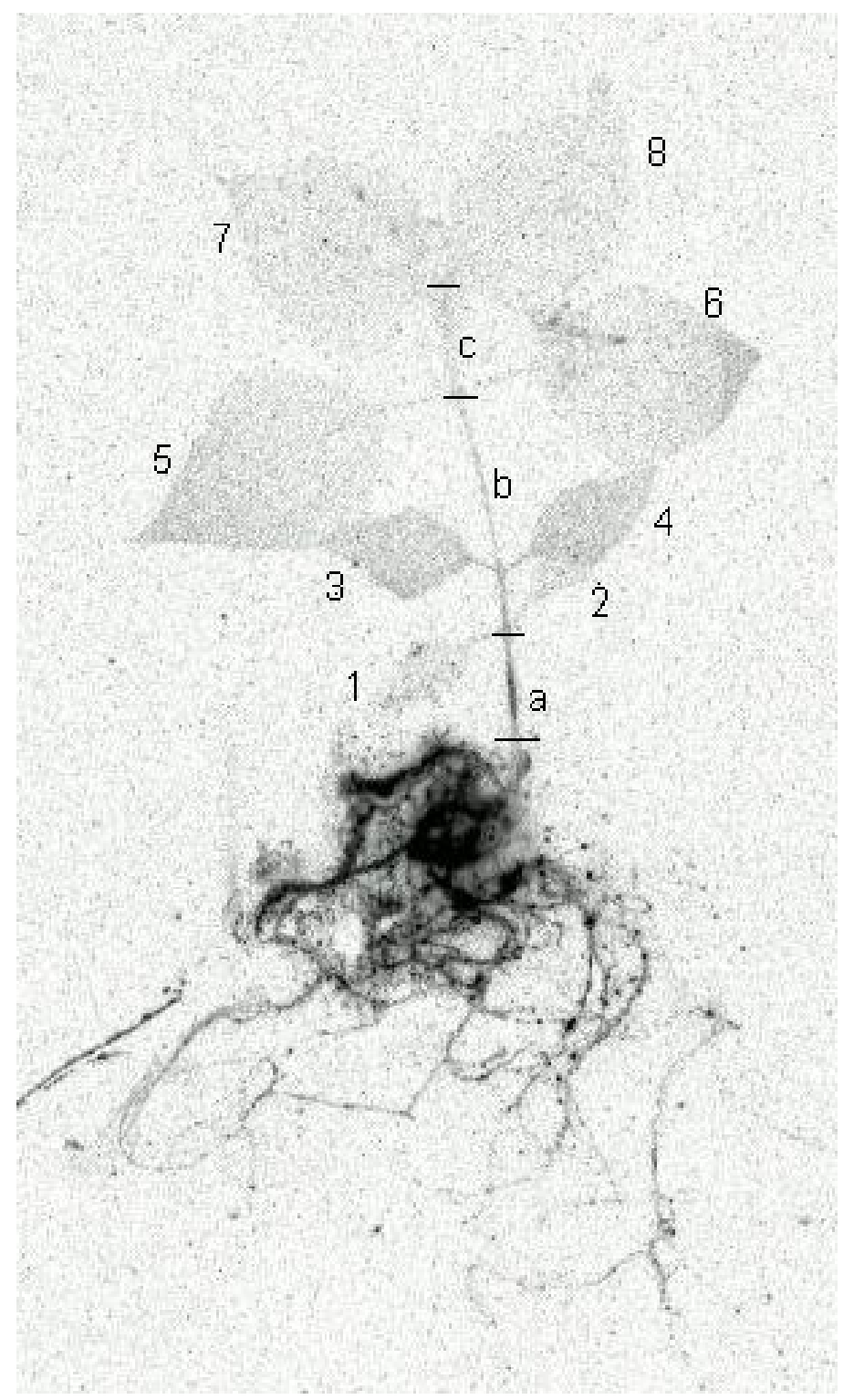

\section{Figure 14:}

Distribution of ${ }^{14} \mathrm{C}$ in the root and shoot of a Chromolaena odorata plant four weeks after inoculation with ${ }^{14} \mathrm{C}$ labelled hyphae of Glomus manihotis. The lines subdivide the stem in three parts ( $a, b$ and $c$ ) and the numbers describe the leaf-numbers (1 to 8). 
The specific activity in the shoots decreased from the base of the stem upwards and from the older to the younger leaves, while the total activity increased from older to younger leaves and the total activity decreased from the base of the stem upwards. Four weeks after inoculation $1645 \mathrm{~Bq} \mathrm{~g}^{-1}$ were retained in the roots, while $93 \mathrm{~Bq} \mathrm{~g}^{-1}$ were stored in the leaves and $138 \mathrm{~Bq} \mathrm{~g}^{-1} \mathrm{~g}$ in the stem (Tab. 14).

Large amounts of labelled carbon were measured in the lower third of the stem (specific activity: $107 \mathrm{~Bq} \mathrm{~g}^{-1}$, total activity: $4.54 \mathrm{~Bq}$ ), whereas only $6 \mathrm{~Bq} \mathrm{~g}^{-1}$ specific activity and 0.2 $\mathrm{Bq}$ total activity were measured in the upper third. The oldest leaf pair contained $46 \mathrm{~Bq} \mathrm{~g}^{-1}$, whereas the specific activities decreased towards the youngest leaf pair to $9 \mathrm{~Bq} \mathrm{~g}^{-1}$. Because of the greater mean of younger leaves, the total activity of the oldest leaf pair contained 0.33 $\mathrm{Bq}$, whereas the activities increased towards the youngest leaf pair to $0.84 \mathrm{~Bq}$. The data show that there was a carbon transfer from the inoculated ${ }^{14} \mathrm{C}$ labelled mycelium to the host plant during four weeks of growth after the inoculation. The transferred $\mathrm{C}$ was translocated to the shoot. The transfer probably occurred in early stage during infection, and transferred $\mathrm{C}$ was retained in the labelled tissues.

\section{Table 14:}

Dry mass $(\mathrm{mg})$ and ${ }^{14} \mathrm{C}$ distribution $\left(\mathrm{Bq} \mathrm{g}^{-1}\right)$ in $C$. odorata plants four weeks after inoculation with ${ }^{14} \mathrm{C}$ labelled hyphae of $G$. manihotis (means of 7 plants).

\begin{tabular}{lcccc}
\hline Plant component & $\begin{array}{c}\text { Weight } \\
\mathrm{mg}\end{array}$ & $\begin{array}{c}\text { Specific } \\
\text { activity } \\
\mathrm{Bq} \mathrm{g}^{-1}\end{array}$ & $\begin{array}{c}\text { Total } \\
\text { activity } \\
\mathrm{Bq}\end{array}$ & $\begin{array}{c}\text { PSL-value } \\
\text { (photostimulated } \\
\text { luminescence) }\end{array}$ \\
\hline leaves 1+2 & $7.2 \mathrm{a}$ & $46 \mathrm{a}$ & $0.33 \mathrm{a}$ & 45.7 \\
leaves 3+4 & $20.6 \mathrm{a}$ & $24 \mathrm{~b}$ & $0.49 \mathrm{a}$ & 116.7 \\
leaves 5+6 & $59.5 \mathrm{~b}$ & $14 \mathrm{~b}$ & $0.83 \mathrm{~b}$ & 223.6 \\
leaves 7+8 & $94.3 \mathrm{c}$ & $9 \mathrm{~b}$ & $0.84 \mathrm{~b}$ & 131.8 \\
all leaves & 181.6 & 93 & 2.49 & 517.8 \\
stem part a & $42.4 \mathrm{a}$ & $107 \mathrm{a}$ & $4.54 \mathrm{a}$ & 59.5 \\
stem part b & $30.6 \mathrm{~b}$ & $25 \mathrm{~b}$ & $0.76 \mathrm{~b}$ & 9.1 \\
stem part c & $32.5 \mathrm{bc}$ & $6 \mathrm{~b}$ & $0.20 \mathrm{c}$ & 16.8 \\
whole stem & 105.5 & 138 & 5.50 & 85.4 \\
roots & 117.7 & 1645 & 193.6 & 2608 \\
\hline
\end{tabular}

Values with same letters are not significantly different by Fisher`s LSD test, $\mathrm{p} \leq 0.05$ 
Photostimulated luminescence values (PSL) were evaluated (chapter 4.15.) to compare the values in Table 14 with these in Table 16 (chapter 5.3.5.). The PSL-values increased from the first leaf-pair towards the third leaf pair, while in leaf pair four the PSL-value decreased. Highest PSL-values were evaluated in the first part of the stem, while lower values were measured in the middle and in the upper part of the stem.

\subsubsection{Use of Gel-Electrophoresis}

During the initial interaction between mycorrhizal fungi and host plant roots enzymatic activities have been observed in different experiments (Spanu et al. 1989; Lambais and Mehdy 1993; Vierheilig et al. 1994; Blilou et al. 2000). Smith and Read (1997) reported that the development of mycorrhiza in the initial phase requires the exchange of signals. Such signals could be important during the penetration of hyphae into the root to form intraradical mycorrhizal hyphae. As shown in chapter 5.5.1. it was possible to label mycorrhizal hyphae and to use these labelled hyphae to infect roots of Chromolaena odorata.

The identification of labelled carbon-compounds via gel electrophoresis was not possible in the present investigation. The dried gel had to be placed between two plastic sheets to protect the surface of the Imager Plates. The weak ${ }^{14} \mathrm{C}$ ( $\alpha$-emitter) signal was not able to pass the foil. The acrylamide gel (fig. 15) showed a low $\mathrm{C}^{14}$ activity in bag 7, 8 and 9 in the upper part of the gel. These labelled compounds were bigger particles, which were in the supernatant after centrifugation and which were not able to run into the gel because of their size. No identifiable bands of radioactive substances were detected. 


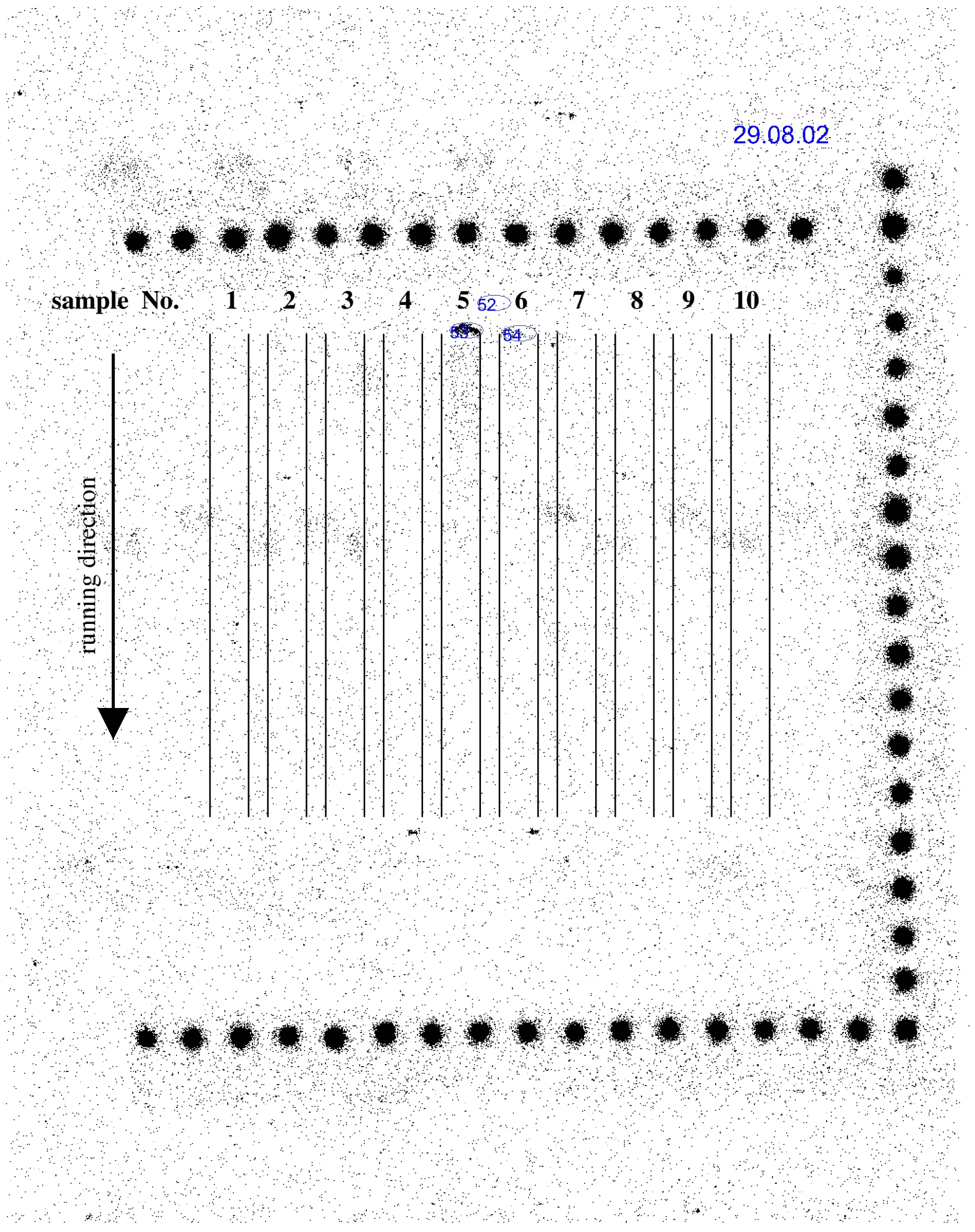

Figure 15:

Autoradiography of Acrylamid-Electrophoresi-Gel: ${ }^{14} \mathrm{C}$ labelled compounds in supernatants of extracted roots and shoots of $C$. odorata 
Table 15 shows the ${ }^{14} \mathrm{C}$ activities in the supernatants of roots and shoots after centrifugation and ${ }^{14} \mathrm{C}$ activities in the pellet remaining after centrifugation. The highest ${ }^{14} \mathrm{C}$ activities were measured in the supernatant and in the pellets of ${ }^{14} \mathrm{C}$ labelled roots of $G$. manihotis (sample 5 and 6).

Activities in the supernatants were too low to permit electrophoretic separation .

\section{Table 15:}

${ }^{14} \mathrm{C}$ radioactivity in extracted supernatant of roots and shoots in $C$. odorata plants and in the pelett after extraction with two different extraction buffer

\begin{tabular}{|c|c|c|c|c|c|c|}
\hline sample & $\begin{array}{c}70 \mu l \\
\text { supernatant } \\
(\mathrm{dpm})\end{array}$ & $\begin{array}{c}350 \mu l \\
\text { supernatant } \\
(\mathrm{dpm})\end{array}$ & $\begin{array}{c}490 \mu l \\
\text { supernatant } \\
(\mathrm{dpm})\end{array}$ & $\begin{array}{r}\text { pellett } \\
(m g)\end{array}$ & $\begin{array}{c}\text { activity } \\
(B q)\end{array}$ & $\begin{array}{c}\text { activity } \\
(B q / 100 m g \text { pellett })\end{array}$ \\
\hline 1 & 24,2 & & & 45,6 & 0,6 & 1,4 \\
\hline 2 & 26,9 & & & 35,2 & 0,5 & 1,5 \\
\hline 3 & $(20,0)$ & 45,5 & & 188,2 & 20,8 & 11,0 \\
\hline 4 & $(30,1)$ & 86,3 & & 267,00 & 18,5 & 6,9 \\
\hline 5 & $(51,3)$ & & 207,8 & 309,2 & 158,0 & 51,1 \\
\hline 6 & $(115,34)$ & & 621,1 & 232,1 & 201,2 & 86,7 \\
\hline 7 & 23,1 & & & 179,5 & 19,4 & 10,8 \\
\hline 8 & 27,9 & & & 241,5 & 8,5 & 3,5 \\
\hline 9 & 19,4 & & & 134,4 & 0,6 & 0,5 \\
\hline 10 & 18,4 & & & 212,9 & 0,6 & 0,3 \\
\hline
\end{tabular}

5.3.5. "Dead" hyphae inoculation

To ensure, that the carbon accumulation in roots and shoots of the Chromolaena plant was due to active transfer through mycorrhizal hyphae, Chromolaena plants were inoculated with dead hyphae (chapter 4.20.).

The autoradiography of the control plants, inoculated with ${ }^{14} \mathrm{C}$ labelled dead hyphae (Fig.16), showed different measurements in the three plants. The lowest accumulation of ${ }^{14} \mathrm{C}$ was found in plant 2, whereas there was a relatively high accumulation in plant 3 . The ${ }^{14} \mathrm{C}$ uptake in 
plant 1 was the twofold of plant 2 but the half of plant 3. The comparison of the total PSLvalues shows significant differences between the three control plants (Tab.16).

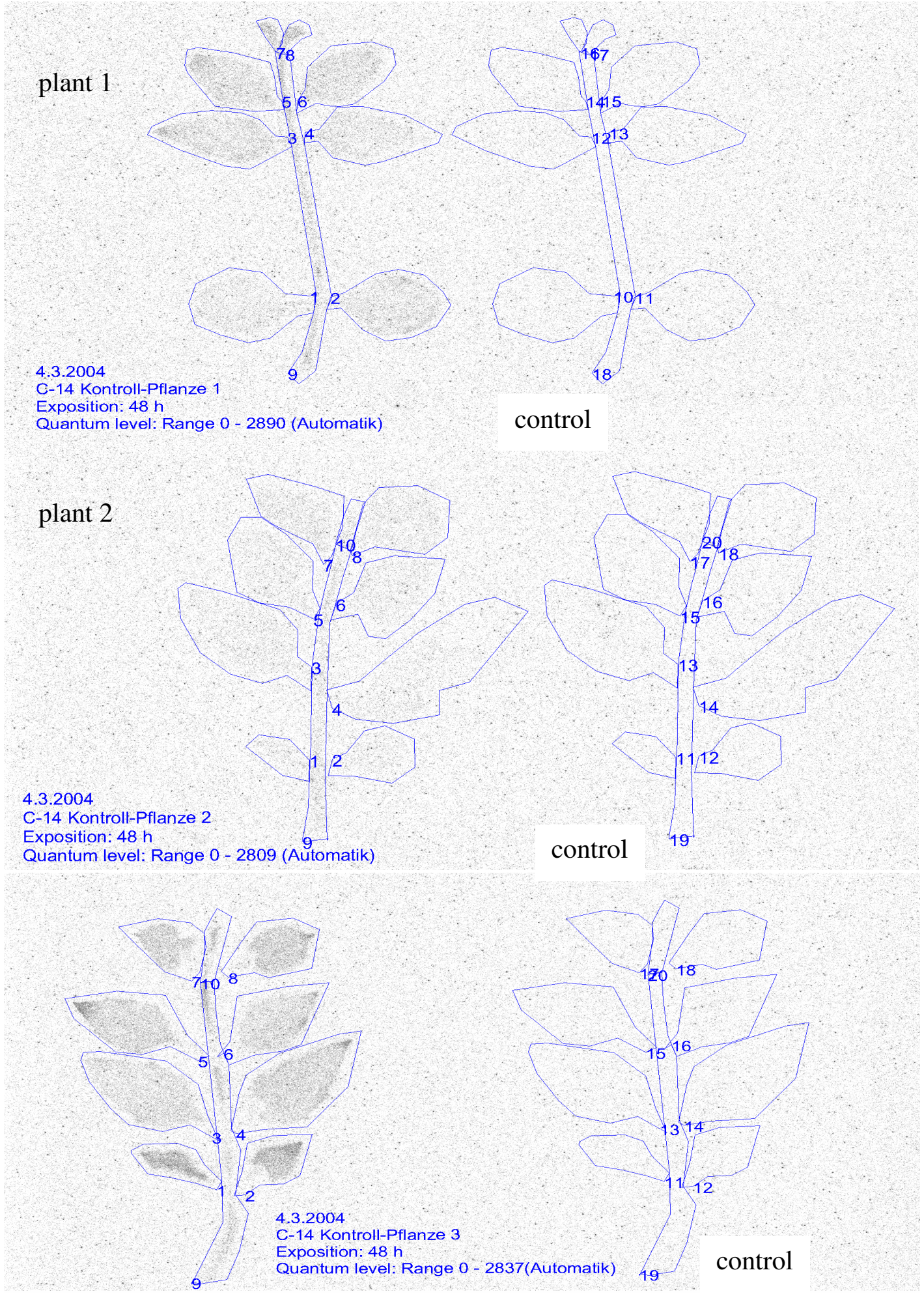

\section{Figure 16:}

Distribution of ${ }^{14} \mathrm{C}$ in the shoots of three Chromolaena odorata plants four weeks after inoculation with ${ }^{14} \mathrm{C}$ labelled dead hyphae of Glomus manihotis. 


\section{Table 16:}

${ }^{14} \mathrm{C}$ values in leaves and stems of the three Chromolaena odorata plants (fig. 16) four weeks after inoculation with ${ }^{14} \mathrm{C}$ labelled dead hyphae of Glomus manihotis.

\begin{tabular}{|c|c|c|c|c|}
\hline \multirow[t]{2}{*}{ Leaf No. } & \multicolumn{4}{|c|}{$P S L-$ value (photostimulated luminescence) } \\
\hline & plant 1 & plant 2 & plant 3 & plant Figure 14 \\
\hline 1 & 57.3 & 9.7 & 132.5 & 25.6 \\
\hline 2 & 91.8 & 20.5 & 137.8 & 20.1 \\
\hline 3 & 101.2 & 42.2 & 154.1 & 68.9 \\
\hline 4 & 57.8 & 28.8 & 241.0 & 47.8 \\
\hline 5 & 97.2 & 40.9 & 193.9 & 124.1 \\
\hline 6 & 87.6 & 30.8 & 141.2 & 94.5 \\
\hline 7 & 15.8 & 35.5 & 89.2 & 70.6 \\
\hline $\begin{array}{l}8 \\
\text { stem No. }\end{array}$ & 20.2 & 33.6 & 143.5 & 61.2 \\
\hline 9 & 98.3 & 49.9 & 97.7 & 64.1 \\
\hline 10 & & 5.8 & 17.8 & 21.3 \\
\hline total & 627.2 & 297.7 & 1348.7 & 598.2 \\
\hline comparison of total & & & & \\
\hline $\begin{array}{l}\text { PSL-values: } \\
\text { plant } 1 \text { versus plant } 2\end{array}$ & $*$ & & & \\
\hline plant 1 versus plant 3 & $* * *$ & & & \\
\hline plant 2 versus plant 3 & $* * *$ & & & \\
\hline
\end{tabular}

significance level was: *** at $\mathrm{P} \leq 0.001 ; * *$ at $\mathrm{P} \leq 0.01 ; *$ at $\mathrm{P} \leq 0.05$

In comparison to the PSL-values of the plant in figure 14 the ${ }^{14} \mathrm{C}$ accumulation in plant 2 was only the half, while the ${ }^{14} \mathrm{C}$ accumulation in plant 1 was the same as show in the total PSLvalues of the plant in figure 14 . Only the ${ }^{14} \mathrm{C}$ accumulation in plant 3 was higher than the plant in figure 14.

The control plants were labelled with the same amount of dead hyphae $(100 \mathrm{mg}$ hyphae $=$ $3000 \mathrm{~Bq}$ ), while the plants in figure 14 were labelled with three times more ${ }^{14} \mathrm{C}$ activity in mycorrhizal hyphae. Because of this, the ${ }^{14} \mathrm{C}$ accumulation into the control plants was very 
high in relative to the total ${ }^{14} \mathrm{C}$ activity in the dead mycorrhizal hyphae. The accumulation of ${ }^{14} \mathrm{C}$ in the shoots strongly varied in these plants. It may be, that the dead hyphal material was an additional organic nutrient source for the plants. The treatment of the labelled hyphae with potassium-hypochlorite could initiate a decomposition of the mycorrhizal hyphae with their chitin (to glucose-amine?), followed by an uptake of dissolved labelled compounds by the control Chromolaena plants (through photosynthesis?), causing the high and even accumulation of ${ }^{14} \mathrm{C}$ in these plants. Therefore, no comparison was possible between live and dead hyphae.

On the other hand, colonization of roots by mycorrhizal fungi can arise from three sources of inoculum, fungal propagules such as spores and external hyphae, beside infected root fragments (Smith and Read, 1997). The hyphal network in soil, together with root fragments, are the main means by which plants become colonized even when significant spore populations being also present (Hepper, 1981; Tommerup and Abott, 1981; Smith and Smith, 1981).

Tommerup and Abott (1981) demonstrated, that mycorrhizal hyphae from Glomus monosporus, G. fasciculatus and Gigaspora calospora arose from dead root fragments including living propagules, which were dried out and stored for 6 months. This finding indicates, that the hyphal network is capable of surviving and retaining infectivity for longer time. There are also evidences of surviving and retaining infectivity during periods when the vegetation with which it developed is dormant or actually dead. Studies in seasonally dry and hot climates showed that mycorrhizal hyphae remained highly infective in soils. Jasper et al. (1989) found, that external hyphae of Acaulospora laevis remained highly infective in soil in which the matric potential had reached $-21 \mathrm{MPa}$ after 36 days since last watering.

This result indicates, that mycorrhizal hyphae are long life propagules and that they are playing a key role in the colonization by mycorrhizal fungi. A decomposition of the living labelled hyphae in the present experiment is improbable, since the experiment was of short duration and the hyphae were the well known long life propagules, to keep their capability of infection in the soil. Even when there was a partial decomposition of the living labelled hyphae in the soil, the release of labelled compounds is not sufficient to cause such a high ${ }^{14} \mathrm{C}$ accumulation in the shoot of $C$. odorata. 


\subsubsection{Conclusion}

1.) The extraction of mycorrhizal hyphae was possible by the modified wet-sieving method (Daniels and Skipper, 1982). The soil suspension including spores, hyphae and soil particles was poured five times through a $45 \mu \mathrm{m}$ sieve after the heavier particles settled down. The hyphae were washed out of the sieve; this method maximized the harvest of the mycorrhizal hyphae from the soil.

2.) The construction of the growing units as described in chapter 4.1 made separation of hyphae from plant roots possible. ${ }^{14} \mathrm{C}$ glucose was pipetted onto the soil surface enabling the two mycorrhizal fungi (A. longula and G. manihotis) to take up ${ }^{14} \mathrm{C}$ glucose out of the soil and both mycorrhizal fungi stored ${ }^{14} \mathrm{C}$ glucose in their hyphal network. G. manihotis stored 4.5 times more ${ }^{14} \mathrm{C}$ glucose in its network than hyphae of A. longula.

3.) The ${ }^{14} \mathrm{C}$ labelled hyphae could be used as an inoculum to infect a new Chromolaena odorata plant. The high radioactivity which was used during the labelling procedure did not damage the mycorrhizal hyphae.

4.) The shoot and root fresh weight of $C$. odorata plants, inoculated with ${ }^{14} \mathrm{C}$ labelled GM-hyphae and AL-hyphae was significantly higher than those of plants inoculated with non-labelled hyphae. The GM-plants produced 2.5 times more plant bio-mass after four weeks of inoculation than plants inoculated with AL-hyphae. Small amounts of ${ }^{14} \mathrm{C}$ glucose were sufficient to reduce the "sink" for sugars in mycorrhizal fungi during the initial phase of the mycorrhizal symbiosis to a minimum.

5.) After inoculation and colonization of new $C$. odorata plants with labelled hyphae, their autoradiography showed a significant ${ }^{14} \mathrm{C}$ activity in roots and shoots. The accumulation of ${ }^{14} \mathrm{C}$ in shoots of control plants, which were inoculated with labelled dead hyphae, varied strongly and correlated highly with the ${ }^{14} \mathrm{C}$ activity in the dead hyphae. Therefore, it is difficult to state, if the ${ }^{14} \mathrm{C}$ was transferred due to mycorrhizal infection or due to its uptake after hyphae digestion. 
6.) The use of dead mycorrhizal hyphae, which were treated with potassium hypochlorite could not be considered as a control treatment for the carbon transfer. Carbon moved from live as well from dead hyphae to the plant, but live hyphae are capable of retaining infectivity for longer time, so that they did not decompose and did not transfer carbon to the plant. How the carbon transferred from dead hyphae to plant is a still open question.

7.) The detection of possible labelled ${ }^{14} \mathrm{C}$ compound via gel-electrophoresis was not possible. The radioactivity was too low and the ${ }^{14} \mathrm{C}$-glucose, as an $\alpha$-emitter, was not able to pass the plastic sheets, which were used to protect the Imager plates.

8.) The experiment "Investigation of a possible carbon transfer" (chapter 5.4.) should answer the question: is a carbon transfer from (V)AM fungi to plant possible?

\subsection{Investigation on a possible carbon transfer}

As mentioned in chapter 5.3., the possible carbon transport via mycorrhizal hyphae to the host plant must be confirmed by reproducible results. Inoculation with dead hyphae led to relatively high carbon transfer to the host, may be due to a possible decomposition of potassium-hypochlorite treated hyphae and the uptake of hyphal decaying $\mathrm{C}$ containing compounds. Direct application of ${ }^{14} \mathrm{C}$ into the application compartment followed by a ${ }^{14} \mathrm{C}$ transport via mycorrhizal hyphae could confirm the carbon transport.

Autoradiography (Fig. 17) shows highest accumulation of ${ }^{14} \mathrm{C}$ in the root system beside considerable activity also in the shoot of the tested Chromolaena odorata plant. Mycorrhizal roots had a PSL-value of 51478 and a PSL-value/ $\mathrm{mm}^{2}$ of 5.4. Highest accumulation of ${ }^{14} \mathrm{C}$ in the shoot was measured in younger leaves while there was a lower activity in the older leaves (Tab. 17). The PSL-value/mm ${ }^{2}$ increased from older (with 0.3 ) to younger leaves (with 1.7). 


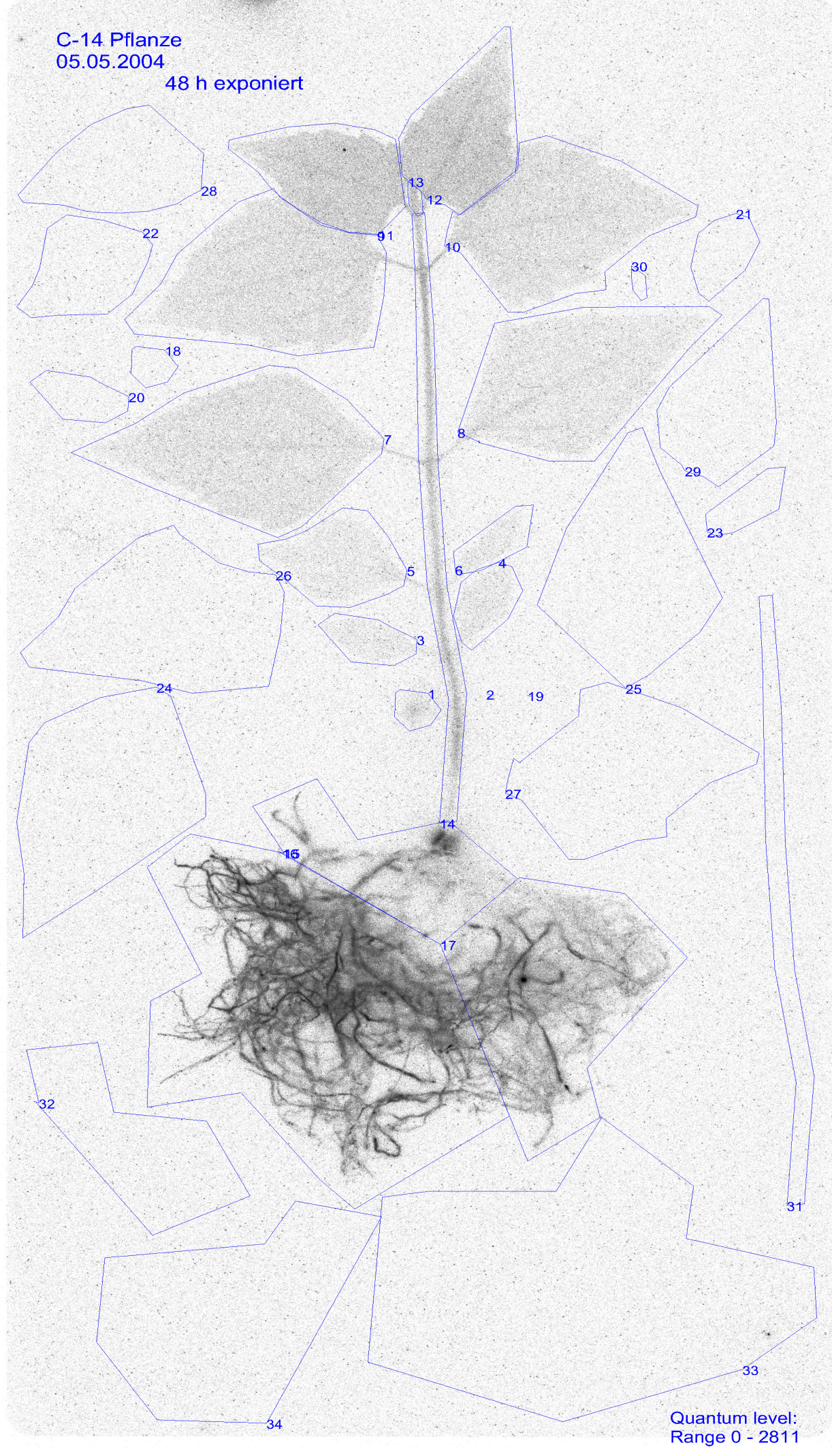

\section{Figure 17:}

Distribution of ${ }^{14} \mathrm{C}$ in the root and shoot of a Chromolaena plant after transferring ${ }^{14} \mathrm{C}$ glucose from the application compartment by mycorrhizal hyphae to the host plant 


\section{Table 17:}

${ }^{14} \mathrm{C}$ values in roots, leaves and stem after ${ }^{14} \mathrm{C}$ glucose transfer by mycorrhizal hyphae of $G$. manihotis to the Chromolaena host plant

\begin{tabular}{l|ccc}
\hline leaf No. & leaf area $\left(\mathrm{mm}^{2}\right)$ & PSL value & PSL/mm \\
\hline 1 & & & \\
2 & 96 & 50 & 0.52 \\
3 & n.d. & n.d. & n.d. \\
4 & 227 & 71 & 0.31 \\
5 & 262 & 86 & 0.33 \\
6 & 645 & 174 & 0.27 \\
7 & 199 & 58 & 0.29 \\
8 & 2035 & 1140 & 0.56 \\
9 & 1789 & 827 & 0.46 \\
10 & 1920 & 1170 & 0.61 \\
11 & 1690 & 1120 & 0.66 \\
12 & 891 & 1210 & 1.35 \\
13 & 953 & 1421 & 1.49 \\
stem & 25 & 44 & 1.76 \\
& & & \\
roots & 754 & 782 & 1.0 \\
\hline
\end{tabular}

The measured ${ }^{14} \mathrm{C}$ accumulation in the inoculated plant (Fig. 17) was much higher than in Figure 14 has shown, so that a water diffusion can not be excluded. Contrary to the autoradiography (Tab. 14), the measured ${ }^{14} \mathrm{C}$ accumulation (Table 17) was highest in older leaves and decreased in younger leaves.

These results of different ${ }^{14} \mathrm{C}$ accumulations in plants demonstrate, that redistribution possibly by diffusion inside the growing units between the hyphal compartment plays a significant role. The reduction of water supply during the growing period and the buffer compartment filled with quarz sand could not prevent the diffusion into the growing units. Because of the 
diffusion problem, the conducted experiments did not provide unequivocal evidence of achive $\mathrm{C}$ transfer from fungus to plants, althought $\mathrm{C}$ distribution patterns in the plants suggest that such transfer occurred. If a carbon transfer occurs, it may expected to be on a lower level than it was shown in the autotadiography (Fig. 17).

\subsubsection{Diffusion prevention}

Evidence from microscopy shows, that mycorrhizal hyphae were able to grow through a Vaseline-treated mesh into the outer hyphae compartment. Vaseline is a hydrophobic barrier for water.

Autoradiography (Fig. 18) showed that there was no accumulation of ${ }^{14} \mathrm{C}$ glucose either in the non-mycorrhizal plant or in the mycorrhizal plant after two weeks of ${ }^{14} \mathrm{C}$ application into the outer hyphae compartment. This is an evidence that no diffusion of water (containing ${ }^{14} \mathrm{C}$ glucose) from the hyphae compartment through the buffer compartment into the growing chamber occurred during the application time of two weeks. Because of the short duration of this test it was not possible to measure a significant carbon transfer into the host plant. If a carbon transport occurs, it is expected to be at a low level and therefore, the experimental time has to be longer to increase the possible carbon compounds transferred to the host. 
leaves after $48 \mathrm{~h}$ exposition

control leaf

${ }^{14} \mathrm{C}$ glucose treated leaf

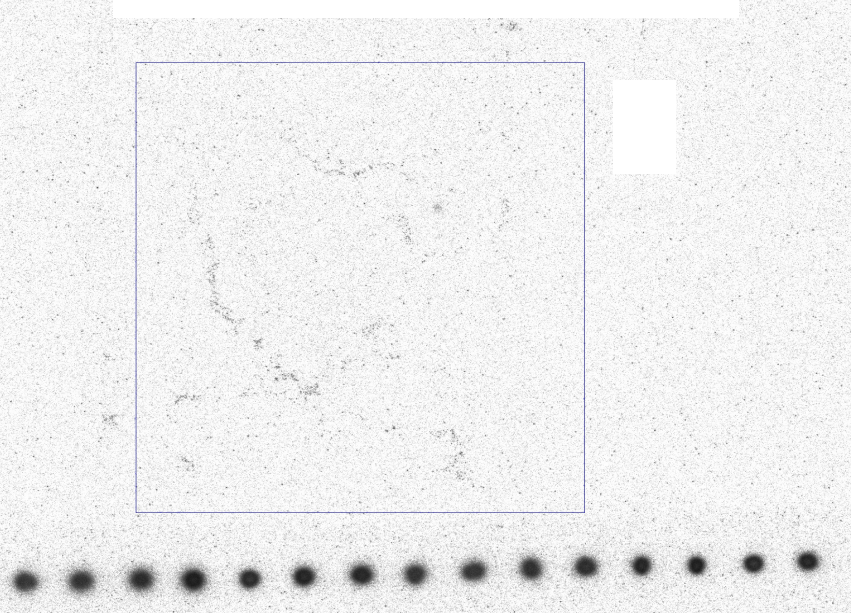

\section{Figure 18:}

Autoradiography of two leaves (control leaf and ${ }^{14} \mathrm{C}$ treated leaf) of Chromolaena odorata. 
Both findings, that the hyphae were able to grow through the Vaseline-treated mesh, and the effect of the Vaseline in preventing the diffusion, were the basis for a fivth experiment to answer the still open question, if there is a bi-directional carbon transfer between the (V)AMF and host plants.

To answer this question, the mesh of the application compartments were rubbed again with Vaseline and ${ }^{14} \mathrm{C}$ was pipetted onto the soil surface of the application compartments containing mycorrhizal hyphae, which were connected to the host plant. The duration of the experiment was four weeks and after harvesting the host plants, radioactivity was measured in shoots and roots of mycorrhizal and non-mycorrhizal plants (Tab. 18).

\section{Table 18:}

Transport of carbon from the outer application compartment to the plant compartment via mycorrhizal hyphae.

\begin{tabular}{l|cc}
\hline & Plant component & Total activity (Bq) \\
\hline Mycorrhizal plants & shoots & 6.7 \\
& roots & 14.7 \\
Non-mycorrhizal plants & & \\
& shoots & 2.2 \\
& roots & 1.5 \\
\hline
\end{tabular}

Three times greater amounts of labelled carbon were measured in shoots of the mycorrhizal plants $(6.7 \mathrm{~Bq})$ whereas $2.2 \mathrm{~Bq}$ were measured in non-mycorrhizal plants. The ${ }^{14} \mathrm{C}$ activity in mycorrhizal roots was 10 times higher than in non-mycorrhizal roots. As described in Table 14, where the transfer of ${ }^{14} \mathrm{C}$ from labelled mycorrhizal hyphae to the host plant was measured, the total ${ }^{14} \mathrm{C}$ activity of $8 \mathrm{~Bq}$ was measured in shoots. Similar amounts of carbon in shoots were presented in Table 18, where the mycorrhizal hyphae transported ${ }^{14} \mathrm{C}$ glucose from the application compartment into the plant compartment. In both experiments, similar amounts of carbon translocation were measured in the shoots and therefore a carbon transport from the mycorrhizal fungi to the host plant must have taken place. As reported by Bidartondo et al. (2002) transferred carbon may remain in fungal structures within roots and therefore a carbon flux between mycorrhizal fungi may be bi-directional. The results in Table 18 confirm, that high amounts of carbon were transferred through the extraradical mycorrhizal hyphae into the intraradical mycorrhizal hyphae and into the shoots and that the fungal 
structures in the root network could be responsible for the carbon transport from the fungi to the host.

The diffusion plays only a minor role in this experiment, because the transfer of carbon into the shoots $(2.2 \mathrm{~Bq})$ and roots $(1.5 \mathrm{~Bq})$ without mycorrhizal were lower than the transferred rates of $6.7 \mathrm{~Bq}$ into shoots and $14.7 \mathrm{~Bq}$ into roots.

\subsubsection{Conclusion}

1.) The first trial of this experiment showed, that a significant transfer of carbon from the mycorrhizal fungi to the plant may exist, but the influence of diffusion within the growing unit was too high to show the carbon flux via mycorrhizal hyphae to the plant.

2.) Vaseline could be used as diffusion barrier, so that the ${ }^{14} \mathrm{C}$ glucose remained in the hyphal compartment and did not diffused into the plant compartment.

3.) Mycorrhizal hyphae were able to grow through the "Vaseline"- treated mesh, which allows a measure of carbon transfer via mycorrhizal hyphae to the host plant.

4.) After application of ${ }^{14} \mathrm{C}$ into the application compartment containing mycorrhizal hyphae, a ${ }^{14} \mathrm{C}$ translocation occurred through the extraradical hyphae network into the intraradical mycorrhizal network.

5.) Beside the transportation within the hyphal network a carbon transfer into the host plant was measured.

6.) Diffusion played a minor role, because the transferred carbon rate into shoots and especially into roots were up to ten times higher than in non-mycorrhizal control plants. 
As shown in chapter 5.3. a carbon accumulation could be measured in Chromolaena odorata plants infected with ${ }^{14} \mathrm{C}$ glucose labelled hyphae of Glomus manihotis. Rausch et al. (2001) identified a Pi transporter gene StPT3 in potato (Solanum tuberosum), which was also found in root sectors infected with mycorrhizal fungi. Such $\mathrm{P}$ transporter could be involved in the $\mathrm{P}$ transfer between mycorrhizal fungi and host plants. The involvement of $\mathrm{P}$ transporter could be at least partly one explanation of the mentioned high ${ }^{14} \mathrm{C}$ accumulation or ${ }^{14} \mathrm{C}$-transfer from mycorrhizal fungi to the Chromolaena plant. It is well known, that mycorrhizal roots can use sources of $\mathrm{P}$ in soil that are not available to roots. This could involve increased rates of solubilization of insoluble Pi or hydrolysis of Po (Smith and Read, 1997). If there is a correlation between C-transfer and fertilization, it is to be expected, that highest $\mathrm{C}$ accumulations in shoots must be measured, where the $\mathrm{P}$ sources is not available and/or difficult accessible for plants.

\section{Hypothesis:}

Non-fertilized mycorrhizal plants have higher ${ }^{14} \mathrm{C}$ transfer rates to the host than HA- and MCP-fertilized mycorrhizal plants, because of a higher effectivity of mycorrhiza under P deficit and because of a higher quantity of $\mathrm{P}$ transporter ( $\mathrm{C}$ containing compounds).

\subsubsection{Dry matter of shoots, infection rate and ${ }^{14} \mathrm{C}$ activity of shoots}

Chromolaena plants, fertilized with phosphorus (HA and MCP), produced significantly higher dry matter than the non-fertilized plants (Tab. 19). However, there was no significant difference between HA-fertilized and MCP-fertilized plants.

Fertilized plants had infection rates of $84 \%$, which was significant higher than those of the non-fertilized plants $(73 \%)$.

No significant ${ }^{14} \mathrm{C}$ activities were measured between all treatments. 


\section{Table 19:}

Effects of fertilization (HA, MCP and non-fertilized plants) as main factor on shoot dry matter, infection rate and ${ }^{14} \mathrm{C}$ accumulation of 6 weeks old Chromolaena odorata plants

\begin{tabular}{|c|c|c|c|c|}
\hline & & $\begin{array}{c}\text { dry matter } \\
(\mathrm{mg})\end{array}$ & $\begin{array}{c}\text { infection-rate } \\
(\%)\end{array}$ & $\begin{array}{c}{ }^{14} \text { C activity } \\
\text { (dpm) }\end{array}$ \\
\hline 1 & HA-fertilized & 343.3 & 84 & 795.8 \\
\hline 2 & MCP-fertilized & 355.2 & 83 & 1020.2 \\
\hline 3 & non-fertilized (control) & 262.3 & 73 & 867.8 \\
\hline \multicolumn{2}{|c|}{1 versus 3} & $* *$ & $* *$ & n.s. \\
\hline \multicolumn{2}{|c|}{2 versus 3} & $* *$ & $* *$ & n.s. \\
\hline
\end{tabular}

significance level was: *** at $\mathrm{P} \leq 0.001$; ** at $\mathrm{P} \leq 0.01$; * at $\mathrm{P} \leq 0.05$

High variability within each fertilized group influenced the significance of ${ }^{14} \mathrm{C}$ activities in the shoots. Ranges between $600 \mathrm{dpm}$ and up to $1400 \mathrm{dpm}$ were measured in each group.

Nevertheless, there was no influence of the amount of labelled hyphae since the host plants were inoculated with a same amount of $100 \mathrm{mg}$ mycorrhizal hyphae which contained in total $3000 \mathrm{~Bq}{ }^{14} \mathrm{C}$. However, the distribution of this activity within the hyphal network may not have been homogeneous. Because of this, the condition for the fertilized and non-fertilized plants was perhaps different. However, the infection of the host plant with same amounts of hyphae and therefore similar amounts of ${ }^{14} \mathrm{C}$ carbon is necessary to give equal conditions to establish mycorrhizal symbiosis and to ensure the same labelled carbon quantity into the hyphae for the plants.

In the present experiment highest dry matter production could be measured in both fertilized plants compared to the non-fertilized plants. A similar result was also found by the author in prior investigations (Ditschar, 2001), where Chromolaena plants infected with G. manihotis and fertilized with HA and MCP produced significantly higher dry matter than non-fertilized plants after six weeks of growth and also by Sieverding (1981). This result and the results in Table 19 confirm, that $\mathrm{P}$ fertilizer in form of HA and MCP improves the dry matter production of Chromolaena odorata plants.

Additionally to the improved growth of the fertilized plants, the infection rates in their roots were also higher, compared with non-fertilized plants. Higher infection rates are caused by intensive root colonisation and external hyphae formation. Therefore, the external hyphae 
enabled the fertilized plants to take up more phosphorus to produce higher dry matter than the non-fertilized plants with lower infection rates.

The accumulation of ${ }^{14} \mathrm{C}$ decreased from older to younger leaf pairs (Tab. 20). The accumulation of ${ }^{14} \mathrm{C}$ in fertilized plants was highly significant higher in the mean of leaf pair 2 and 3 compared with leaf pair 4 and 5. Significant differences were also measured between leaf pair 2 and leaf pair 3 in fertilized plants (HA and MCP).

\section{Table 20:}

Effects of fertilization (HA, MCP and non-fertilized plants) as main factor on ${ }^{14} \mathrm{C}$ accumulation $\left(\mathrm{Bq} \mathrm{mg}{ }^{-1}\right.$ ) into leaf pairs (No.: 2, 3, 4 and 5) of 6 weeks old Chromolaena odorata plants

\begin{tabular}{l|ccc}
\hline leaf pair & \multicolumn{3}{|c}{ fertilization with phosphorus } \\
\hline \multirow{2}{*}{} & control & HA & MCP \\
3 & 2.9 & 3.6 & 3.1 \\
4 & 2.0 & 2.0 & 1.8 \\
5 & 1.4 & 0.8 & 1.0 \\
& 1.8 & 0.9 & 1.0 \\
2 versus 3 & & & $*$ \\
4 versus 5 & n.s. & $* * *$ & n.s. \\
mean gr. 2 and 3 versus mean gr. 4 and 5 & n.s. & n.s. & $* * *$ \\
\hline
\end{tabular}

significance level was: *** at $\mathrm{P} \leq 0.001 ; * *$ at $\mathrm{P} \leq 0.01$; * at $\mathrm{P} \leq 0.05$;

Leaf pair 2 contained $3 \mathrm{~Bq} \mathrm{mg}^{-1}$ and more in the three groups (non-, HA- and MCP- fertilized plants) while in leaf pair 3 the ${ }^{14} \mathrm{C}$ accumulation decreased in all treatments to about $2 \mathrm{~Bq} \mathrm{mg}^{-}$ 1. No significant differences could be measured within each of leaf pair 2 and 3 of the three groups because of the high fluctuations within each group (Fig. 19).

Leaf pair 2 and leaf pair 3 showed no effect of $P$ fertilization; they were totally developed at the time of inoculation with the labelled mycorrhizal hyphae, which may explain that no differences in ${ }^{14} \mathrm{C}$ accumulation were measured within these pairs. 

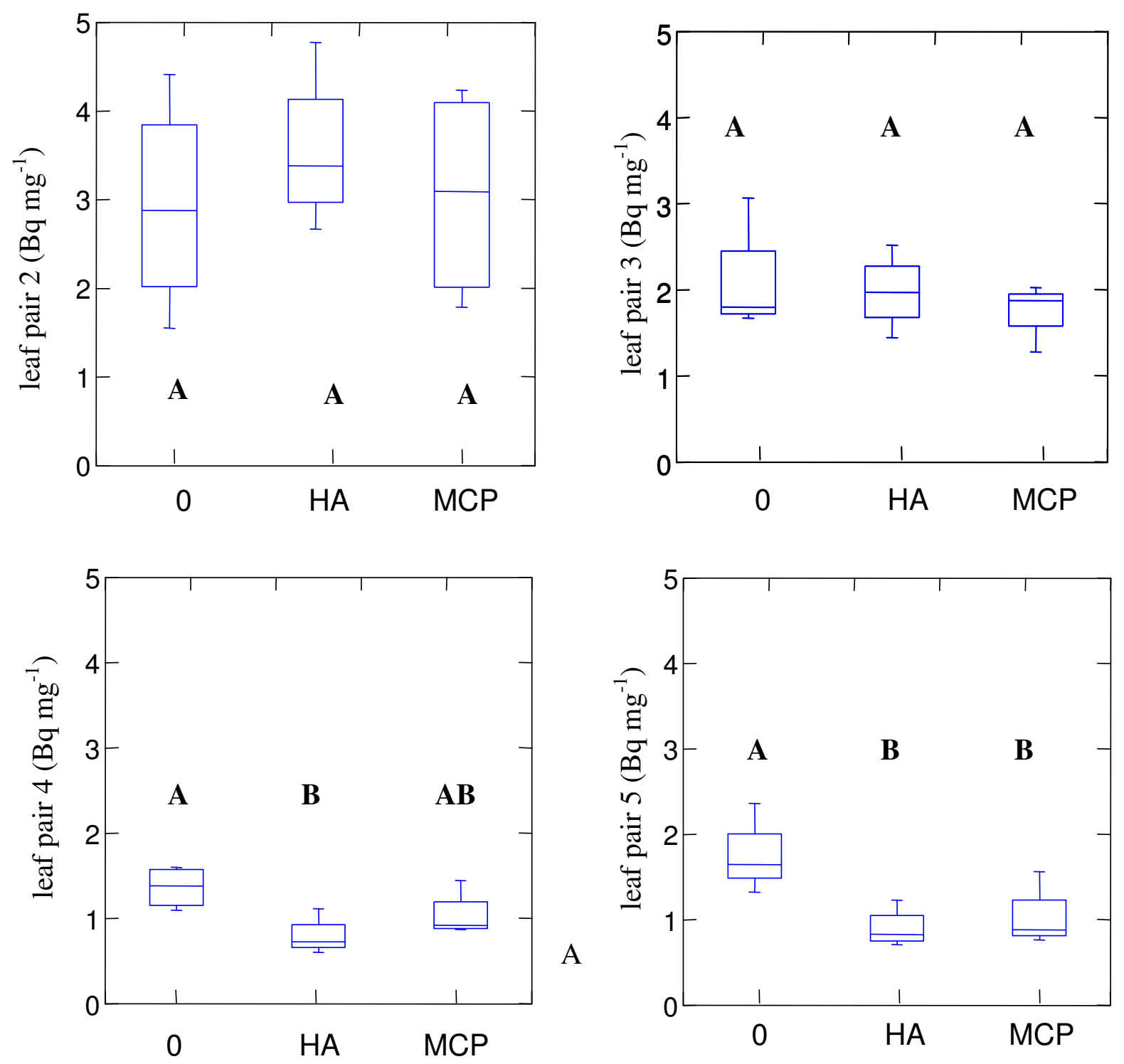

Figure 19:

Effects of fertilization (HA, MCP and non-fertilized plants) as main factor on ${ }^{14} \mathrm{C}$ accumulation $\left(\mathrm{Bq} \mathrm{mg}^{-1}\right)$ in leaf pairs (No.: 2, 3, 4 and 5) of 6 weeks old Chromolaena odorata plants.

Significant differences due to fertilization were measured in leaf pair 4 and 5 (Fig. 19). These two leaf pairs were developed after inoculation with ${ }^{14} \mathrm{C}$ labelled mycorrhizal hyphae.

Highest ${ }^{14} \mathrm{C}$ accumulation was measured in leaf pair 4 of non-fertilized plants, which was significant to HA-fertilized plants but not to $\mathrm{MCP}$ fertilized plants. Also highest ${ }^{14} \mathrm{C}$ accumulation was measured in leaf pair 5 of non-fertilized plants and this accumulation was significantly different to both fertilized groups. If $\mathrm{P}$ transporter may play a role in the $\mathrm{P}$ uptake 
mechanisms in mycorrhiza, and that highest effectivity of mycorrhizal occurs, where $\mathrm{P}$ is hardly accessible for plants, the highest ${ }^{14} \mathrm{C}$ accumulation in younger leaves in the nonfertilized treatment caused by improved carbon transport to these leaves. If there is a correlation between ${ }^{14} \mathrm{C}$ accumulation and phosphorus transportation into plants, a "Double labelling experiment" with ${ }^{14} \mathrm{C}$ and ${ }^{32} \mathrm{P}$ was conducted to investigate these correlations.

\subsubsection{Conclusion}

1.) Chromolaena odorata plants fertilized with phosphorus (HA or MCP) produced significantly higher dry matter and showed significantly higher infection rates compared with non-fertilized plants.

2.) High fluctuations within each fertilized group eliminated the significance of ${ }^{14} \mathrm{C}$ activities in shoots.

3.) The ${ }^{14} \mathrm{C}$ accumulation decreased from older to younger leaf pairs. The ${ }^{14} \mathrm{C}$ accumulation was highly significant in the leaf pair 2 and 3 compared with leaf pair 4 and 5, which was not well developed at the point of harvest.

4.) Significant higher accumulations of ${ }^{14} \mathrm{C}$ were measured in leaf pair 4 and 5 of nonfertilized plants compared to the fertilized plants. Because of highest effectivity of mycorrhiza in soils where $\mathrm{P}$ is hardly accessible for plants or fixed, the higher ${ }^{14} \mathrm{C}$ accumulation in younger leaves in the non-fertilized treatment could be caused by an improved carbon transport to these leaves.

5.) The "Double labelling experiment" (chapter 5.6.) should answer the question: is there a correlation between carbon transfer and phosphorus transfer in mycorrhiza, so that the ivolvement of $\mathrm{P}$ transporter in mycorrhizal could be possible? 


\subsection{Double labelling experiment}

Vesicular-arbuscular Mycorrhiza improves the nutrient uptake, especially of phosphorus by the plant due to exploration of a larger soil volume by its hyphae. Different $\mathrm{P}$ uptake mechanisms and a possible role of carbon are well discussed in the literature (chapter 3.). One of the possible $\mathrm{P}$ uptake mechanisms suggests that $\mathrm{P}$ transporter could be involved in the $\mathrm{P}$ transfer between the host and the mycorrhizal fungi (Rausch et al. 2001). This finding suggests, that carbon as a main component in proteins could be involved in such transport molecules.

Results of the "hyphae labelling" experiment are showing, that mycorrhizal hyphae were able to take up ${ }^{14} \mathrm{C}$ glucose out of the soil and that ${ }^{14} \mathrm{C}$ glucose was stored and transported into the hyphal network. The next experiment tested, what correlations between labelled carbon and phosphorus in mycorrhizal hyphae, roots and plants exist. ${ }^{14} \mathrm{C}$ glucose was used to label mycorrhizal hyphae to obtain on a ${ }^{14} \mathrm{C}$ inoculum and ${ }^{32} \mathrm{P}$ was used as a phosphorus source, which was made only available to the mycorrhizal hyphae.

\subsubsection{Fresh and dry matter}

No significant differences in dry matter production were measured in roots and shoots among treatments (Tab. 21). At the time of harvest roots had similar dry weights at about $0.5 \mathrm{mg}$ and no differences were measured between MCP-fertilized and non-fertilized plants.

Dry matter production in the shoots was also similar in all treatments. Inoculated plants with mycorrhizal hyphae grown in Kankab and quarz sand, showed higher dry matter production in MCP-fertilized than in non-fertilized pots. In contrast, non-fertilized plants with hyphae grown in Tzekel, showed 10\% higher dry matter production than fertilized plants. 


\section{Table 21:}

Effects of fertilizers (MCP and non-fertilized plants) and different soil types (Tzekel, Kankab and quarz sand) in the application compartments as main factors on root and shoot dry matter production of Chromolaena odorata after six weeks of growth.

\begin{tabular}{l|cc}
\hline soil & Root dry matter $(\mathrm{mg})$ & Shoot dry matter $(\mathrm{mg})$ \\
\hline & & 660.1 \\
Tzekel (non-fertilized) & 0.5 & 601.1 \\
Tzekel (fertilized with MCP) & 0.4 & 580.4 \\
Kankab (non-fertilized) & 0.4 & 614.5 \\
Kankab (fertilized with MCP) & 0.4 & 615.7 \\
quarz sand (non-fertilized) & 0.4 & 662.7 \\
quarz sand (fertilized with MCP) & 0.5 & $*$ \\
\hline
\end{tabular}

* no significance between all treatments

As shown in Table 1 (chapter 4.3.) the phosphorus content of the Paleustox was approximately $0.70 \mathrm{mg} \mathrm{P} 100 \mathrm{~g}$ dry soil $^{-1}$. This phosphorus content seems to be high enough to cover the plants phosphorus needs through mycorrhizal hyphae during the 6 week growing period. This could be one reason, that no significant differences in dry matter production were found between MCP-fertilized and non-fertilized plants in the plant compartments.

Previous experiments with Chromolaena odorata plants showed significant differences after 6 weeks of growth between MCP-fertilized and non-fertilized plants. Ditschar (2001) measured a threefold increase of dry matter production by Chromolaena plants fertilized with MCP and grown in $2 \mathrm{~kg}$ soil, compared with non-fertilized plants. This result demonstrate that the soil volume could influence the growth and dry matter production of Chromolaena plants.

5.6.2. ${ }^{14} \mathrm{C}$ and ${ }^{32} \mathrm{P}$ activity in mycorrhizal hyphae

One week after the addition of ${ }^{32} \mathrm{P}$ in the outer application compartment, mycorrhizal hyphae were washed out from the buffer compartment containing quarz sand. Differences of up to $50 \%$ of hyphal-growth were measured, between MCP-fertilized and non-fertilized plants (Tab. 22). These differences were not significant, because of the high variabilities in hyphal 
weights in the buffer compartments. The twofold amount of mycorrhizal hyphae in the fertilized treatment with quarz sand compared to the non-fertilized plants was only significant at $\mathrm{p} \leq 0.08$.

\section{Table 22:}

Hyphae fresh weight $(\mathrm{mg}),{ }^{14} \mathrm{C}(\mathrm{dpm})$ and ${ }^{32} \mathrm{P}(\mathrm{dpm})$ activities in mycorrhizal hyphae out of the buffer compartment.

\begin{tabular}{|c|c|c|c|c|}
\hline & Soil & $\begin{array}{c}\text { Hyphae } \\
(m g)\end{array}$ & $\begin{array}{c}{ }^{14} C \\
\text { in hyphae } \\
(\text { dpm })\end{array}$ & $\begin{array}{c}{ }^{32} P \\
\text { in hyphae } \\
(\text { dpm })\end{array}$ \\
\hline 1 & Tzekel (non-fertilized) & 96 & 40 & 52283 \\
\hline 2 & Tzekel (fertilized with MCP) & 120 & 36 & 77675 \\
\hline 3 & Kankab (non-fertilized) & 94 & 30 & 121277 \\
\hline 4 & Kankab (fertilized with MCP) & 142 & 47 & 115974 \\
\hline 5 & quarz sand (non-fertilized) & 61 & 70 & 769175 \\
\hline \multirow[t]{6}{*}{6} & quarz sand (fertilized with MCP) & 121 & 62 & 1086952 \\
\hline & 1 versus 2 & n.s. & n.s. & n.s. \\
\hline & 3 versus 4 & n.s. & n.s. & n.s. \\
\hline & 5 versus 6 & + & n.s. & $* * *$ \\
\hline & Mean of gr. Tzekel versus mean of gr. quarz sand & n.s. & + & $* * *$ \\
\hline & Mean of gr. Kankab versus mean of gr. quarz sand & n.s. & + & $* * *$ \\
\hline
\end{tabular}

No significant differences were measured in ${ }^{14} \mathrm{C}$ quantities of mycorrhizal hyphae between Tzekel and Kankab. Highest ${ }^{14} \mathrm{C}$ quantities (mean $65 \mathrm{dpm}$ ) were measured, where the outer application compartment was filed with quarz sand.

Highest and strongly significant ${ }^{32} \mathrm{P}$ activities were measured in hyphae of the MCP-fertilized quarz sand treatment compared with the non-fertilized treatment. This significance is correlated with the higher hyphae quantity in the MCP-fertilized treatment. 
Also significant differences were measured between the group of quarz sand and the two Mexican soils, whereas there was no significant difference between the Tzekel and Kankab treatment.

The results in Table 22 show, that there was an active carbon transport through the mycorrhizal mycelium. Chromolaena plants inoculated with ${ }^{14} \mathrm{C}$ labelled mycorrhizal hyphae and after colonisation, hyphae were grown through the buffer compartment into the outer application compartment. The hyphae out of the buffer compartment showed relatively high ${ }^{14} \mathrm{C}$ activities, which must come from hyphae, which infected the host plant. Pfeffer et al. (1999) proposed a model for major fluxes of carbon in arbuscular mycorrhizal fungi. In this model, lipids are synthesized by the fungus within the root and are stored or exported in such forms to the extraradical mycelium, where they are stored or metabolized. This export, storage and metabolism of lipids could be responsible for the ${ }^{14} \mathrm{C}$ activities in the mycelium, even though the labelled carbon compounds could not be identified in the present investigation. Beside lipids as one form of exported carbon from intraradical to extraradical hyphae Bago et al. (2003) reported about a significant flux of glycogen into extraradical mycelium, and therefore glycogen is probably the predominant carbohydrate moved within the fungus.

Figure 20 shows the correlation between hyphal fresh weight (washed out from the buffercompartment) and ${ }^{14} \mathrm{C}$ content $(\mathrm{dpm})$ in mycorrhizal hyphae, which was transported from the inoculum from the plant compartment throught the mycorrhizal network.

All the three figures show a positive regression between the hyphal fresh weight and their ${ }^{14} \mathrm{C}$ content. An increase of hyphal fresh weight increased the ${ }^{14} \mathrm{C}$ quantity in the hyphal network, but only the hyphal fresh weight and ${ }^{14} \mathrm{C}$ content in the treatment with quarz sand showed a very close linear correlation. The correlation between hyphal fresh weight and ${ }^{14} \mathrm{C}$ content in the treatment of Tzekel and Kankab was also positive, but were charactericed by higher variabilities. However, the figures of these two soils show the same tendency as the treatment with quarz sand.

Similar correlations were found between hyphal fresh weight and the quantity of ${ }^{32} \mathrm{P}$ in mycorrhizal hyphae (Fig. 21). Highest correlations were measured in hyphae grown beside the application compartment containing quarz sand and Tzekel, whereas the correlation in the treatment with Kankab show slight variabilities but same tendency as in the other both treatments. 
Both correlations between hyphal fresh weight and ${ }^{14} \mathrm{C}$ content and ${ }^{32} \mathrm{P}$ content were positive. The positive correlation between hyphal fresh weight and ${ }^{14} \mathrm{C}$ content leads to the suggestion, that the mycorrhizal fungi used the stored and labelled carbon from the inoculum to build up new mycorrhizal hyphae. Therefore it could be assumed, that the mycorrhizal fungi did not only use carbohydrates from the host, but also carbon, which is stored in its network.

The positive correlation between hyphal fresh weight and ${ }^{32} \mathrm{P}$ content leads to the suggestion, that mycorrhizal hyphae transferred same rates of phosphorus through its network.

The third figure (Fig. 22) shows the correlation between ${ }^{32} \mathrm{P}$ and ${ }^{14} \mathrm{C}$ quantities in mycorrhizal hyphae grown in the buffer compartment. High positive correlations were found in the treatment, where the hyphae grown beside the application compartment containing quarz sand. Similar positive correlation was found in the treatment, where the hyphae grown beside Tzekel, but with higher variabilities. No significant correlations were found in the Kankab treatments.

The growth of mycorrhizal hyphae was influenced in the present investigation when MCPfertilization was applied in the plant compartment and -more relevant- when different soils in the application compartments were used. It seems to be, that the three substrate types differ significantly in their capabilities of fixing P. It seems to be, that quarz sand showed the lowest P-fixing capacity, because mycorrhizal hyphae transported 10 times more ${ }^{32} \mathrm{P}$ through their network, than hyphae from the Tzekel and Kankab treatment. The higher P-fixing capacity of both Mexican soils compared to quarz sand have led to higher fluctuations in the correlation between ${ }^{14} \mathrm{C}$ and ${ }^{32} \mathrm{P}$ transport. Therefore, the lower P-fixing capacity of sand, compared to both Mexican soils, and so with the higher availability of $\mathrm{P}$ in the application compartment, have led to a more pronounced/ higher correlation between ${ }^{14} \mathrm{C}$ and ${ }^{32} \mathrm{P}$ activities in the mycorrhizal hyphae in the buffer compartment, of course being influenced by the development of the plant growing in its neighbourhood compartment. 

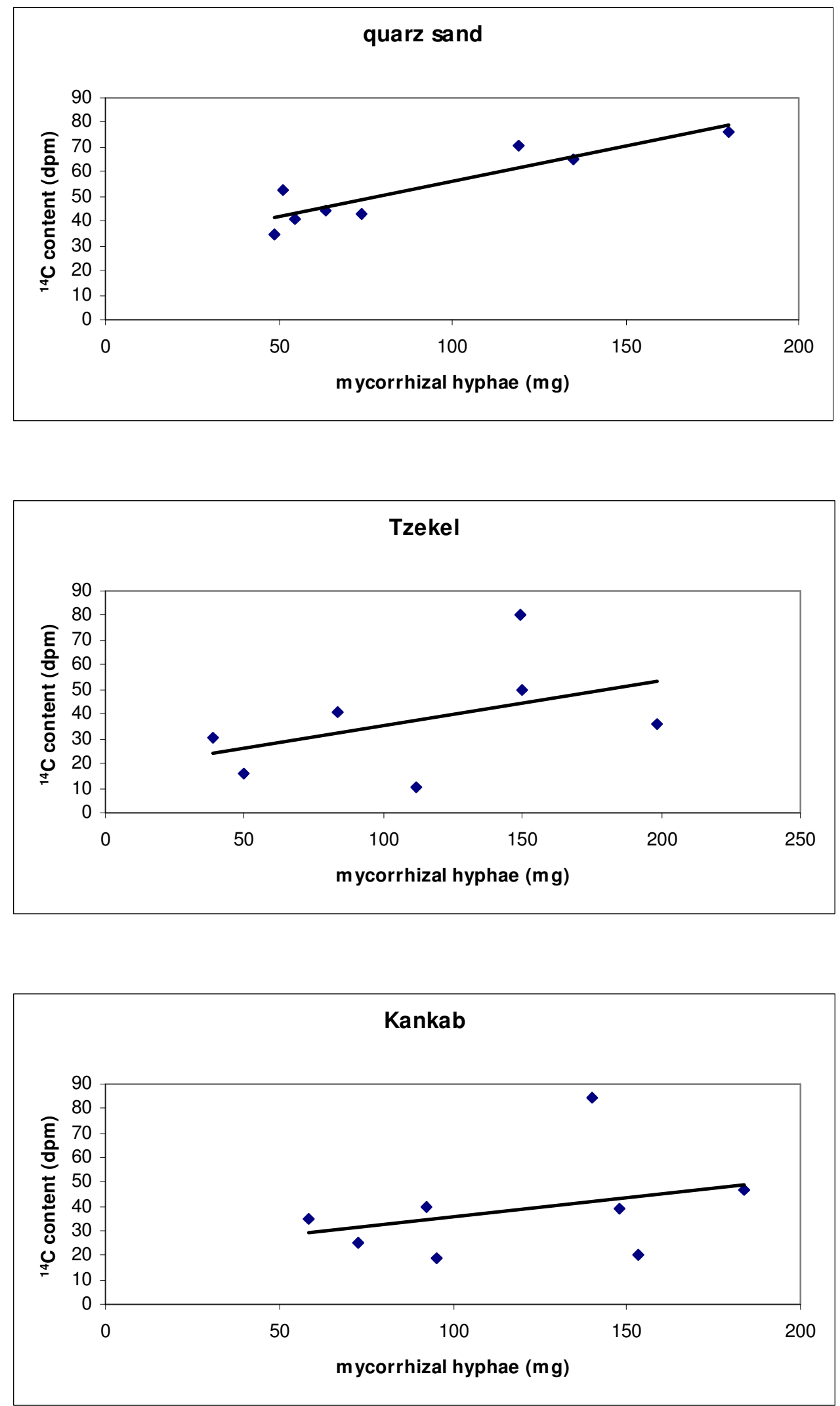

Figure 20:

Correlation between mycorrhizal hyphae weight $(\mathrm{mg})$ and their ${ }^{14} \mathrm{C}$ content $(\mathrm{dpm})$, grown in the buffer compartment containing quarz sand. 

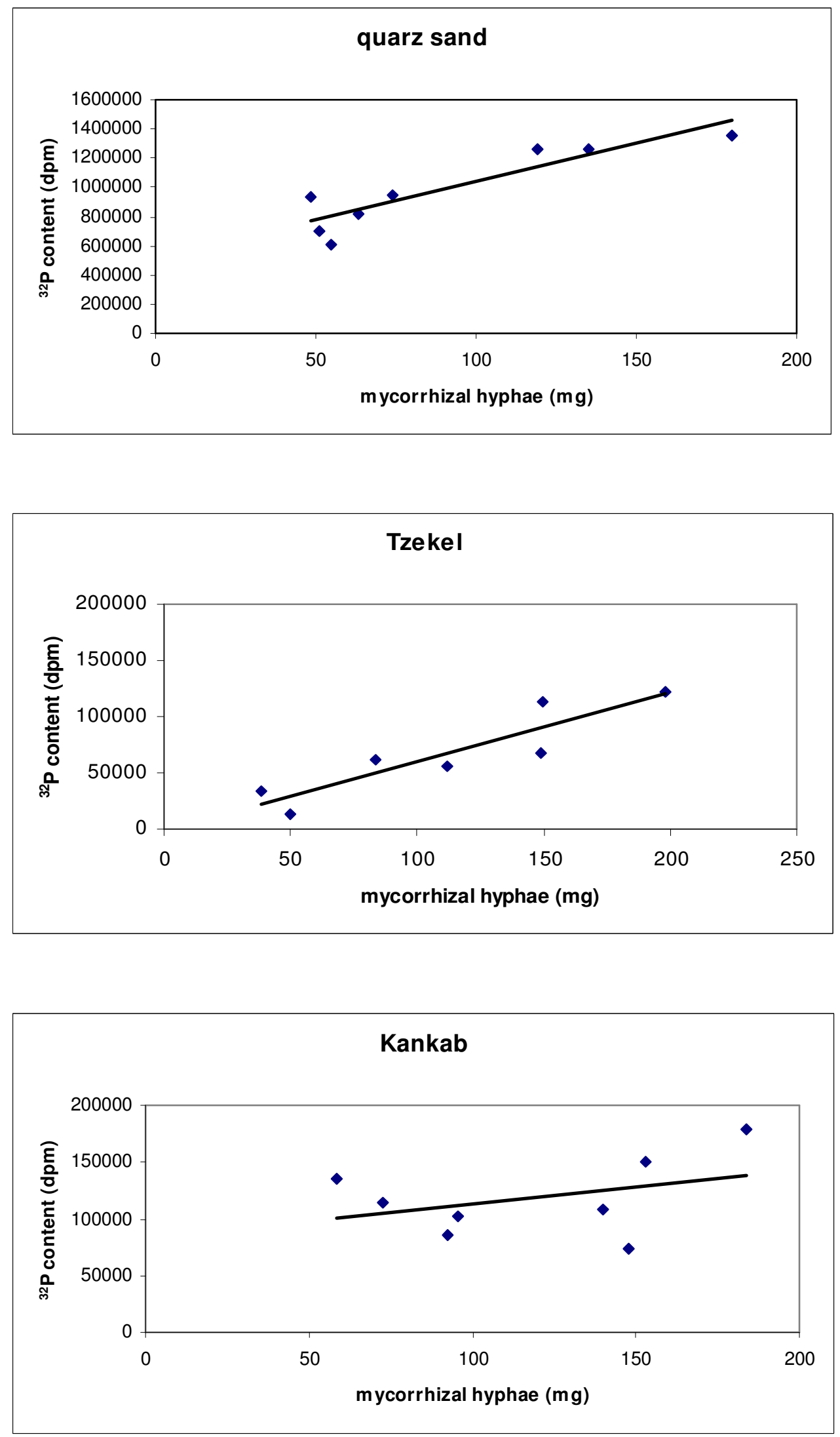

Figure 21:

Correlation between mycorrhizal hyphae weight $(\mathrm{mg})$ and their ${ }^{32} \mathrm{P}$ content $(\mathrm{dpm})$, grown in the buffer compartment. 

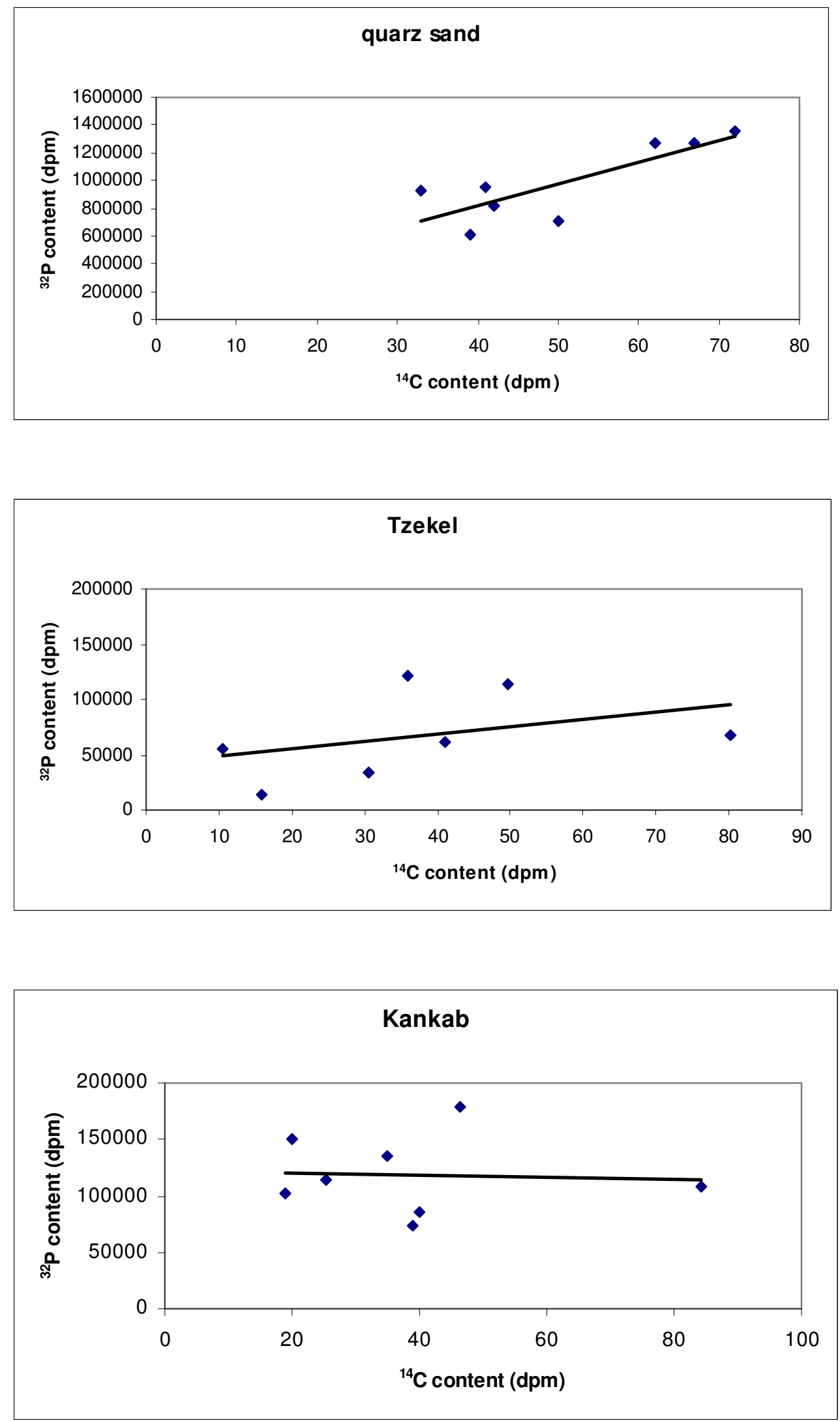

Figure 22:

Correlation between ${ }^{14} \mathrm{C}(\mathrm{dpm})$ and ${ }^{32} \mathrm{P}(\mathrm{dpm})$ in mycorrhizal hyphae, grown in the buffer compartment containing quarz sand. 
To sum up, the different substrate types and their behaviour to fix phosphorus, the P fixation is considered to be the most important factor, which influenced the hyphal fresh weight and their quantities of ${ }^{32} \mathrm{P}$ and ${ }^{14} \mathrm{C}$. Therefore, the treatment of the lowest $\mathrm{P}$ fixation in the application compartment (quarz sand) showed always high interactions between hyphal fresh weight and ${ }^{14} \mathrm{C}$ and ${ }^{32} \mathrm{P}$ quantities (Fig. 20 and Fig. 21) and as well between ${ }^{32} \mathrm{P}$ and ${ }^{14} \mathrm{C}$ (Fig. 22).

Jakobson et al. (1992) found out by using Trifolium subterraneum inoculated with three different mycorrhizal fungi, that the hyphal spread is an important factor influencing the fungal phosphorus supply to the host plant. The authors reported, that the P uptake by the Acaulospora laevis symbiosis was more than twofold of the Scutellospora calospora symbiosis although their total hyphal lengths were similar. The still open question is, if the higher $\mathrm{P}$ uptake was due to higher uptake capacity per unit length of the hyphae or to a better spread in the soil?

In the present experiment of ${ }^{32} \mathrm{P}$ uptake by mycorrhizal hyphae, the $\mathrm{P}$ uptake was correlated strongly with the hyphal fresh weight. According to the experiments of Jakobson et al. (1992) one explanation could be, that the phosphorus uptake by vesicular-arbuscular mycorrhizal fungi was strongly affected by the distribution of hyphae in the soil or through different uptake capacities per unit length of the hyphae. The question which remains open is, why hyphae of the same mycorrhizal fungus could have different $\mathrm{P}$ uptake-capacities?

\subsection{3. ${ }^{14} \mathrm{C}$ activity in shoots and roots}

Table 23 shows the ${ }^{14} \mathrm{C}$ activities in shoots and roots of the Chromolaena odorata plants, which were inoculated with ${ }^{14} \mathrm{C}$ labelled mycorrhizal hyphae. No significant differences were measured in shoots of the mycorrhizal plants between all treatments. ${ }^{14} \mathrm{C}$ activities ranged between $26 \mathrm{~Bq}$ and $32 \mathrm{~Bq}$. The highest ${ }^{14} \mathrm{C}$ activities were measured in plants of the Kankab treatment and the lowest radio-activity was measured in the Tzekel treatment.

The roots of the Chromolaena plants showed higher ${ }^{14} \mathrm{C}$ activities than in the shoots. Highest ${ }^{14} \mathrm{C}$ activities were measured in non-fertilized plant roots, where the mycorrhizal hyphae grown in the outer compartment in Kankab (476 Bq) and quarz sand $(504 \mathrm{~Bq})$. These high ${ }^{14} \mathrm{C}$ activities were significantly higher compared with the MCP-fertilized roots of each treatment. In contrast to the Kankab and quarz sand treatment, highest ${ }^{14} \mathrm{C}$ activities in the Tzekel treatment were measured in roots of the MCP-fertilized plants, which were the half of the 
non-fertilized Kankab and quarz sand treatment. Non-fertilized roots of the Tzekel treatment showed ${ }^{14} \mathrm{C}$ activities of $79 \mathrm{~Bq}$, which was the same activity as measured in the non-fertilized Kankab and quarz sand treatment.

\section{Table 23:}

${ }^{14} \mathrm{C}$ activities $(\mathrm{Bq})$ in shoots and roots of the Chromolaena odorata plant.

\begin{tabular}{l|lcc}
\hline & \multicolumn{2}{|l}{$\begin{array}{c}\text { Roots } \\
\left(\text { Bq roots }^{-1}\right)\end{array}$} & $\begin{array}{c}\text { Shoots } \\
\left(\text { Bq shoot }^{-1}\right)\end{array}$ \\
\hline 1 & Tzekel (non-fertilized) & 78.9 & 26.5 \\
2 & Tzekel (fertilized with MCP) & 233.3 & 27.3 \\
3 & Kankab (non-fertilized) & 476.0 & 31.6 \\
4 & Kankab (fertilized with MCP) & 77.9 & 31.6 \\
5 & quarz sand (non-fertilized) & 504.2 & 26.1 \\
6 & quarz sand (fertilized with MCP) & 76.3 & 30.2 \\
& & & n.s. \\
& 1 versus 2 & n.s. & n.s. \\
3 versus 4 & $*$ & n.s. \\
& 5 versus 6 & $*$ & n.s. \\
mean of gr. Tzekel versus mean of gr. Kankab & n.s. & n.s. \\
\hline
\end{tabular}

significance level was: *** at $\mathrm{P} \leq 0.001 ; * *$ at $\mathrm{P} \leq 0.01 ; *$ at $\mathrm{P} \leq 0.05$

No significant different ${ }^{14} \mathrm{C}$ activities in shoots and roots of the mycorrhizal host plant were expected in the present investigation. All plants of each treatment were transplanted to the same Paleustox and were labelled with same amounts of ${ }^{14} \mathrm{C}$ labelled mycorrhizal hyphae. The treatments differed only through the different substrate types in the outer compartment, which had no influence on the effectivity of the mycorrhizal hyphae in the plant compartment and therefore no influence on the transferred carbon via mycorrhizal hyphae.

The significant differences in roots are surprising, but it could be possible, that parts of the remained ${ }^{14} \mathrm{C}$ labelled inoculum were responsible for the high ${ }^{14} \mathrm{C}$ activities in roots. However, no comparable investigations were done in the past, therefore it is difficult to explain the different ${ }^{14} \mathrm{C}$ activities which were measured in the root network. On the other hand, it is not 
sure, that the high ${ }^{14} \mathrm{C}$ activities were caused by the remained inoculum. Mycorrhizal roots were rinsed out carefully during the harvest and furthermore the first $2 \mathrm{~cm}$ of the root network were removed to avoid that surplus and/or attached inoculum could influence the measurements of the ${ }^{14} \mathrm{C}$ activities in the roots.

Figure 23 shows the contribution of ${ }^{14} \mathrm{C}$ in the shoots of the Chromolaena plants. Highest and significant amounts of ${ }^{14} \mathrm{C}$ quantities were measured in the lower part of the shoots compared to those in the upper part.

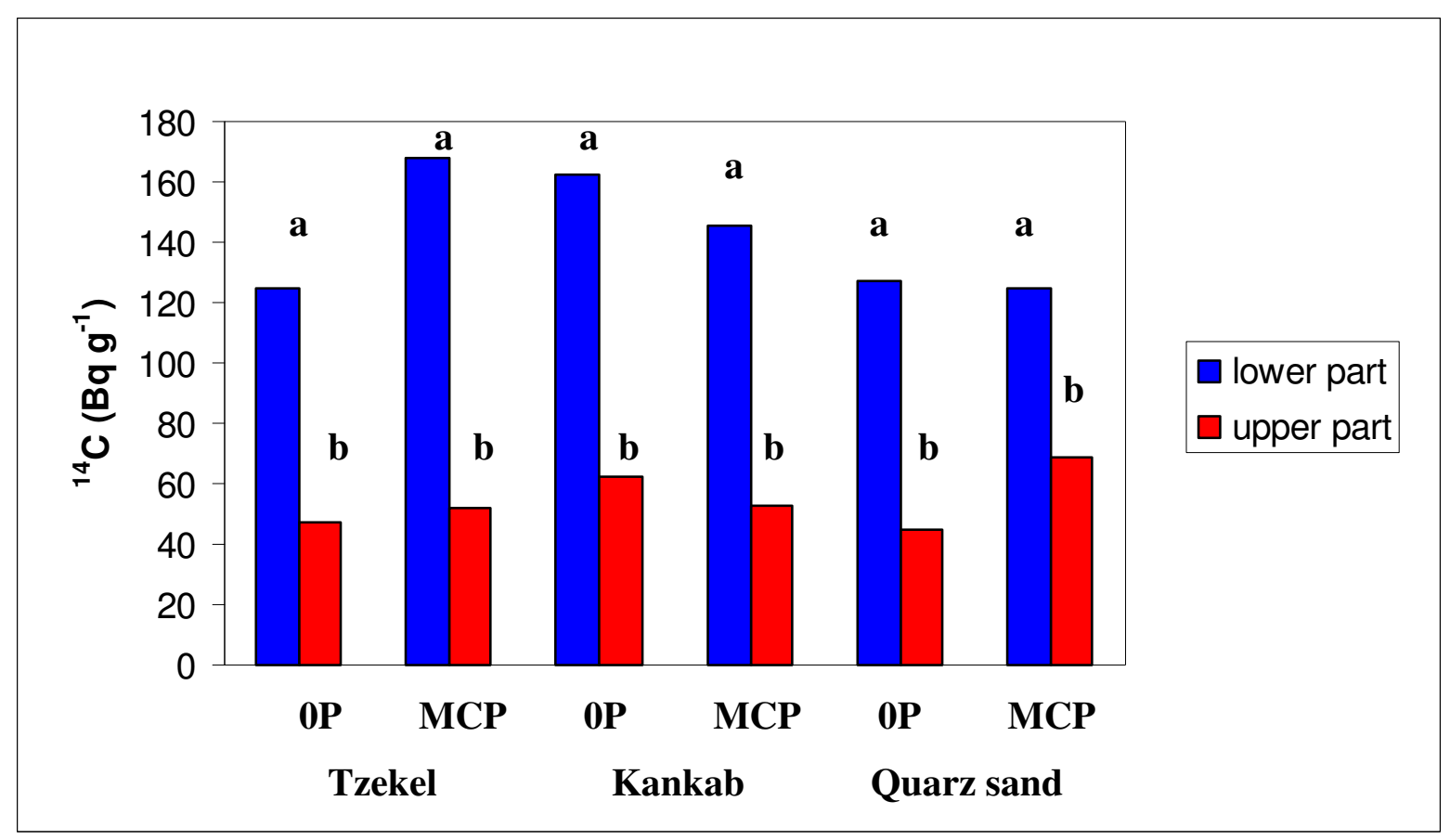

\section{Figure 23:}

Effect of soil-type and phosphorus fertilization on ${ }^{14} \mathrm{C}$ contribution in lower (blue) and upper (red) part of the 6 week old Chromolaena odorata shoots. Bars with same letters are not significantly different at $\mathrm{P} \leq 0.05$ (Fisher`s LSD).

\subsection{4. ${ }^{32} \mathrm{P}$ activity in shoots and roots}

One of the well discussed mechanisms of phosphorus uptake by mycorrhizal plants is, that including the active role of the extraradical hyphae. Therefore, the extraradical hyphae are considered to be involved in the following three processes (Smith and Read, 1997): 

a) absorption of phosphate from the soil,
b) translocation of $\mathrm{P}$ for considerable distances in the soil and into the fungus structures within the root and
c) transfer of $\mathrm{P}$ from fungus to plant across the symbiotic interfaces.

All these three processes lead to the improved phosphorus uptake in mycorrhizal plants, which based among other factors such as the greater exploration of soil by the hyphae network. Table 24 and Figure 24 show the ${ }^{32} \mathrm{P}$ uptake and ${ }^{32} \mathrm{P}$ translocation from soil into roots and shoots of the Chromolaena host plant by mycorrhizal hyphae over a distance of about 3 $\mathrm{cm}$. 


\section{Table 24:}

Effects of fertilization (MCP and non-fertilized plants) and soil type (Tzekel, Kankab and quarz sand) as main factors on ${ }^{32} \mathrm{P}$ translocation into roots and shoots of Chromolaena odorata.

\begin{tabular}{|c|c|c|c|c|c|}
\hline \multicolumn{2}{|r|}{ Substrate type } & $\begin{array}{c}\text { roots } \\
\left(B q g^{-1}\right)\end{array}$ & $\begin{array}{c}\text { roots } \\
\left(\log B q g^{-1}\right)\end{array}$ & $\begin{array}{l}\text { shoots } \\
\left(B q g^{-1}\right)\end{array}$ & $\begin{array}{c}\text { shoot } \\
\left(\log B q g^{-1}\right)\end{array}$ \\
\hline 1 & Tzekel (non-fertilized) & 25307 & 4.38 & 35963 & 4.54 \\
\hline 2 & Tzekel (fertilized with MCP) & 28866 & 4.38 & 42817 & 4.58 \\
\hline 3 & Kankab (non-fertilized) & 49424 & 4.67 & 97181 & 4.95 \\
\hline 4 & Kankab (fertilized with MCP) & 47792 & 4.64 & 86037 & 4.90 \\
\hline 5 & quarz sand (non-fertilized) & 327942 & 5.49 & 536876 & 5.72 \\
\hline \multirow[t]{7}{*}{6} & quarz sand (fertilized with MCP) & 268671 & 5.39 & 458561 & 5.64 \\
\hline & 1 versus 2 & & n.s. & & n.s. \\
\hline & 3 versus 4 & & n.s. & & n.s. \\
\hline & 5 versus 6 & & n.s. & & n.s. \\
\hline & mean of gr. Tzekel & & $*$ & & $* * *$ \\
\hline & versus mean of gr. Kankab & & & & \\
\hline & $\begin{array}{l}\text { mean of gr. } 1-4 \text { versus mean of gr. } \\
5 \text { u. } 6\end{array}$ & & $* * *$ & & $* * *$ \\
\hline
\end{tabular}

significance level was: *** at $\mathrm{P} \leq 0.001 ; * *$ at $\mathrm{P} \leq 0.01 ; *$ at $\mathrm{P} \leq 0.05$

No significant effect on ${ }^{32} \mathrm{P}$ uptake $\left(\log \mathrm{Bq} \mathrm{g}^{-1}\right)$ by roots of non-fertilized and MCP-fertilized plants was measured due to substrate treatment (Tzekel, Kankab and quarz sand). Roots grown in fertilized and non-fertilized substrates showed same ${ }^{32} \mathrm{P}$ contents in each of the three types.

Hyphae grown in quarz sand (with low $\mathrm{P}$ fixation) showed the significantly highest ${ }^{32} \mathrm{P}$ transport from the hyphal compartment to the plant root system -caused by higher $\mathrm{P}$ availability- compared with the ${ }^{32} \mathrm{P}$ transport by hyphae grown in the two mexican soils. Mycorrhizal hyphae grown in Kankab transported $83 \%$ less ${ }^{32} \mathrm{P}$ to the root network than from 
quarz sand and $79.5 \%$ more ${ }^{32} \mathrm{P}$ than from Tzekel, so that the difference between the two mexican soils was highly significant.

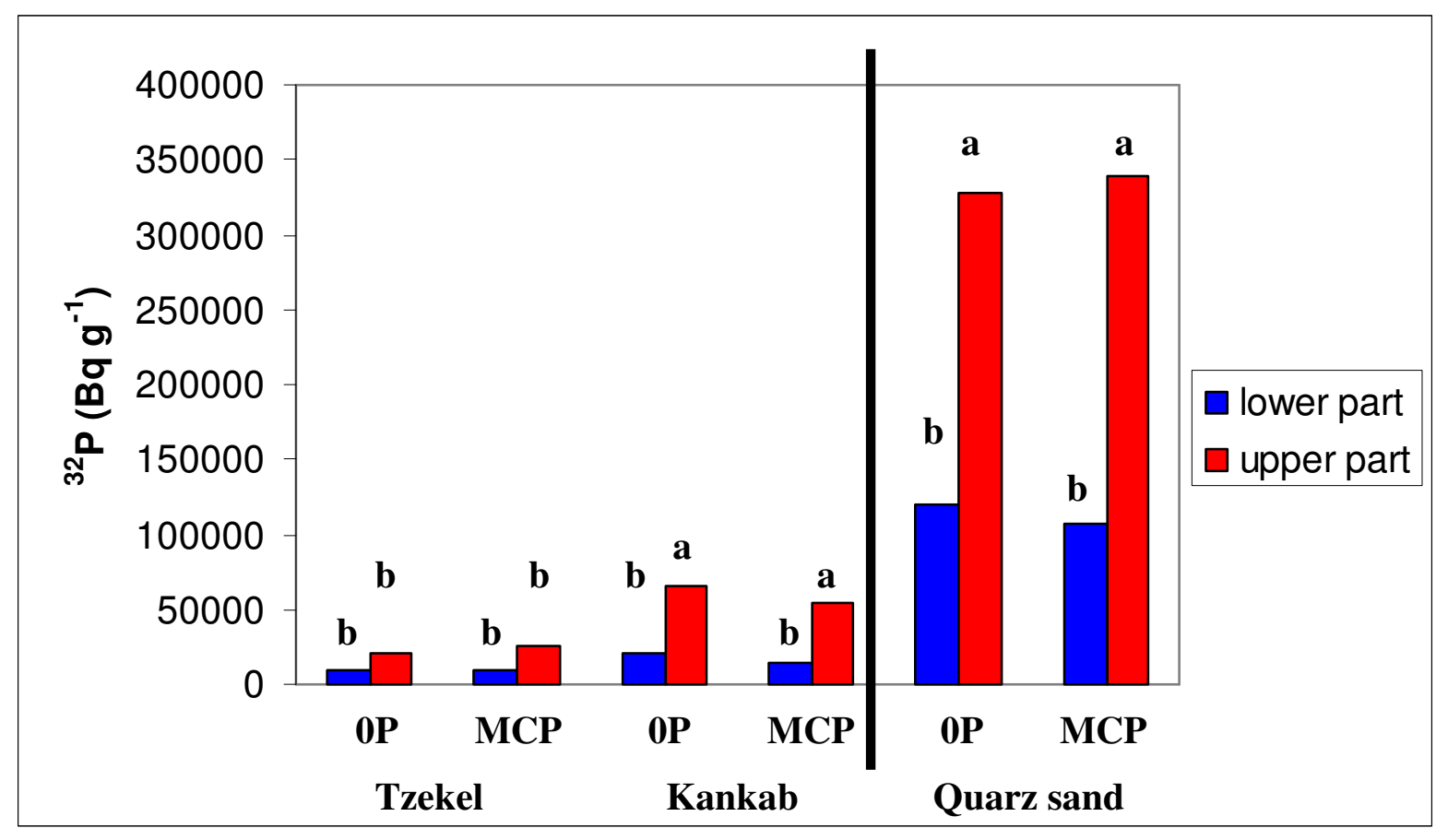

\section{Figure 24:}

Effect of substrate-type and fertilization on ${ }^{32} \mathrm{P}$ accumulation in lower (blue) and upper (red) part of the 6 week old Chromolaena odorata shoot.

The ${ }^{32} \mathrm{P}$ transport from the hyphal compartment containing quarz sand was the highest and showed significant differences in comparison with the two mexican soils.

The ${ }^{32} \mathrm{P}$ transport from the hyphal compartment containing Kankab was higher than twofold of the ${ }^{32} \mathrm{P}$ transport from the hyphal compartment containing Tzekel, and therefore highly significant different.

The highest transport of ${ }^{32} \mathrm{P}$ via mycorrhizal hyphae into shoots and roots was measured in quarz sand. Quarz sand is a neutral growing medium with low $\mathrm{P}$ fixation, so that the availability of phosphorus is not affected by the soil type. In contrast, the two soils from Mexico showed higher P fixation compared with quarz sand.

The high phosphorus transport via mycorrhizal hyphae over a $3 \mathrm{~cm}$ distance confirms the early findings by Hattingh et al. (1973), Cooper and Tinker (1978,1981) and Jakobson et al. (1992), that mycorrhizal hyphae are able to transport phosphorus over longer distances to the host plant. 
Jakobson et al. (1992) used two-compartment systems, in which the hyphal compartment was separated from the plant compartment by a fine mesh. The hyphal compartment contained a layer of ${ }^{32} \mathrm{P}$ labelled soil in defined distances to the plant compartment. Trifolium subterraneum plants infected with three different mycorrhizal fungi were tested for phosphorus uptake. The experiments showed, that the used mycorrhizal fungi (Acaulospora laevis, Glomus sp. and Scutellospora calospora) were able to take up ${ }^{32} \mathrm{P}$, which was applied up to $7 \mathrm{~cm}$ away from the plant roots.

The results of increased ${ }^{32} \mathrm{P}$ accumulation in the upper part of the Chromolaena plant as shown in Figure 24 correlate strongly with the higher ${ }^{14} \mathrm{C}$ accumulation in the upper part in the "Hyphae labelling experiment" (Fig. 14; Tab. 14), but in the "Double labelling experiment" the $\mathrm{C}$ was higher in the lower part.

\subsubsection{Use of gel-electrophoresis}

Figure 25 shows the acrylamide gels containing several ${ }^{32} \mathrm{P}$ labelled bands in the gel. Gel A shows in the first row two labelled bands, the first at $4 \mathrm{~cm}$ and the second at $10.5 \mathrm{~cm}$. Because of the gradient gel, the extracted labelled molecules at $4 \mathrm{~cm}$ are bigger then those at $10.5 \mathrm{~cm}$. These two labelled bands were identified in mycorrhizal hyphae, which were grown in the outer application compartment. In comparison to the measurement of possible ${ }^{14} \mathrm{C}$ labelled molecules via gel electrophoresis, the ${ }^{32} \mathrm{P}$ activity was high enough to detect such bands as shown in Figure 25.

While it was possible to detect two different bands in mycorrhizal hyphae, there was only one labelled band in the extract of roots and shoots. The labelled band was detected at $10.5 \mathrm{~cm}$. Therefore, the band at $4 \mathrm{~cm}$ could be specific molecules, which occur only in mycorrhizal hyphae and which may be involved in the phosphorus translocation through the hyphae to the roots of the host plant. 
Substrate in outer compartment:
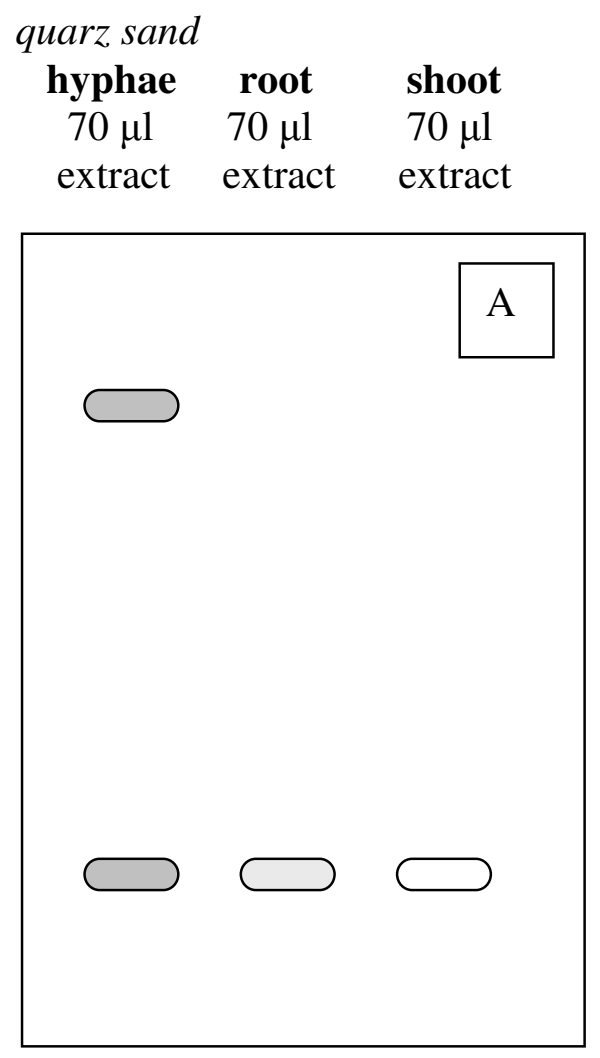

Substrate in outer compartment:

$\begin{array}{cccc}\begin{array}{c}\text { quarz sand } \\ \text { hyphae }\end{array} & \text { Tzekel } & \text { Kankab } & \text { quarz sand } \\ 20 \mu \mathrm{loot} & 20 \mu \mathrm{l} & 20 \mu \mathrm{root} & \text { root } \\ \text { extract } & \text { extract } & \text { extract } & \text { extract }\end{array}$

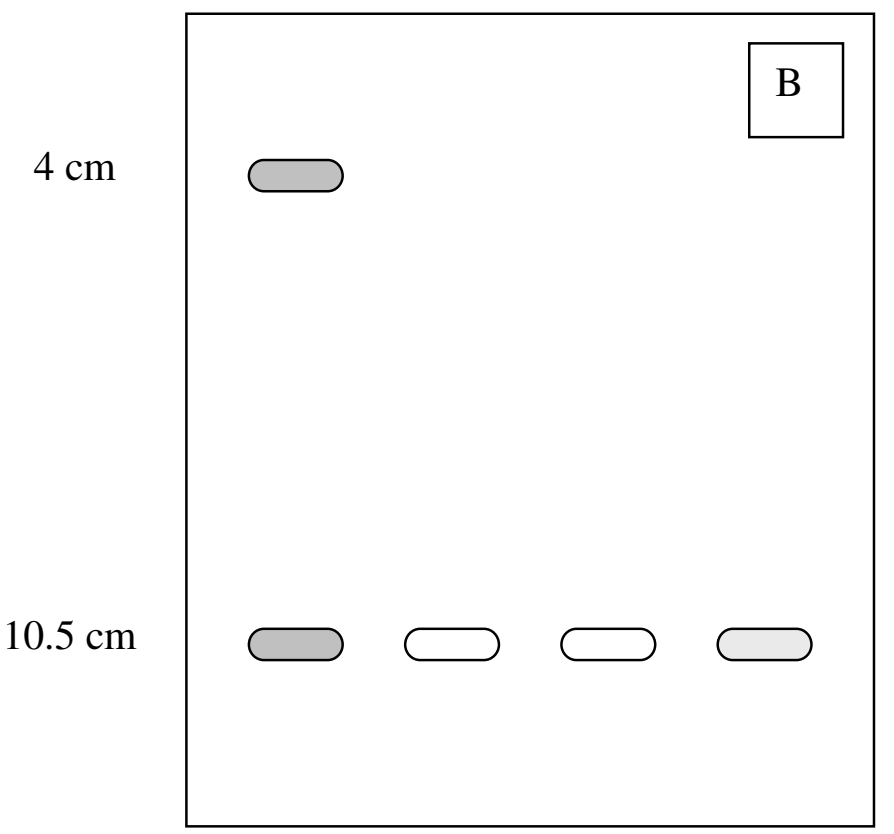

\section{Figure 25:}

${ }^{32} \mathrm{P}$ labelled compounds, visible in acrylamide-gel, extracted out of hyphae, roots and shoots of plants, where the hyphae grown in different substrates in the ${ }^{32} \mathrm{P}$ outer application compartments.

Gel B shows again the two labelled bands in the first row, containing labelled molecules, which were extracted out of mycorrhizal hyphae grown in quarz sand. The other three different bands show labelled compounds, which were extracted out of the inoculated roots in those treatments, where the hyphae grown in Tzekel-soil, Kankab-soil and in quarz sand. The highest labelled band was detected in roots, where the hyphae grown in quarz sand, while the bands of the Tzekel and Kankab treatments showed similar intensities.

The higher intensity of the band out of the quarz sand treatment may be caused by the substrate (quarz sand) in the outer compartment. As described in chapter 5.6.4. the highest transport of ${ }^{32} \mathrm{P}$ via mycorrhizal hyphae into shoots and roots was measured in the treatments, where the mycorrhizal hyphae grown in quarz sand, and therefore in a neutral medium with a low P fixation. The high phosphorus transport into roots and shoots out of the compartment 
filled with quarz sand, correlates with the higher intensity of the labelled bands in this treatment.

\subsubsection{Conclusion}

1.) No significant differences in the dry matter production were found in roots and shoots with different phosphorus treatments (MCP-fertilized and non-fertilized) and different substrate types in the outer hyphal compartment (Tzekel, Kankab and quarz sand).

2.) Higher amounts of hyphae were found in the buffer compartments, where the hyphae grown from MCP-fertilized plants, but because of high fluctuations in hyphal weight no significant differences were measured.

3.) No significant differences were measured in ${ }^{14} \mathrm{C}$ quantities in mycorhizal hyphae grown in the buffer compartment between treatments.

4.) Highest ${ }^{32} \mathrm{P}$ activities in hyphae were measured in those treatments, where the outer compartment was filled with quarz sand. The hyphae in the buffer compartment of the quarz sand treatment grown from MCP-fertilized plants showed significantly higher ${ }^{32} \mathrm{P}$ activities than hyphae grown from non-fertilized plants.

5.) No significant ${ }^{32} \mathrm{P}$ differences were found in hyphae between the Tzekel and Kankab treatment.

6.) An increase of hyphae fresh weight in the buffer compartment increased the ${ }^{14} \mathrm{C}$ quantity in the hyphal network, but only the treatment of quarz sand showed high correlations compared to both Mexican soil treatments.

7.) An increase of hyphae fresh weight increased the ${ }^{32} \mathrm{P}$ quantity in hyphae grown in the buffer compartment. High correlations were measured in the treatment of quarz sand and in the treatment were the hyphae in the outer compartment grown in Tzekel.

8.) High correlations between ${ }^{32} \mathrm{P}$ and ${ }^{14} \mathrm{C}$ quantities in the hyphae were found in the treatment, where the hyphae were grown beside the application compartment 
containing quarz sand. Similar tendencies were found in the treatments of Tzekel and Kankab.

9.) No significant differences were found in the ${ }^{14} \mathrm{C}$ activities in shoots and roots of the Chromolaena odorata plants between treatments. Significant higher amounts of ${ }^{14} \mathrm{C}$ were translocated in the lower part of the shoot in all treatments than in the upper part.

10.) No significant differences in ${ }^{32} \mathrm{P}$ uptake $\left(\log \mathrm{Bq} \mathrm{g}^{-1}\right)$ into roots were measured in each treatment (Tzekel, Kankab and quarz sand).

11.) Hyphae grown in the outer compartment filled with quarz sand transferred significantly highest amounts of phosphorus to the host plant than hyphae grown in the two Mexican soils. Mycorrhizal hyphae grown in Kankab soil transported $1 / 4$ of ${ }^{32} \mathrm{P}$ to the root network then when grown in quarz sand and double amounts of ${ }^{32} \mathrm{P}$ than from Tzekel.

12.) Highest amounts of the translocated ${ }^{32} \mathrm{P}$ were measured in the upper part of the host plant. Hyphae of the treatments containing quarz sand in the outer compartment transported six times more ${ }^{32} \mathrm{P}$ to the upper and lower part than hyphae grown in the two Mexican soils. Hyphae grown in Kankab translocated significantly more ${ }^{32} \mathrm{P}$ to the upper plant part than hyphae grown in Tzekel.

13.) Acrylamid-gel-electrophoresis showed two different labelled bands (first band at $4 \mathrm{~cm}$ and second band at $10.5 \mathrm{~cm}$ ), which were extracted out of the mycorrhizal hyphae. Only one labelled band was found in the inoculated roots and in the shoots of the host plant (band at $10.5 \mathrm{~cm}$ ). The labelled ${ }^{32} \mathrm{P}$ bands must be organically because they were stucked in the gel where big pore sizes occured. 


\subsection{Experiment on the role of (V)AM in plant water uptake}

The main objective of the "water uptake experiment" was to use the growth units with two additional compartments (chapter 4.1., Fig. 6) to test, if the mycorrhizal hyphae are able to transport water from the outer hyphae compartment to the Sorghum bicolor host plant, which was grown in the plant compartment.

The content of mycorrhizal hyphae in the outer compartments was tested by harvesting of one additional replicate from each treatment before ${ }^{18} \mathrm{O}$ was added to all outer compartments of the experimental growing units. Mycorrhizal hyphae were washed out of the soil and were checked by microscopy. Mycorrhizal hyphae were found in all soils of the three treatments. Highest amounts of hyphae were found in the treatment, where the Sorghum plants were grown in the Paleustox and were inoculated with G. manihotis. Only few amounts of hyphae were found in the treatment, where the plant was grown in Tzekel, and one third of hyphae compared to the Paleustox treatment were found in the Kankab treatment.

The Vaseline treated mesh, to prevent water diffusion, decreased the water flow from the application compartment to the plant compartment. It was not possible to reduce the water diffusion over the whole experiment. As described in chapter 5.4.1. Vaseline could be used to prevent the water diffusion over a short growing period, but the Vaseline was degraded over the growing period of eight weeks.

\subsubsection{Growth parameters of plants}

After five weeks of transplanting, significantly thicker shoots of Sorghum plants grown in sterilized Kankab and Tzekel soils were measured, compared to plants, which were grown in natural Kankab and Tzekel soils (Tab. 25). No significant differences were measured in the shoot thickness between plants grown in the sterile and G. manihotis (GM) inoculated Paleustox. Plants grown in sterile Paleustox showed a significantly smaller shoot diameter than plant grown in sterile Kankab and Tzekel soils, while the plant diameters of GM inoculated plants in the Paleustox were only significantly wider compared to the diameter of plants grown in Kankab soil. 


\section{Table 25:}

Effect of three different natural soils and their sterilisation on shoot diameter ( $\mathrm{mm}$ ) and shoot height $(\mathrm{cm}) 5$ and 8 weeks after transplanting and their increase (\%) between the observation time. Results with same letters are not significant different at $\mathrm{P} \leq 0.05$ (Fisher`s LSD).

\begin{tabular}{|c|c|c|c|c|c|c|}
\hline Soil & $\begin{array}{c}\text { Shoot } \\
\text { diameter } \\
\text { after } 5 \\
\text { weeks }\end{array}$ & $\begin{array}{c}\text { Shoot } \\
\text { diameter } \\
\text { after } 8 \\
\text { weeks }\end{array}$ & $\begin{array}{l}\text { Increase } \\
\text { of shoot } \\
\text { diameter }^{+}\end{array}$ & $\begin{array}{l}\text { Shoot } \\
\text { height } \\
\text { after } 5 \\
\text { weeks }\end{array}$ & $\begin{array}{l}\text { Shoot } \\
\text { height } \\
\text { after } 8 \\
\text { weeks }\end{array}$ & $\begin{array}{l}\text { Increase } \\
\text { of shoot } \\
\text { height }^{+}\end{array}$ \\
\hline Kankab, sterile & $3.8 \mathrm{a}$ & $4.5 \mathrm{~b}$ & $18.1 * * *$ & $42.0 \mathrm{a}$ & $43.2 \mathrm{ac}$ & 2.7 n.s. \\
\hline Kankab, natural & $2.7 \mathrm{c}$ & $3.2 \mathrm{c}$ & $21.0 * * *$ & $30.1 \mathrm{c}$ & $32.1 \mathrm{e}$ & 6.6 n.s. \\
\hline Tzekel, sterile & $3.8 \mathrm{a}$ & $5.4 \mathrm{a}$ & $41.7 * * *$ & $41.6 \mathrm{a}$ & $46.0 \mathrm{a}$ & $10.6 *$ \\
\hline Tzekel, natural & $3.1 \mathrm{~b}$ & $4.2 \mathrm{~b}$ & $35.6 * * *$ & $32.4 \mathrm{c}$ & $44.3 \mathrm{ab}$ & $36.4 * * *$ \\
\hline Paleustox, sterile & $3.1 \mathrm{~b}$ & $3.3 \mathrm{c}$ & 5.3 n.s. & $37.0 \mathrm{~b}$ & $39.8 \mathrm{~d}$ & 7.7 n.s. \\
\hline Paleustox, GM & $3.1 \mathrm{~b}$ & $3.1 \mathrm{c}$ & 1.6 n.s. & $40.4 \mathrm{a}$ & $42.1 \mathrm{bdc}$ & 4.3 n.s. \\
\hline
\end{tabular}

${ }^{+}$significance level was: $* * *$ at $\mathrm{P} \leq 0.001 ; * *$ at $\mathrm{P} \leq 0.01 ; *$ at $\mathrm{P} \leq 0.05$

After eight weeks of growth and before the application of ${ }^{18} \mathrm{O}$ the greatest and significantly different (to all other treatments) shoot diameter was measured in plants grown in sterilized Tzekel soil. Also the shoot diameter of plants grown in sterile Kankab was significantly different to plants grown in natural Kankab. Only small and not significant differences of shoot diameters were produced by plants grown in the sterile Paleustox and by plants, grown in the inoculated Paleustox.

In the treatments, where thicker shoots were measured, the plant height in sterile Kankab and Tzekel soil was also significantly higher than in both natural soils, where the plants have had similar heights. The difference between the natural and sterile soils was in both treatments $10 \mathrm{~cm}$. The Glomus manihotis inoculated plants, grown in the Paleustox, had a significantly bigger size than the plants in the same, but sterilized soil. Compared to the both Mexican soils, the GM inoculated plants grown in the Paleustox had significantly bigger sizes than plants grown in natural Kankab and Tzekel soils.

The shoot height ranged in all soil treatments between $40 \mathrm{~cm}$ and $46 \mathrm{~cm}$, only plants grown in the natural Kankab soil had the significantly smallest shoot height of all treatments $(32 \mathrm{~cm})$. No significant differences were measured between the two treatments of Tzekel and the 
Paleustox (sterile/ natural). Only the shoot height of sterile and natural Kankab soil was significantly different.

Wolde-Yohannes (1974) reported, that the productivity of Ethiopian soil increased up to the threefold by burning the soil and its organic material. The burning of the soils initiated a mineralization of the organically bound $\mathrm{N}, \mathrm{P}$ and $\mathrm{Ca}$ and a release of $\mathrm{Ca}, \mathrm{Mg}$ and $\mathrm{K}$ from silicates, which increased the nutrient availability in this soil. The two Mexican soils, which were used in the present investigation, have also high amounts of organic compounds. By heating the two soils at $120^{\circ} \mathrm{C}$ for three days, there could be also a mineralization of the organically bound $\mathrm{N}, \mathrm{P}$ and $\mathrm{Ca}$ has taken place and therefore, there was an increase of the nutrient availability, in these soils. The higher nutrient availability after soil heating in the present experiment lead to greater shoot diameters and bigger sizes of the Sorghum plants, grown in the Mexican soils. No influence of heating was found in plants, which were grown in the red Paleustox, because of its sandy property and its lower content of organic matter.

It is in general well known, that heating of soils rich in organic matter can increase the availability of some nutrients e.g. P, and leads to mineralization of organically bound elements (e.g. P, N, Ca etc.).

Plants grown in sterile and natural Tzekel soil showed highest differences in their growth after eight weeks compared to five weeks. The shoot diameter was increased by $42 \%$ in plants grown in sterile soil and $36 \%$ in plants grown in natural soil (Tab. 25), while the increase of the shoot height in natural soil was $36 \%$ compared with an increase of $10 \%$ in sterile soil. The plants grown in Kankab soils (sterile and natural) showed an increase in their shoot diameter of $20 \%$, while the increase of the shoot height was only $2.7 \%$ in sterile and $6.6 \%$ in natural soil. Plants grown in sterile and natural Paleustox showed only very small differences in their growth between five and eight weeks.

\subsubsection{Physiological observations before harvest}

Some visual physiological differences were observed before harvesting (Tab. 26). Plants, grown in each sterile soil showed darker green colours than plants grown in the natural soils. The darker plant colour could be resulted by the increased nutrient availability, because of soil-heating, and therefore by the enhanced nutrient uptake by the plants. As compared in figure 29 and figure 30, plants with greater heights and thicker shoot diameters, had also 
darker green colours, and these observations underline the advantage of plants, when they were grown in heated soils.

Table 26:

Observations of visual physiologicaly plant parameters before harvesting the experimental plants.

\begin{tabular}{|c|c|c|c|c|c|c|}
\hline Soil & Colour & $\begin{array}{l}\text { Green } \\
\text { leaves }\end{array}$ & $\begin{array}{c}\text { Yellow- } \\
\text { brownish } \\
\text { leaves }\end{array}$ & $\begin{array}{l}\text { Dead } \\
\text { leaves }\end{array}$ & $\begin{array}{l}\text { Leaflet } \\
\text { wilting/ } \\
\text { folding }\end{array}$ & Flowering \\
\hline Kankab, sterile & dark green, bluish & 4 & 2 & 3 & - & - \\
\hline Kankab, natural & green & $3-4$ & 2 & 2 & + & - \\
\hline Tzekel, sterile & green, bluish & 3 & 2 & 3 & +++ & - \\
\hline Tzekel, natural & green & 4 & 2 & 3 & - & - \\
\hline Paleustox, sterile & green & 3 & 2 & 3 & - & - \\
\hline Paleustox + GM & green, yellowish & $3-4$ & 1 & 4 & - & +++ \\
\hline
\end{tabular}

+ low; ++ medium; +++ high

Low differences were observed in the number of green, yellow-brownish and dead leaves between all treatments. Four green leaves were observed in plants grown in natural Tzekel soil compared with three leaves in its sterile treatment. Same tendencies were observed in the Paleustox, while plants grown in the sterile Kankab soil showed four green leaves compared with three to four leaves in the sterile treatment. The total number of leaves were higher by plants which grown in natural Tzekel and Paleustox compared to their sterile treatments. No differences were measured by plants in the Kankab soil. The higher number of total leaves in the mycorrhizal treatments could be formed therefore as an effect of the used mycorrhizal fungi G. manihotis in the Paleustox and the mycorrhizal propagules in the natural Tzekel soil. A very high leaflet wilting and/or folding was observed in plants, which grown in the sterile Tzekel soil, while the plants grown in natural Tzekel soil showed no wilting or folding. As shown in Table 25, plants of the Tzekel treatment showed similar shoot heights and as shown in Table 26, plants grown in the natural Tzekel had more formed green leaves before harvesting. The data suggest that mycorrhizal colonization of Sorghum bicolor grown in Tzekel soil can improve their growth through direct drought avoidance. The enhanced water 
absorption by mycorrhizal plants and their root system suggest also, that mycorrhizal infection could reduce the water stress in plants (Huang et al., 1985).

Plants grown in the Paleustox inoculated with G. manihotis, produced small flowers and were therefore the only flowering plants in the experiment. However, it is still unclear, if the flowers were a result of mycorrhizal infection or a result of an emergency flower. Significant differences in shoot heights five weeks after transplanting, same shoot diameters and a higher number of green leaves, allow to suggest, that the mycorrhizal plants grown in the Paleustox were of a better vitality than the non-mycorrhizal plants in the same soil.

\subsubsection{Shoots and roots dry matter and water content}

Significantly higher differences in dry matter production by plants were measured in shoots of the two heated Kankab and Tzekel soils compared to their natural soil-form (Tab. 27). Highest differences in shoot dry matter of more than $100 \%$ were measured between the heated and natural Kankab soil, while the difference between the heated and natural Tzekel soils was 50\%. In comparison of both natural Mexican soils, the Tzekel soil produced $100 \%$ more plant material than Kankab soil and therefore the natural Tzekel soil had a significantly higher production potential in the experiment than the natural Kankab soil. Contrary to both Mexican soils, the plants, grown in the Paleustox had significantly higher shoot dry weights in the treatment, where the plants were inoculated with Glomus manihotis than the plants grown in the heated soil. The increased dry matter production by plants, grown in both heated Mexican soils, correlates positively with the shoot height and shoot diameter as shown in Table 25 . Heating the soil, to get a better nutrient availability, and the advantage of (V)AMF-root association could explain the differences between mycorrhizal and non-mycorrhizal shoots and roots dry matter. As shown in Table 25, the increase in shoot height by mycorrhizal plants grown in Tzekel soil was $36 \%$ between the two observations (after five and eight weeks), while there was only an increase of $10 \%$ by non-mycorrhizal plants. The $\mathrm{C}$ loss by the plant may was compensated by enhanced photosynthesis or metabolic processes, so that mycorrhizal plants have higher growing rates than non-mycorrhizal plants.

The root dry matter was only significant between the sterile and natural Kankab soil, while the roots in the Tzekel soil and in the Paleustox showed similar dry matter $(1.5 \mathrm{~g}$ and $1.0 \mathrm{~g}$ dry matter). 


\section{Table 27:}

Shoots and roots dry matter and water content of Sorghum bicolor plants after eight weeks of growth. Values with same letters are not significantly different at $\mathrm{P} \leq 0.05$ (Fisher`s LSD).

\begin{tabular}{l|cccc}
\hline Soil & $\begin{array}{c}\text { Dry matter } \\
\text { shoot }\end{array}$ & $\begin{array}{c}\text { Dry matter } \\
\text { root }\end{array}$ & $\begin{array}{c}\text { Water content } \\
\text { shoot }\end{array}$ & $\begin{array}{c}\text { Water content } \\
\text { root }\end{array}$ \\
& $(g)$ & $(g)$ & $(\%)$ & $(\%)$ \\
\hline Kankab, heated & $2.2 \mathrm{~b}$ & $1.8 \mathrm{a}$ & $68.7 \mathrm{~b}$ & $85.2 \mathrm{a}$ \\
Kankab, natural & $0.9 \mathrm{f}$ & $1.0 \mathrm{~b}$ & $71.8 \mathrm{a}$ & $86.0 \mathrm{a}$ \\
Tzekel, heated & $2.9 \mathrm{a}$ & $1.5 \mathrm{a}$ & $67.6 \mathrm{~b}$ & $86.0 \mathrm{a}$ \\
Tzekel, natural & $2.0 \mathrm{c}$ & $1.6 \mathrm{a}$ & $69.1 \mathrm{~b}$ & $86.1 \mathrm{a}$ \\
Paleustox, heated & $1.6 \mathrm{e}$ & $0.9 \mathrm{~b}$ & $63.8 \mathrm{c}$ & $89.6 \mathrm{a}$ \\
Paleustox + GM & $1.8 \mathrm{~d}$ & $1.0 \mathrm{~b}$ & $62.3 \mathrm{c}$ & $88.8 \mathrm{a}$ \\
\hline
\end{tabular}

Sorghum plants grown in both natural Mexican soils, containing mycorrhizal propagules, had higher water contents in shoots compared to plants grown in their heated variant. The water content in shoots grown in natural Kankab soil was significantly higher than in the heated soil, while there were no significant differences in water contents between natural and heated soils of the Tzekel and the Paleustox.

No significant differences were measured in water contents of the roots between all soils, wheras improved water contents in mycorrhizal Leucaena leucocephala plants over those of non-mycorrhizal plants were found by Huang et al. (1985). Xylem pressure potentials, leaf conductance and transpiration rates per unit leaf area in mycorrhizal plants were twice as in non-mycorrhizal plants, which lead to the suggestion of higher water use and/or higher drought tolerance and improved water relations in mycorrhizal plants.

The higher water content in mycorrhizal Sorghum plants, grown in Kankab soil (Table 27), indicates, that mycorrhizal plants depleted soil water more effectively than non-mycorrhizal plants. The enhanced water absorption by mycorrhizal plants, and therefore, the reduction of water stress in the plant was also reported by Huang et al. (1985).

Additionally to Table 26 the variability of shoot dry weights is shown in Figure 26. The results show a very small variability within each treatment and suggest that the harvested plants were similar in their growth. The similar growth, same soil weights in each growing 
unit and same water supplies within each treatment will be the most important feature in chapter 5.7.6.

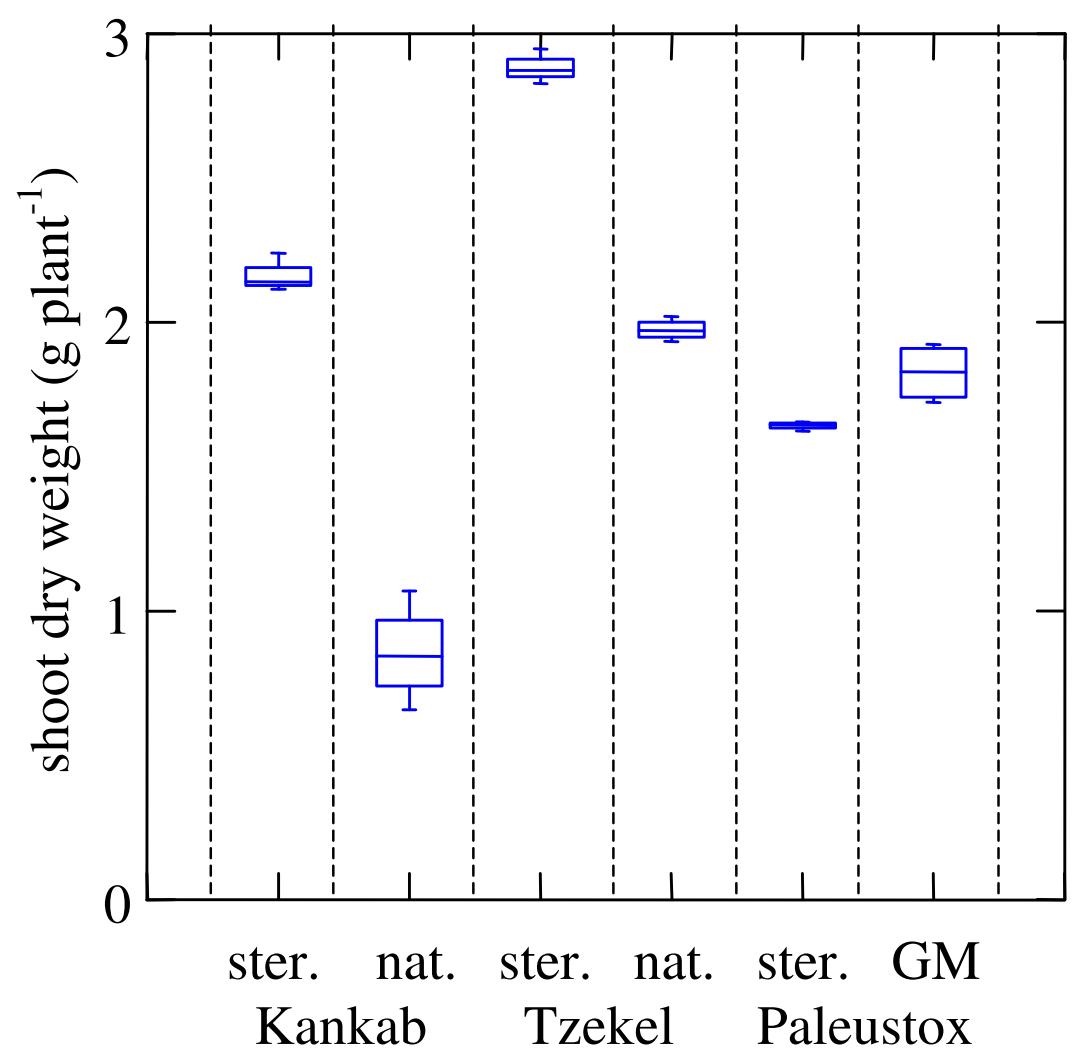

\section{Figure 26:}

Variabilities of shoot dry weights in three different soils with sterile (ster.), natural (nat.) or Glomus manihotis (GM) inoculated treatments

\subsubsection{Mycorrhizal infection}

Soil heating eliminated all microorganisms in three soils, so that no mycorrhizal infection occurred (Tab. 28). Plants grown in natural Kankab and in GM-inoculated Paleustox had highest infection rates of $73 \%$ and $75 \%$, which were significant higher than those of the plants grown in Tzekel (50\%). The Mexican soil Kankab had a higher infection potential than Tzekel, and showed a 25\% higher mycorrhizal infection than the Tzekel soil. 


\section{Table 28:}

Effect of three different natural soils and their sterilisation, as main factor on mycorrhizal infection (\%). Results with same letters are not significantly different at $\mathrm{p} \leq 0.05$ (Fisher`s LSD).

\begin{tabular}{l|c}
\hline Soil & Mycorrhizal infection rate (\%) \\
\hline Kankab, heated & $0 \mathrm{c}$ \\
Kankab, natural & $73 \mathrm{a}$ \\
Tzekel, heated & $0 \mathrm{c}$ \\
Tzekel, natural & $50 \mathrm{~b}$ \\
Paleustox, heated & $0 \mathrm{c}$ \\
Paleustox + GM & $75 \mathrm{a}$ \\
\hline
\end{tabular}

\subsection{5. ${ }^{18} \mathrm{O}$ content in shoots and roots}

Generally, diffusion between the plant and hyphae compartments could not be suppressed over the eight weeks of the experimental growth period. As mentioned in chapter 5.7.4. all treatments contained same soil weights and were watered with identical water amounts. Because of the same growing conditions, the Sorghum bicolor plants produced dry matter with low variabilities within all treatments. Therefore, the water transport was influenced by diffusion and by mycorrhizal infections. Because of the same conditions it could be suggested, that the diffusion was similar in all treatments.

Significantly higher ${ }^{18} \mathrm{O}$ water contents in shoots were measured by mycorrhizal plants grown in the natural Tzekel soil and in the GM-inoculated Paleustox compared to their sterile treatments (Fig. 27). Highest differences of ${ }^{18} \mathrm{O}$ contents in shoots were measured in plants grown in the Paleustox, a sandy soil with low amounts of organic matter. 


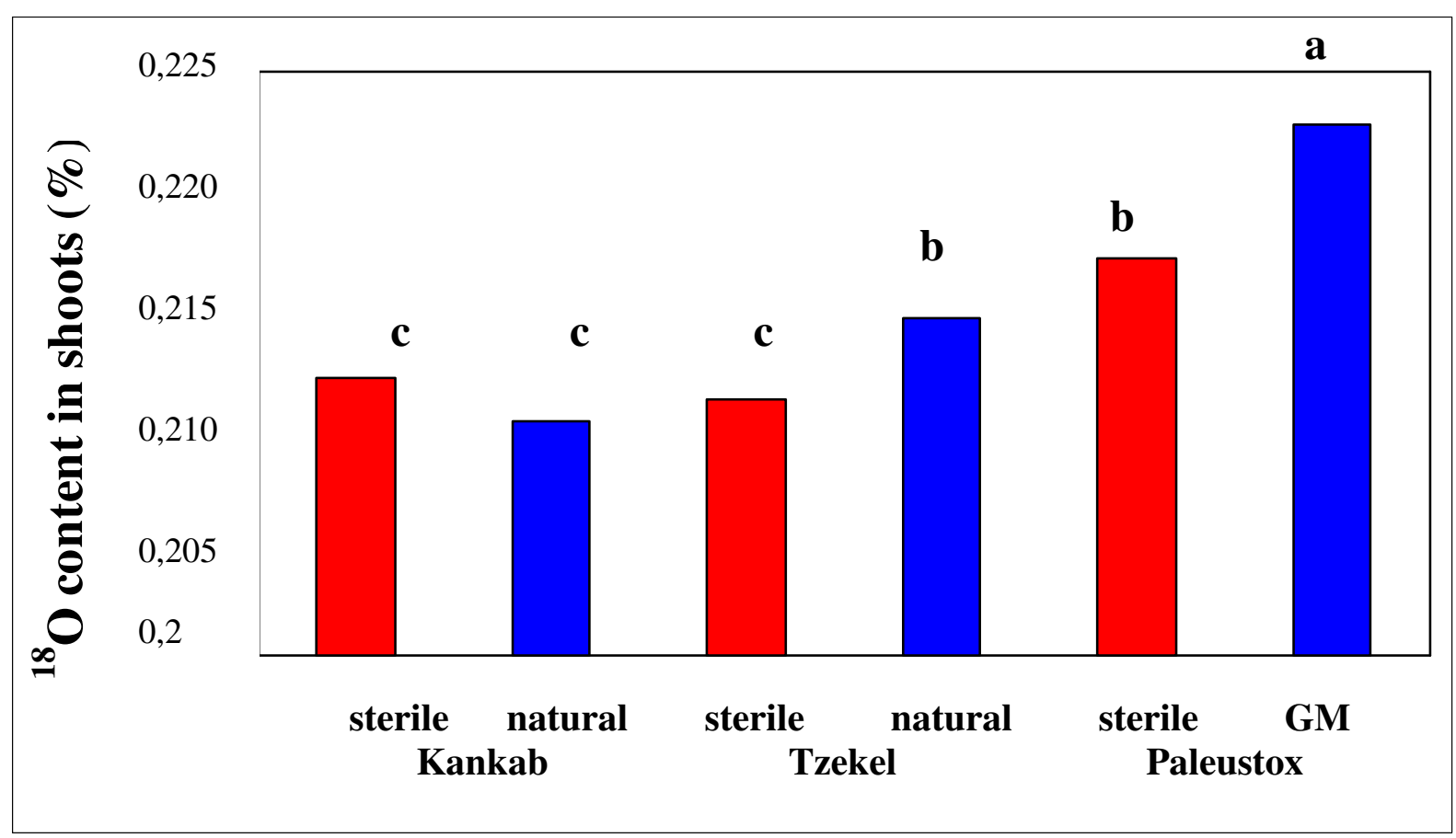

\section{Figure 27:}

${ }^{18} \mathrm{O}$ content of water in shoots of Sorghum bicolor grown in three different natural soils and their sterilisation. Columns with same letter are not significantly different at $\mathrm{p} \leq 0.05$ (Fisher`s LSD).

No significant differences in ${ }^{18} \mathrm{O}$ water contents in shoots were measured by plants grown in the Kankab soil. The total amount of ${ }^{18} \mathrm{O}$ was significantly higher by plants grown in the GMinoculated Paleustox $(8 \mu \mathrm{l})$ compared to plants grown in the sterile treatment $(6 \mu \mathrm{l})$, while no differences between plants grown in natural and sterile Tzekel were measured. The total amount of transferred water was also influenced by diffusion. The total amount of water, which was transferred to the shoots seems to be very low in correlation to the $1000 \mu{ }^{18} \mathrm{O}$ enriched normalized water (nominal ${ }^{18} \mathrm{O}$ concentration 10 atom\%) which was pipetted to the soil surface in the application chamber, nevertheless an increase of a $33 \%$ higher ${ }^{18} \mathrm{O}$ content was measured by plants grown in the GM-inoculated Paleustox compared to plants grown in the sterile Paleustox.

Faber et al. (1991) demonstrated also a role of (V)AMF in long water transport by using a "rhizobox" system, where the hyphae were separated by a screen from plant roots. Water vapour transfer was limited by applying oil to the screens and $5 \mathrm{mM}$ solution of $\mathrm{RbCl}$ was injected into the outer soil chamber. The $\mathrm{Rb}^{+}$content was measured in shoots of Helianthus annuus and the water depletion was measured in the outer soil chamber. Water losses and $\mathrm{Rb}^{+}$ 
contents in the sunflower plants indicated, that mycorrhizal hyphae were capable of transporting significant amounts of water to host plants.

These results of Faber et al. (1991) and the significant higher ${ }^{18} \mathrm{O}$ transfer rates in the natural Tzekel and GM-inoculated Paleustox compared to their sterile treatments, indicated an active transport of ${ }^{18} \mathrm{O}$ via mycorrhizal hyphae to the host plant in the present investigation.

Similar results of an active water transport by mycorrhizal plants were found by Ruiz-Lozano and Azcón (1995). The authors used plant containers, which had three compartments arranged vertically. The plant containers were separated with a $62 \mu \mathrm{m}$ mesh that allowed penetration by mycorrhizal hyphae into the lowest hyphae compartment, which was watered daily by injection to reach $-0.05 \mathrm{MPa}$ or $-0.01 \mathrm{MPa}$. The results confirm that mycorrhizal fungi influence plant nutrition, water uptake and leaf-gas exchange and contribute to an alleviation of plant water stress. Results also indicated, that the mycorrhizal fungi isolates differ in their efficiency for hyphal water uptake and transport. The difference in the efficiency for hyphal water uptake and transport could be shown also in the present investigation. Plants grown in the GM-inoculated Paleustox had higher ${ }^{18} \mathrm{O}$ contents in shoots than plants, which were grown in the Tzekel soil. The effectiveness of natural mycorrhiza in the natural Tzekel soil may have lower effectivity.

In summary, the results of the improved water uptake by plants grown in natural Tzekel and the GM-inoculated Paleustox indicated that plant tolerance to drought stress was improved by VAM colonization.

\subsubsection{Conclusion}

1.) Plants grown in the heated Kankab and Tzekel soils grew better compared to their natural soil treatment after five weeks of growth. No differences were found by plants grown in the sterile and GM-inoculated Paleustox.

2.) Plants grown in the natural and heated Tzekel soil showed highest increases of shoot diameter $(+35.6 \%)$ and shoot height $(+41.7 \%)$ between the two observation times, while the increase by plants grown in Kankab was only the half. Plants of the GMinoculated Paleustox showed only an increase of $1.6 \%$ in shoot diameters. 
3.) Plants grown in all the three heated soils showed darker green colours than plants grown in each natural and GM-inoculated soil, may be due to a higher nutrient availability and so with increased nutrient uptake, but the total number of leaves was higher by mycorrhizal plants.

4.) Leaflet wilting and folding was observed on plants grown in sterile Tzekel soil, while no influence of drought was observed on plants in the natural soil.

5.) A light Vaseline film, which was covered the mesh of the application compartment could not be used to prevent diffusion over the whole experimental growing period. The Vaseline film was degraded with the expansion of the growing period to about eight weeks.

6.) In spite of water diffusion, significantly higher ${ }^{18} \mathrm{O}$ water content was measured in plants grown in the GM-inoculated Paleustox and in the Tzekel soil compared to their sterile treatment. No significant difference was measured between the sterile and natural Kankab soil.

7.) Mycorrhizal hyphae are capable of transporting significant amounts of water to host plants demonstrating the potential of mycorrhizal colonisation of protecting plants against drought stress, which occurs in different climatic zones world-wide, but frequently in the semi-arid regions of the subtropics.

\section{General conclusion}

For a better understanding of the potential of the mycorrhizal symbiosis and to understand its utilisation in the practise, some events of the symbiosis were investigated in the present study. Of these, are the coherence between both partners in their needs of energy source and its possible influence on the uptake of nutrients especially phosphorus, which is the main feature of the positive effect of the symbiosis on the plant growth. To carry out such research work, it was necessary to investigate the role of the external hyphae. Therefore, and because of lack of precise techniques of the isolation of the external hyphae out of the soil, a method was created and/ or modified to maximize the separation of the external hyphae from the soil and the 
rhizosphere of the host plants. Furthermore, growth units used by Lange-Neß (1998) were modified and used in the present study.

The present investigation shows, that mycorrhizal hyphae took up and stored ${ }^{14} \mathrm{C}$ glucose from a glucose solution applied to the soil. This result confirms the utilisation and accumulation of glucose in extraradical hyphae as reported by (Solaiman and Saito (1997). Furthermore, the utilisation of glucose varied with the different mycorrhizal fungi, so that highly effective mycorrhizal fungi have taken up more glucose out of the soil solution than mycorrhizal fungi, which are less effective.

The mycorrhizal colonisation created a `sink` for carbohydrates, which caused an additional 4-26\% drain of $\mathrm{C}$ from the host to the fungus (Pang and Paul, 1980; Kucey and Paul, 1982; Snellgrove et al., 1982; Black et al., 2000). The "hyphae labelling experiment" showed, that the ${ }^{14} \mathrm{C}$ labelled hyphae could be used as an inoculum to infect a new Chromolaena odorata plant, and that the high radioactivity which was used during the labelling procedure did not damage the mycorrhizal hyphae. Additionally, plants inoculated with these labelled hyphae produced $100 \%$ more plant and root dry matter than plants inoculated with non-labelled hyphae. During the ${ }^{14} \mathrm{C}$ labelling procedure, the mycorrhizal hyphae were able to take up ${ }^{14} \mathrm{C}$ glucose out of the soil to cover their carbon needs and therefore the fungus was not more a `sink` for carbon. In other words, small amounts of ${ }^{14} \mathrm{C}$ glucose accumulated in the labelled fungal network were sufficient to reduce its `sink` functions for sugars in the initial phase of the mycorrhizal symbiosis.

Autoradiography of Chromolaena plants, which were inoculated with ${ }^{14} \mathrm{C}$ labelled mycorrhizal hyphae, showed high accumulations of ${ }^{14} \mathrm{C}$ in roots and shoots four weeks after inoculation. Highest ${ }^{14} \mathrm{C}$ activities were measured in the roots, while the specific activity in shoots decreased from the base of the stem upwards and from older to younger leaves. The ${ }^{14} \mathrm{C}$ accumulation of control plants, which were inoculated with dead mycorrhizal hyphae, varied strongly. Lower and higher ${ }^{14} \mathrm{C}$ activities were measured in shoots of the control plants, compared with the accumulated ${ }^{14} \mathrm{C}$ by using living mycorrhizal hyphae. The high variations of ${ }^{14} \mathrm{C}$ activities within the three control plants and the contribution of ${ }^{14} \mathrm{C}$ in their shoots lead to the suggestion that a decomposition of the hyphae was responsible for the relatively high ${ }^{14} \mathrm{C}$ accumulations. To obtain an evidence of a carbon transfer from the mycorrhizal fungi to the host plant, the growing compartments were used, where the mycorrhizal hyphae were separated from the plant roots. Four weeks after addition of ${ }^{14} \mathrm{C}$ glucose to the compartment, where only mycorrhizal hyphae were grown, a significant carbon transfer through the mycorrhizal hyphae to the host plant must have taken place. The suggestion of Bidartondo et 
al. (2002), that a carbon flow in Mycorrhiza may be bi-directional, was confirmed in the present investigation, but it was not possible to identify the transferred carbon compounds. Remaining fungal structures within roots (Bidartondo et al., 2002), signalling molecules (Peters and Verma, 1990; Gollotte et al., 1993; Bonfante-Fasolo, 1987), enzymatic activities (Blilou et al., 2000; Dumas-Gaudot et al., 1992a; Dassi et al., 1996; Pozo et al., 1998), P transporters (Rausch et al., 2001; Harrison and Buuren, 1995) or other unknown organic compounds could be possible for the bi-directional carbon transfer in Mycorrhizae.

The occurrence of P transporters in Solanum tuberosum (StPF3, Rausch et al., 2001) and in external hyphae (GvPT, Harrison and van Buuren, 1995) of Glomus versiforme could be so explained, that $\mathrm{C}$ and $\mathrm{P}$ move together in the symbiosis. The "double labelling experiment" showed, that highest amounts of hyphae in the buffer compartment were found, when the ${ }^{14} \mathrm{C}$ labelled hyphae were grown from MCP-fertilized plants through the buffer compartment into the ${ }^{32} \mathrm{P}$ application compartment. The ${ }^{14} \mathrm{C}$ was transported within the mycorrhizal network and after ${ }^{32} \mathrm{P}$ application, ${ }^{32} \mathrm{P}$ was transported to the host plants. Therefore, a carbon and phosphorus flow was measured in the hyphae, which were grown in the buffer compartment. Highest ${ }^{14} \mathrm{C}$ amounts were found, when the hyphae in the application compartment were grown in quarz sand. However, an increase of hyphae fresh weight in the buffer compartment increased the ${ }^{14} \mathrm{C}$ quantity in the hyphal network. Here, highly significant positive correlations were measured. Beside ${ }^{14} \mathrm{C}$ quantities, also highest ${ }^{32} \mathrm{P}$ activities were measured in the treatments, where the application compartment was filled with quarz sand. Similar significantly positive correlations were estimated between the hyphae fresh weight and their contents of ${ }^{32} \mathrm{P}$ and ${ }^{14} \mathrm{C}$.

High correlations between ${ }^{14} \mathrm{C}$ and ${ }^{32} \mathrm{P}$ quantities in the hyphae of the buffer compartment were found, when they were grown beside the application compartment containing quarz sand. Same tendencies were found in the treatments of both Mexican soils, but because of the high P-fixing capacity of both soils and their heterogeneity the differences were not significant. These results confirm the suggested coherence between $\mathrm{C}$ and $\mathrm{P}$ within the mycorrhizal networks.

Acrylamid-gel-electrophoresis showed, that two different labelled bands of organic compounds, containing high amounts of ${ }^{32} \mathrm{P}$ (may be also $\mathrm{C}$ ?), were extracted out of mycorrhizal hyphae, while only one labelled compound was found in the inoculated roots and shoots. The identification of these labelled bands could contribute to a better understanding of the function of these compounds in the mycorrhizal symbiosis. 
Higher WUE values in arbuscular mycorrhizal plants compared to non-mycorrhizal plants indicate that mycorrhizal fungi improved the ability of mycorrhizal roots to absorb soil moisture or increased the amount of soil surface, which is contacted by roots for water extraction to enhance dry matter production (Kothari et al., 1990; Bryla and Duniway, 1998). The mycorrhizal Sorghum bicolor plants in the present investigation, grown in the red Paleustox, produced more dry matter than non-mycorrhizal plants in the same soil under same water conditions. Contrary, the non-mycorrhizal plants, grown in both heated Mexican soils (Kankab and Tzekel) produced more dry matter than the mycorrhizal plants, due to but the effect of soil heating and consequently the mineralization of organic sources of nutrients in these soils. Soil heating in the red Paleustox played a secondary role, because of the high content of sand and the low nutrient availability in this soil. Plants grown in all heated soils showed darker green colours than plants in each natural and Glomus manihotis inoculated soils, may be due to a higher nutrient availability and uptake. However, the total number of leaves was higher in the mycorrhizal plants. A thin Vaseline film, which has covered the mesh of the application compartment could not prevent the water diffusion between this compartment and the buffer compartment, but in spite of water diffusion, significantly higher ${ }^{18} \mathrm{O}$ water content was measured in plants grown in the GM-inoculated Paleustox and in the Tzekel soil compared to their sterile treatment. Active water transports in Mycorrhiza were also reported by Faber et al. (1990) and Ruiz-Lozano and Azcón (1995). These results and the results of the present investigation demonstrate, that mycorrhizal hyphae are capable of transporting significant amounts of water to the host, demonstrating the potential of mycorrhizal colonisation of protecting plants against drought stress.

In summary, the present study clearly demonstrates a role of vesicular arbuscular fungi in long distance water, carbon and nutrient transport in a system, in which secondary effects of infection are abscent. ${ }^{14}$ Carbon was taken up by mycorrhizal hyphae out of the soil and was stored in its network. After the inoculation with this ${ }^{14} \mathrm{C}$ labelled hyphae the carbon was transported to the host plant. Furthermore, the additional ${ }^{14} \mathrm{C}$ glucose reduced the `sink` nature of the fungi in the initial phase of the symbiosis, and accordingly led a higher dry matter production after using their ${ }^{14} \mathrm{C}$ labelled mycorrhizal hyphae as inoculum. The ${ }^{14} \mathrm{C}$ transport within the mycorrhizal network and the addition of ${ }^{32} \mathrm{P}$ to mycorrhizal hyphae demonstrate also high correlations between ${ }^{32} \mathrm{P}$ and ${ }^{14} \mathrm{C}$ amounts in the mycorrhizal networks. Two different ${ }^{32} \mathrm{P}$ labelled substances were extracted out of the hyphae, while only one substance was found in the roots and shoots. Further investigations are needed to identify these 
extracted substances to clarify if $\mathrm{P}$ transporters in the mycorrhizal network are involved in transporting $\mathrm{P}$ from soil, through the network to the host plant. Beside $\mathrm{P}$ transfer via mycorrhizal hyphae also an active water transport through mycorrhizal hyphae was measured. The improved growth, nutrient acquisition, carbon storage and/or transport beside improved water uptake of mycorrhizal plants demonstrate the potential of mycorrhizal colonisation in protecting the plants against drought stress, which frequently occurs in the semi-arid regions of the subtropics. 


\section{Appenidx}

\section{Table 30:}

Activities $(\mathrm{Bq})$ of labelled $A$. longula hyphae after addition of ${ }^{14} \mathrm{C}$ - glucose to hyphal compartments

\begin{tabular}{|c|c|c|}
\hline sample No. & mycorrhizal fungi & total hyphae activity $(B q)$ \\
\hline 1 & A. longula & 223,1 \\
\hline 2 & A. longula & 491,5 \\
\hline 3 & A. longula & 701,1 \\
\hline 4 & A. longula & 441,5 \\
\hline 5 & A. longula & 1111,9 \\
\hline 6 & A. longula & 266,8 \\
\hline 7 & A. longula & 1017,4 \\
\hline 8 & A. longula & 1169,8 \\
\hline 9 & A. longula & 1004,7 \\
\hline 10 & A. longula & 1073,7 \\
\hline 11 & A. longula & 448,2 \\
\hline 12 & A. longula & 623,3 \\
\hline 13 & A. longula & 1229,7 \\
\hline 14 & A. longula & 2214,1 \\
\hline 15 & A. longula & 1831,6 \\
\hline 16 & A. longula & 741,3 \\
\hline 17 & A. longula & 1035,9 \\
\hline 18 & A. longula & 1026,2 \\
\hline mean & & 925,1 \\
\hline
\end{tabular}


Table 31:

Activities $(\mathrm{Bq})$ of labelled $G$.manihotis hyphae after addition of ${ }^{14} \mathrm{C}$ - glucose to hyphal compartments

\begin{tabular}{|c|c|c|}
\hline sample No. & mycorrhizal fungi & total hyphae activity $(B q)$ \\
\hline 19 & G. manihotis & 2321,5 \\
\hline 20 & G. manihotis & 1373,2 \\
\hline 21 & G. manihotis & 1199,4 \\
\hline 22 & G. manihotis & 821,2 \\
\hline 23 & G. manihotis & 2618,1 \\
\hline 24 & G. manihotis & 13005,4 \\
\hline 25 & G. manihotis & 3520,0 \\
\hline 26 & G. manihotis & 5881,8 \\
\hline 27 & G. manihotis & 5649,9 \\
\hline 28 & G. manihotis & 2378,23 \\
\hline 29 & G. manihotis & 2964,1 \\
\hline 30 & G. manihotis & 4521,0 \\
\hline 31 & G. manihotis & 2236,8 \\
\hline 32 & G. manihotis & 4784,0 \\
\hline 33 & G. manihotis & 3248,6 \\
\hline 34 & G. manihotis & 10751,0 \\
\hline 35 & G. manihotis & 3543,9 \\
\hline 36 & G. manihotis & 4202,8 \\
\hline mean & & 4167,8 \\
\hline
\end{tabular}




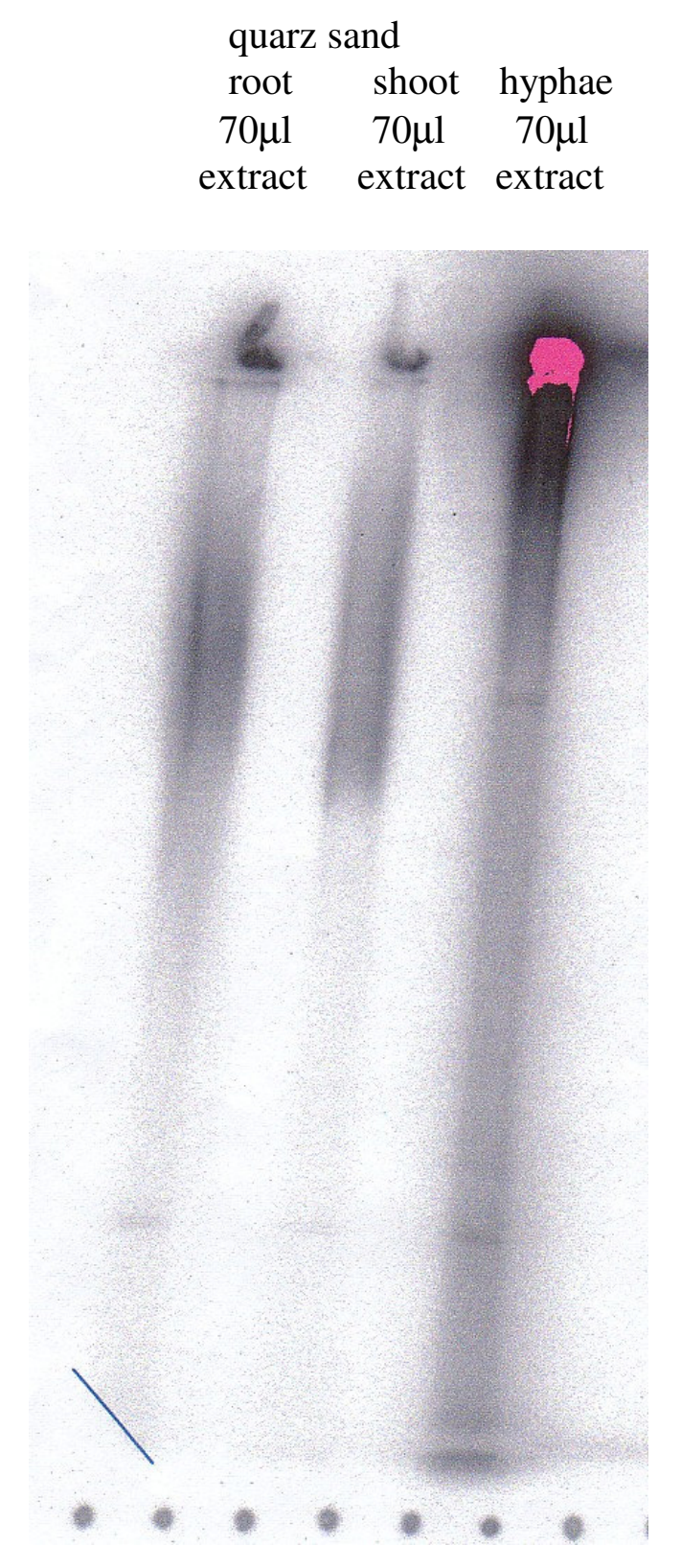
quarz sand Tzekel Kankab quarz sand hyphae root root root $20 \mu 1 \quad 20 \mu 1 \quad 20 \mu l \quad 20 \mu 1$ extract extract extract extract

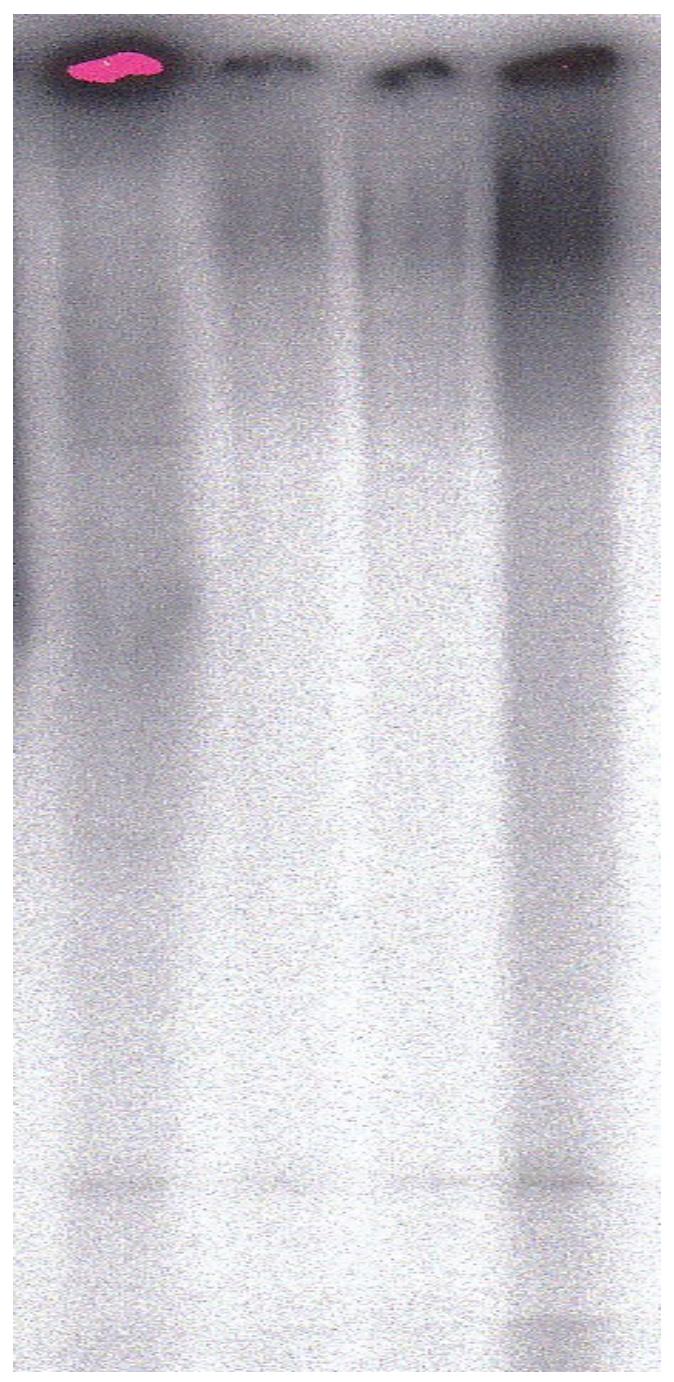

Figure 28:

${ }^{32} \mathrm{P}$ labelled compounds, visible in acrylamide-gel, extracted out of hyphae, roots and shoots of plants 


\section{References}

Al-Karaki, G.N., 1998. Benefit, cost and water-use efficiency of arbuscular mycorrhizal durum wheat grown under drought stress. Mycorrhiza 8, 41-45.

Al-Karaki, G.N., Clark, R.B., 1998. Growth, mineral acquisition, and water use by mycorrhizal wheat grown under water stress. Journal of Plant Nutrition 21(2), 263-276.

Allen, M.F., Moore, T.S., Christensen, M., 1982. Phytohormone changes in Bouteloua gracilis infected by vesicular-arbuscular mycorrhizae. II. Altered levels of gibberellin-like substances and abscisic acid in the host plant. Can. J. Bot. 60, 468-471.

Aly, R.A.T., 2002. Einfluss der Schwermetalle Zink, Cadmium und Blei auf Wachstum und Nährstoffaufnahme von Acacia saligna, Casuarina equisetifolia und Cupressus sempervirens. Dissertation Universität Göttingen.

Augé, R.M., Schekel, K.A., Wample, R.L., 1986. Greater leaf conductance of well-watered VA mycorrhizal rose plants is not related to phosphorus nutrition. New Phytologist 103, 107116.

Bago, B., Pfeffer, P.E., Shachar-Hill, Y., 2000. Carbon metabolism and arbuscular Mycorrhizas. Plant Physiology 124, 949-957.

Bago, B., Pfeffer, P.E., Abubaker, J., Jun, J., Allen, J.W., Brouillette, J., Douds, D.D., Lammers, P.J., Shachar-Hill, Y., 2003. Carbon export from arbuscular mycorrhizal roots involves the translocation of carbohydrates as well as lipid. Plant Physiology 131, 1496-1507.

Barea, J.M., Azcòn-Aguilar, C., 1982. Production of plant growth-regulating substances by the vesicular-arbuscular mycorrhizal fungus Glomus mosseae. Applied and Environmental Microbiology 43, 810-813.

Barley, K.P., 1970. The configuration of root systems in relation to nutrient uptake. Adv. Agron. 22, 159-201. 
Bécard, G., Piché, Y., 1989. New aspects on the acquisition of biotrophic status by a vesicular-arbuscular mycorrhizal fungus, Gigaspora margarita. New Phytologist 112, 77-83.

Bevege, D.I., Bowen, G.D., Skinner, M.E., 1975. Comparative carbohydrate physiology of ecto- and endomycorrhizas. In: Sanders, F.E. (Eds.), Mosse, B., Tinker, P.T., Endomycorrhizas. Academic Press, London, 149-174.

Bidartondo, M.I., Redecker, D., Hijri, I., Wiemken, A., Bruns, T.D., Dominguez, L., Sérsic, A., Leake, J.R., Read, D.J., 2002. Epiparasitic plants specialized on arbuscular mycorrhizal fungi. Nature 419, 389-391.

Black, K.G., Mitchell, D.T., Osborne, B.A., 2000. Effect of mycorrhizal-enhanced leaf phosphate status on carbon partitioning, translocation and photosynthesis in cucumber. Plant, Cell and Environment 23, 797-809.

Blilou, I., Bueno, P., Ocampo, J.A., García-Garrido, J.M., 2000. Induction of catalase and ascorbate peroxidase activities in tabacco roots inoculated with the arbuscel mycorrhizal Glomus mosseae. Mycological Research 104, 722-725.

Bonfante-Fasolo, P., 1984. Anatomy and morphology. In:. Powell, C.L., Bagyaraj, D.J. (Eds.), VA Mycorrhizas, CRC Press, Boca Raton, USA, 5-33.

Bonfante-Fasolo, P., 1987. Vesicular-arbuscular mycorrhizae: fungus-plant interactions at the cellular level. Symbiosis 3, 249-268.

Bryla, D.R., Duniway, J.M., 1998. The influence of the mycorrhizal Glomus etunicatum on drought acclimation in safflower and wheat. Physiologia Plantarum 104, 87-96.

Buee, M., Rossignol, M., Jauneau, A., Ranjeva, R., Bécard, G., 2000. The pre-symbiotic growth of arbuscular mycorrhizal fungi is induced by a branching factor partially purified from plant root exudates. Molecular plant-microbe interactions 13, 693-698. 
Breitenstein, U., 1988. Wirkung der VA-Mykorrhiza auf Wachstum und Nährstoffaufnahme von Vigna unguiculata und Pennisetum americanum im Mischanbau bei gleichzeitiger Rhizobienbeimpfung im Hinblick auf die Nutzung marginaler Standorte. Dissertation, GeorgAugust-Universität Göttingen.

Brundrett, M.C., Piche, Y., Peterson, R.L., 1985. A development study of the early stages in vesicular-arbuscular mycorrhiza formation. Can. J. Bot. 63, 184-194.

Cooper, K.M., Lösel, D.M., 1978. Lipid physiology of vesicular-arbuscular Mycorrhiza. I. Composition of lipids in roots of onion, clover and ryegrass infected with Glomus mosseae. New Phytologist 80, 143-151.

Cooper, K.M., Tinker, P.B., 1978. Translocation and transfer of nutrients in vesicular arbuscular mycorrhizas. New Phytologist 81, 43-52.

Cooper, K.M., Tinker, P.B., 1981. Translocation and transfer of nutrients in vesicular arbuscular mycorrhizas. IV. Effect of environmental variables on movement of phosphorus. New Pytologist 88, 327-339.

Cox, G., Sanders, F.E., Tinker, P.B., Wild, J.A., 1975. Ultrastructural evidence relating to host-endophyte transfer in vesicular-arbuscular mycorrhizas. In Sanders, F.E. Morse, B., Tinker, P.B., eds, Endomycorrhizas. Academic Press, London, 297-312.

Daniels, B.A., Skipper, H.D., 1982. Methods for the recovery and quantitative estimation of propagules from soil. In: Schenk, N.C. (Eds.), Methods and Principles of Mycorrhizal Research. St. Paul, The American Phytopathological Society, 29-36.

Dassi, B., Dumas-Gaudot, E., Asselin, A., Richard, C., Gianinazzi, S., 1996. Chitinase an b1,3-glucanase isoforms expressed in pea roots inoculated with arbuscular mycorrhizal or pathogenic fungi. European Journal of Plant Pathology 102, 105-108.

Ditschar, B., 2001. Rolle von Enzymen im Phosphat-Aufnahmemechanismus durch (vesicular-) arbuskuläre Mykorrhiza ((V)AM) bei Chromolaena odorata. M. Sc. thesis, Institute of Agronomy in the Tropics, Georg-August Universtität Göttingen. 
Dumas-Gaudot, E., Grenier, J., Furlan, V., Asselin, A., 1992a. Chitinase, chitosanase and $\beta$ 1,3 glucanase activities in Allium and Pisum roots colonized by Glomus species. Plant Sci. 84, 17-24.

Dumas-Gaudot, E., Grenier, J., Furlan, V., Asselin, A., 1992b. New acidic chitinase isoform induced in tobacco roots by vesicular-arbuscular mycorrhizal fungi. Mycorrhiza 1, 133-136.

Eissenstat, D.M., Graham, J.H., Syvertsen, J.P., Drouillard, D.L., 1993. Carbon economy of sour orange in relations to mycorrhizal colonisation and phosphorus status. Annals of Botany 71, 1-10.

Faber, B.A., Zasoski, R.J., Munns, D.N., 1991. A method for measuring hyphal nutrient and water uptake in mycorrhizal plants. Can. J. Bot. 69, 87-94.

Fabig, B., Vielhauer, K., Moawad, A.M., Achtnich, W., 1989. Gas-chromatographic seperation of organic acids and electrophoretic determination of phosphatases from VA mycorrhizal roots. Z. Pflanzenernähr. Bodenk. 152, 261-265.

Fitter, A.H., 1988. Water relatiosn of red clover Trifolium pratense L. as affected by VA mycorrhizal infection and phosphorus supply before and during drought. Journal of Experimental Botany 202, 595-603.

Fitter, A.H., Graves, J.D., Watkins, N.K., Robinson, D., Scrimgeour, C., 1998. Carbon transfer between plants and its control in networks of arbuscular mycorrhizas. Functional Ecology 12, 406-412.

García-Garrido, J.M., Ocampo, J.A., 2002. Regulation of the plant defence response in arbuscular mycorrhizal symbiosis. Journal of Experimental Botany 53, 1377-1386.

Gaspar, M.L., Pollero, R.J., Cabello, M.N., 1994. Variations in the lipid composition of alfalfa roots during colonization with the arbuscular mycorrhizal fungus Glomus versiforme. Mycologia 89 (1), 37-42. 
George, E., Häussler, K.U., Vetterlein, D., Gorgus, E., Marschner, H., 1992. Water and nutrient translocation by hyphae of Glomus mosseae. Can. J. Bot. 70, 2130-2137.

Gianinazzi-Pearson, V., Gianinazzi, S., 1988. Morphological integrations and functional compatibility between symbionts in vesicular-arbuscular mycorrhizal associations. NATO ASI Series H17, 73-84.

Gollotte, A., Gianinazzi-Pearson, V., Giovanetti, M., Sbrana, C., Avio, L., Gianinazzi, S., 1993. Cellular localization and cytochemical probing of resistance reactions to arbuscular mycorrhizal fungi in a `locus a `myc-mutant of Pisum sativum. Planta 191, 112-122.

Graham, J.H., Syvertsen, J.P., 1984. Influence of vesicular-arbuscular mycorrhizal on the hydraulic conductivity of roots of two citrus rootstocks. New Phytologist 97, 277-284.

Gryndler, M., Hrŝelová, H., Chvátalová, I., 1997. An improved procedure for root surface disinfection suitable for observations of proliferation of intraradical hyphae of arbuscular mycorrhizal fungus Glomus fistulosum. Folia Microbiol. 42 (5), 489-494.

Gryndler, M., Vosátka, M., Hrŝelová, H., Chvátalová, I., Skrdelta, V., 1998. Effect of glucose on the development of Glomus fistulosum colonization and extraradical mycelium on maize roots. Folia Microbiol. 43 (6), 635-643.

Hardie, K., Leyton, L., 1981. The influence of vesicular-arbuscular mycorrhizal on growth and water relations of red clover. I. in phosphate deficient soil. New Phytologist 89, 599-608.

Hardie, K., 1985. The effect of removal of extraradical hyphae on water uptake by vesiculararbuscular mycorrhizal plants. New Phytologist 101, 677-684.

Harley, J.L., Smith, S.E., 1983. Mycorrhizal Symbiosis. Academic Press, London, UK.

Harrison, M.J., van Buuren, M.L., 1995. A phosphate transporter from the mycorrhizal fungus Glomus versiforme. Nature 378, 626-629. 
Hattingh, M.J., Gray, L.E., Gerdmann, J.W., 1973. Uptake and translocation of ${ }^{32} \mathrm{P}$ labelled phosphate to onion roots. Soil Sci. 116, 383-387.

Hepper, C.M., 1981. Techniques for studying the infection of plants by vesicular-arbuscular mycorrhizal fungi under axenic conditions. New Phytologist 88, 641-647.

Ho, I., Trappe, J.M., 1973. Translocation of ${ }^{14} \mathrm{C}$ from Festuca plants to their endomycorrhizal fungi. Nature 224, 30-31.

Holford, I.C.R., 1997. Soil phosphorus: its measurement, and its uptake by plants. Aust. J. Soil Res. 35, 227-239.

Huang, R.S., Smith, W.K., Yost, Y.S., 1985. Influence of vesicular-arbuscular mycorrhizal on growth, water relations, and leaf orientation in Leucaena leucocephala (LAM.) De wit. New Phytologist 99, 229-243.

Jakobson, I., Rosendahl, L., 1990. Carbon flow into soil and external hyphae from roots of mycorrhizal cucumber plants. New Phytologist 115, 77-83.

Jakobsen, I., Abbott, L.K., Robson, A.D., 1992. External hyphea of vesicular-arbuscular mycorrhizal fungi associated with Trifolium subterraneum L. 2. Hyphal transport of ${ }^{32} \mathrm{P}$ over defined distances. New Phytologist 120, 509-516.

Jasper, D.A., Abbott, L.K., Robson, A.D., 1989. Hyphae of a vesicular-arbuscular mycorrhizal fungus maintain infectivity in dry soil, except when the soil is disturbed. New Phytologist 112, 101-107.

Jennings, D.H., 1995. The physiology of fungal nutrition. Cambridge University Press, Cambridge, UK.

Johnson, D., Leake, J.R., Read, D.J., 2002. Transfer of recent photosynthate into mycorrhizal mycelium of an upland grassland. Short term respiratory losses and accumulation of ${ }^{14} \mathrm{C}$. Soil Biology \& Biochemistry 34, 1521-1524. 
Kaya, C., Higgs, D., Kirnak, H., Tas, I., 2003. Mycorrhizal colonisation improves fruit yield and water use efficiency in watermelon (Citrullus lanatus Thunb.) grown under well-watered and water stressed conditions. Plant and Soil 253, 287-292.

Koch, K.E., Johnson, C.R., 1984. Photosynthate partitioning in split-root citrus seedlings with mycorrhizal and nonmycorrhizal root systems. Plant Physiologist 75, 26-30.

Kothari, S.K., Marschner, H., George, E., 1990. Effect of VA mycorrhizal fungi and rhizosphere microorganisms on root and shoot morphology, growth and water relations in maize. New Phytologist 116, 303-311.

Kucey, R.M.N., Paul, E.A., 1982. Carbon flow, photosynthese, and $\mathrm{N}_{2}$ fixation in mycorrhizal and nodulated faba beans (Vicia faba L.). Soil Biol. Biochem. 407 (14), 407-412.

Lambais, M.R., Mehdy, M.C., 1993. Suppression of endochitinase, $\beta-1,3$-endoglucanase, and chalone isomerase expression in bean vesicular-arbuscular mycorrhizal roots under different soil phosphate conditions. Molecular Plant-Microbe Interactions 6, 75-83.

Lange-Ness, R.L., 1998. Aufnahme con Calcium und Phosphat aus Hydroxylapatit durch mykorrhizierte Maispflanzen. Dissertation, Georg-August Universität Göttingen, Cuvillier Verlag, Göttingen

Lee, D.P., Lord, A.D., 1987. A high performance phase for the organic acids. Liquid Chromatograph-Gas Chromatography 5, 261-265.

Mathur, N., Vyas, A., 1995. Changes in isozyme patterns of peroxidase and polyphenol oxidase by VAM fungi in roots of Ziziphus species. J. Plant Physiol. 145, 498-500.

Miller, R.M., Miller, S.P., Jastrow, J.D., Rivetta, C.B., 2002. Mycorrhizal mediated feedbacks influence net carbon gain and nutrient uptake in Andropogon gerardii. New Phytologist 155, $149-162$. 
Mosse, B., Hepper, C., 1975. Vesicular-arbuscular mycorrhizal infections in root organ cultures. Physiol. Plant Pathology 5, 215-223.

Mosse, B., 1988. Some studies relating to "independent" growth of vesicular- arbuscular endophytes. Can. J. Bot. 66, 2533-2540.

Muchhal, U.S., Raghothama, K.G., 1999. Transcriptional regulation of plant phosphate transporters. Proc. Natl. Acad. Sci. USA 96 (10), 5868-5872.

Nelson, C.E., Safir, G.R., 1982. Increased drought tolerance of mycorrhizal onion plants caused by improved phosphorus nutrition. Planta 154, 407-413.

Okeefe, D.M., Sylvia, D.M., 1992. Chronology and mechanisms of P-uptake by mycorrhizal sweet potato plants. New Phytologist 122, 651-659.

Patrik, J.W., 1989. Solute efflux to the apoplast at plant/ microorganisms interfaces. Australian Journal of Plant Physiology 16, 53-67.

Pang, P.C., Paul, E.A., 1980. Effects of vesicular-arbuscular mycorrhiza on ${ }^{14} \mathrm{C}$ and ${ }^{15} \mathrm{~N}$ distribution in nodulated fababeans. Can J. Soil Sci. 60, 241-250.

Pearson, J.N., Jakobson, I., 1993. The relative contribution of hyphea and roots to phosphorus uptake by arbuscular mycorrhizal plants, measured by dual labelling with ${ }^{32} \mathrm{P}$ and ${ }^{33} \mathrm{P}$. New Phytologist 124, 489-494.

Peters, N.K., Verma, D.P.S., 1990. Phenolic compounds as regulators of gene expressionin plant-microbe interactions. Molecular Plant-Microbe Interactions 3, 4-8.

Pfeffer, P.E., Douds Jr., D.D., Becard, G., Shachar-Hill, Y., 1999. Carbon uptake and the metabolism and transport of lipids in an arbuscular mycorrhiza. Plant Physiology 120, 587598. 
Phillips, J.M., Hayman, D.S., 1970. Improved procedures for clearing roots and staining parasitic and vesicular-arbuscular mycorrhizal fungi for rapid assessment of infection. Transactions British Mycological Society 55, 158-161.

Pozo, M.J., Azcon-Aguilar, C., Dumas-Gaudot, E., Barea, J.M., 1998. Chitosanase and chitinase activities in tomato roots during interactions with arbuscular mycorrhizal fungi or Phytophthora parasitica. Journal of Experimental Botany 49 (327), 1729-1739.

Rausch, C., Daram, P., Brunner, S., Jansa, J., Laloi, M., Leggewis, G., Amrhein, N., Bucher, M., 2001. A phosphate transporter expressed in arbuscule-containing cells in potato. Nature 414, 462-466.

Robinson, D., Fitter, A., 1999. The magnitude and control of carbon transfer between plants linked by a common mycorrhizal network. Journal of Experimental Botany 330, 9-13.

Rosendahl, S., Sen, R., 1992. Isozyme analysis of mycorrhizal fungi and their mycorrhizas. In Methods in microbiology, Vol 24: Experiments with Mycorrhizae. (A.K., Varma, D.J., Read and J.R., Norris, Eds), pp. 169-194. Academic Press, New york.

Riuz-Lozano, J.M., Azcón, R., 1995. Hyphal contribution to water uptake in mycorrhizal plants as affected by the fungal species and water status. Physiologia Plantarum 95, 472-478.

Safir, G.R., Boyer, J.S., Gerdemann, J.W., 1971. Mycorrhizal enhancement of water transport in soybean. Science 172, 581-583.

Shachar-Hill, Y., Pfeffer, P.E., Douds, D., Osman, S.F., Doner, L.W., Ratcliff, R.G., 1995. Partitioning of intermediary carbon metabolism in vesicular-arbuscular mycorrhizal leek. Plant Physiology 108, 7-15.

Sieverding, E., 1981. Influence of soil water regimes on VA Mycorrhiza. I. Effect on plant growth, water utilization and development of Mycorrhiza. J. Agronomy \& Crop Science 150, 400-411. 
Simard, S.W., Perry, D.A., Jones, M.D., Myrolds, D.D., Durall, D.M., Molina, R., 1997. Net transfer of carbon between ectomycorrhizal tree species in the field. Nature 388, 579-582.

Smith, F.A., Smith, S.E., 1981. Mycorrhizal infection and growth of Trifolium subterraneum: comparison of natural and artificial inocula. New Phytologist 88, 311-325.

Smith, S.E., Smith, F.A., 1990. Structure and function of the interfaces in biotrophic symbioses as they relate to nutrient transport. New Phytologist 114, 1-38.

Smith, S.E., Dickson, S., Morris, C., Smith F.A., 1994. Transfer of phosphate from fungus to plant in VA mycorrhizas: calculation of the area of symbiotic interface and of fluxes of $\mathrm{P}$ from two different fungi to Allium porrum L.. New Phytologist 127, 93-99.

Smith, S.E., Read, D.J., 1997. Mycorrhizal Symbiosis. Academic Press, San Diego, CA.

Snellgrove, R.C., Splittstoesser, W.E., Stribley, D.P., Tinker, P.B., 1982. The distribution of carbon and the demand of the fungal symbiont in leek plants with vesicular-arbuscular mycorrhizas. New Phytologist 92, 75-87.

Solaiman, Z.M.D., Saito, M., 1997. Use of sugars by intraradical hyphae of arbuscular mycorrhizal fungi revealed by radiorespirometry. New Phytologist, 533-538.

Spanu, P., Boller, T., Ludwig, A., Wiemken, A., Faccio, A., Bonfante-Fasolo, P., 1989. Chitinase in roots of mycorrhizal Allium porrum: regulation and localisation. Planta 177, 447455 .

Tawaraya, K., Watanabe, S., Yoshida, E., Wagatsuma, T., 1996. Effect of onion (Allium cepa) root exudates on the hyphal growth of Gigaspora margarita. Mycorrhiza 6, 57-59.

Tinker, P.B., 1978. Effects of vesicular- arbuscular mycorrhizas on plant nutrition and plant growth. Physiol. Veg. 16 (4), 743-751.

Tommerup, I.C., Abbott, L.K., 1981. Prolonged survival and viability of VA mycorrhizal hyphae after root death. Soil Biol. Biochem. 13, 431-433. 
Toth, R., Miller, R.M., 1984. Dynamics of arbuscule development and degeneration in a Zea mais Mycorrhiza. Amer. J. Bot 71 (4), 449-460.

Vierheilig, H., Alt, M., Mohr, U., Boller, T., Wiemken, A., 1994. Ethylene biosynthesis and activities of chitinase and $\beta$-1,3-glucanase in the roots of host and non-host plants of vesicular-arbuscular mycorrhizal fungi after inoculation with Glomus mosseae. Journal of Plant Physiology 142, 337-343.

Viets, F.G., 1972. Water deficits and nutrient availability. In: Kozlowski, T.T. (ed) Water deficits and plant growth, vol 3. Academic, New York, 217-239.

Wolde-Yohannes, L., 1974. Das Bodenbrennen "GUIE" in Äthiopien und seine Wirkungen auf Boden und Pflanze. Dissertation 1974, TU Hannover.

Wright, D.P., Read, D.J., Scholes, J.D., 1998. Mycorrhizal sink strength influences whole plant carbon balance of Trifolium repens L.. Plant, Cell and Environment 21, 881-891. 